NASA-TM--100228

NASA Technical Memorandum 100228

\title{
Small Space Reactor Power Systems for Unmanned Solar System Exploration Missions
}

Harvey S. Bloomfield

Lewis Research Center

Cleveland, Ohio

December 1987

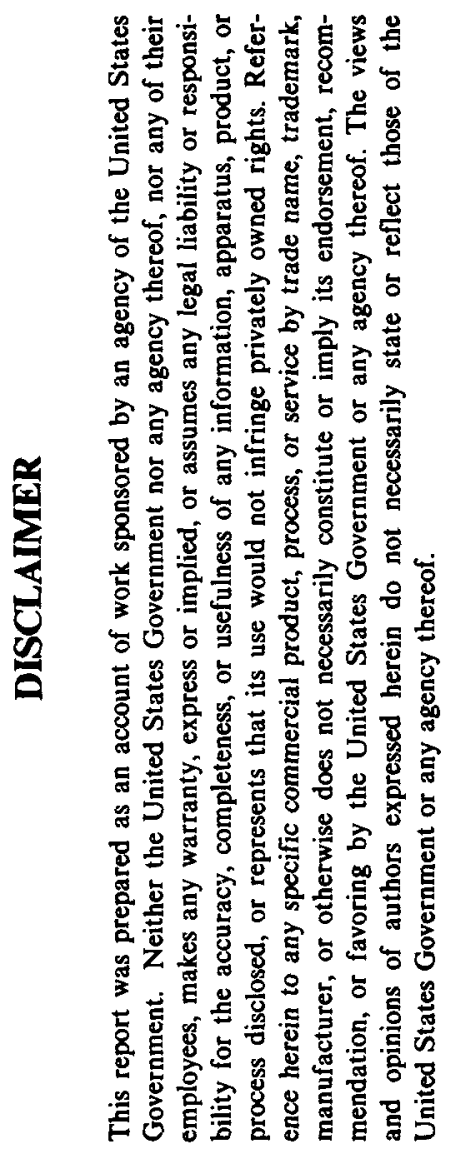




\section{DISCLAIMER}

This report was prepared as an account of work sponsored by an agency of the United States Government. Neither the United States Government nor any agency Thereof, nor any of their employees, makes any warranty, express or implied, or assumes any legal liability or responsibility for the accuracy, completeness, or usefulness of any information, apparatus, product, or process disclosed, or represents that its use would not infringe privately owned rights. Reference herein to any specific commercial product, process, or service by trade name, trademark, manufacturer, or otherwise does not necessarily constitute or imply its endorsement, recommendation, or favoring by the United States Government or any agency thereof. The views and opinions of authors expressed herein do not necessarily state or reflect those of the United States Government or any agency thereof. 


\section{DISCLAIMER}

Portions of this document may be illegible in electronic image products. Images are produced from the best available original document. 


\section{CONTENTS}

Page

SUMMARY . . . . . . . . . . . . . . . . . . . . . . . . . . . . . 1

INTRODUCTION AND OVERVIEW . . . . . . . . . . . . . . . . . . . . . . . 1

DISCUSSION OF APPROACH AND SUMMARY OF RESULTS . . . . . . . . . . . . . . . . 2

ACKNOWLEDGMENTS . . . . . . . . . . . . . . . . . . . . . . . 5

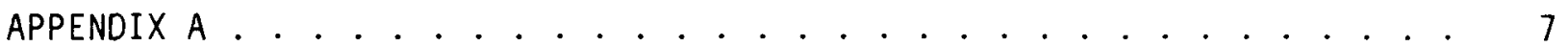

APPENDIX B . . . . . . . . . . . . . . . . . . . . . . . . . 59

APPENDIX C . . . . . . . . . . . . . . . . . . . . 105

TABLES . . . . . . . . . . . . . . . . . . . . . . . 117

FIGURES . . . . . . . . . . . . . . . . . . . . . . 120 
SMALL SPACE REACTOR POWER SYSTEMS FOR UNMANNED SOLAR SYSTEM

EXPLORATION MISSIONS

\author{
Harvey S. Bloomfield \\ National Aeronautics and Space Administration \\ Lewis Research Center \\ Cleveland, Ohio 44135
}

\begin{abstract}
SUMMARY
A preliminary feasibility study of the application of small nuclear reactor space power systems to the Mariner Mark II Cassini spacecraft/mission has been conducted. The purpose of the study was to identify and assess the technology and performance issues associated with the reactor power system/ spacecraft/mission integration. The Cassini mission was selected because study of the Saturn system has been identified as a high priority outer planet exploration objective by the Space Science Board of the National Academy of Science. Reactor power systems applied to this mission were evaluated for two different uses. First, a very small 1 kWe reactor power system was used as a Radioisotope thermoelectric generator (RTG) replacement for the nominal spacecraft mission science payload power requirements while still retaining the spacecraft's usual bipropellant chemical propulsion system. The second use of reactor power involved the additional replacement of the chemical propulsion system with a small reactor power system and an electric propulsion system. In this concept, a single reactor power system provides electricity for both nuclear electric propulsion and for an enhanced mission science payload power supply. The study also provides an examination of potential applications for the additional power available for scientific data collection.
\end{abstract}

The reactor power system characteristics utilized in the study were based on a parametric mass model that was developed specifically for these low-power applications. The model was generated following a neutronic safety and operational feasibility assessment of six small reactor concepts solicited from U.S. industry. This assessment provided the validation of reactor safety for all mission phases and generated the reactor mass and dimensional data needed for the system mass model.

\title{
INTRODUCTION AND OVERVIEW
}

This report documents the results of a 9-month study to assess the feasibility of small reactor power systems application to a representative unmanned solar system exploration mission. The study, which was initiated in November 1986, was jointly sponsored by NASA Headquarters Codes RP and EL with technical management provided by the NASA Lewis Research Center's Nuclear and Thermal Systems Office.

The study consisted of three major tasks: (1) a safety and operational feasibility study of small reactor concepts, (2) development of a parametric system mass model, and (3) a combined reactor power system/spacecraft/mission integration study for a representative NASA mission. 


\section{DISCUSSION OF APPROACH AND SUMMARY OF RESULTS}

The first task was accomplished by soliciting small reactor power system concepts from U.S. industry and conducting an independent neutronic safety and operational assessment of the reactor concepts. This assessment was conducted by the Oregon State University, Department of Nuclear Engineering under a grant from NASA Lewis and the complete results of this task are included in appendix $A$ of this report.

The assessment of nuclear feasibility and criticality safety for a variety of mission profiles that include! both normal and abort scenarios was accomplished by conducting a neutronic evaluation based on three dimensional model Monte Carlo neutron and photon transport code calculations of the effective neutron multiplication factor for four reactor configurations. Each configuration represented a specific geometry case to evaluate: (1) startup and operational life capability, (2) launch pad and ascent shutdown capability, (3) launch abort water immersion criticality and safety for a normal shutdown launch reactor configuration, and (4) launch abort water immersion and flooding criticality and safety for a configuration with all reactor exterior control and shutdown systems removed (assumed to exist after a violent reentry and impact).

A summary of the nuclear feasibility and criticality safety results is shown in table I. Although these results represent only a relatively modest reactor design effort, all the concepts are potentially capable of meeting, or approaching, the desired target reactivity goals with the exception of the launch abort water flooding case. However, this case is quite severe and is probably overly conservative.

The second task was accomplished by generating a total reactor power system mass model that consisted of three major subsystems; reactor, shield, and all nonnuclear subsystem elements. The reactor mass model was based on a composite of all reactor concepts examined in task 1 . Figure 1 is a plot of reactor mass versus power level and shows calculated mass points for each concept and the composite model used for the reactor model. The calculated mass values are based on reactor geometry (volumes) and material densities of all reactor components used in the criticality assessment. Since these masses do not include any noncriticality or reactivity related components, such as control rod or reflector drives and motors or instrumentation, the composite model mass values shown include an additional 15 percent to account for them.

Shadow shield mass calculations were carried out at NASA Lewis using an in-house shielding code. This code utilizes a shield thickness algorithm based on Monte Carlo analyses and can provide shield mass as a function of reactor power level, reactor-to-payload distance, payload diameter and payload neutron and gamma radiation flux and dose constraints for a wide variety of shield geometries. The nonnuclear subsystem mass model shown in figure 2 was based on data obtained from a literature search of past reactor power system designs and a detail mass breakdown of the SNAP-1OA flight hardware. Because of the predominance of a thermoelectric power conversion data base, the mass model used for the power conversion component was arbitrarily based on this data base. The other nonnuclear components modeled as a function of power level included electrical power management and distribution, radiator, and structure. The radiator model shown is based on a conical design at $8 \mathrm{~kg} / \mathrm{m}^{2}$. 
A typical total mass tabulation, based on combining all subsystem mass model results, is shown in table II. This table includes shield masses for payload gamma radiation dose constraints ranging from 300 KRAD for hardened electronics down to 7.5 KRAD which represents about twice the expected natural space radiation background integrated gamma dose level for the Cassini mission.

The mass summary includes both 20 and $40 \mathrm{~m}$ reactor-to-payload separation (boom) distances; additional 5, 10 , and $60 \mathrm{~m}$ cases were also calculated. Shield masses are provided for a payload diameter (spot) of $6 \mathrm{~m}$; however, additional spot sizes of 2 and $10 \mathrm{~m}$ were also calculated. The multiplicity of variations in radiator geometry, boom length, payload diameter and radiation dose level were provided to allow the reactor/spacecraft integration task team to investigate a wide range of design configuration options.

The third task was accomplished by conducting a reactor power system/ spacecraft integration study at the NASA Jet Propulsion Laboratory (JPL) utilizing the Mariner Mark II Cassini spacecraft and mission concepts. This task relied on a wide variety of propulsion, spacecraft, and mission design input from the JPL team as well as the reactor power system parametric mass model results from task 2. The complete results of this task are included in appendix $B$ of this report.

This task was structured to satisfy two objectives: (1) investigation of the integration of a very small reactor power system and the Mariner Mark II Cassini spacecraft and mission, and (2) determination of the utility of a low power nuclear electric propulsion (NEP) system for the Cassini mission. The approach used to meet the first objective was based on using a reactor power system to replace the usual radioisotope thermolectric generator (RTG) power supply to perform the same science payload functions with the same launch vehicle using the same spacecraft. The approach used to meet the second objective was based on using a previously developed NEP spacecraft configuration using ion engine system projections.

A summary of the results for the reactor power system/Cassini spacecraft "RTG replacement" integration study is shown in figure 3 . This figure displays the flight time penalty incurred by the additional mass of a 1 kWe reactor power system located on a 20-m boom attached to the spacecraft. The reference flight time of 6.8 years is based on a 1995 launch of a Titan IV and Centaur $G$ ' launch vehicle combination ( $308 \mathrm{I}_{S p}$ ) and utilizes a Delta V Earth-Jupiter gravity assist trajectory (available only 3 years out of 20 ; the next window is from 1995 to 1997) to arrive at Saturn. Three 1 kWe reactor power system masses are shown as a function of integrated gamma radiation dose over a 6-m diameter payload. The 300 KRAD gamma radiation dose represents a near term projection for a wide variety of electronic integrated circuits and the 7.5 KRAD value is the current Mariner Mark II radiation specification. This specification is based solely on the expected natural environment dose and is not directly related to an electronics radiation hardness value.

Based on the reactor power system mass model shown in table II, a 300 KRAD gamma radiation dose specification will be met by a $371 \mathrm{~kg}$ reactor power system mass. This mass will incur a flight time penalty of about 0.8 year. Even at the natural environment radiation dose level of $7.5 \mathrm{kRAD}$ the flight time penalty is only about 1.3 years. 
A summary of the results of the determination of the utility of a low power NEP system for the Cassini mission is shown in figure 4. Reactor power system mass is plotted as a function of power output (for T/E conversion) for the range of integrated gamma radiation dose levels from 7.5 to $300 \mathrm{kRAD}$. All reactor mass values are based on a $40 \mathrm{~m}$ reactor-to-payload separation distance and a payload dose plane diameter of $6 \mathrm{~m}$. Mission flight times of 7,8 , and 9 years are displayed for a conservative NEP subsystem based on $30 \mathrm{~cm}$ Xenon ion thruster technology.

The major conclusion derived from figure 4 is that a relatively low power 25 to $30 \mathrm{kWe}$ nuclear electric propulsion (NEP) system can deliver the Cassini spacecraft to Saturn with no flight time penalty. It may also be asserted that the use of higher power levels can provide a trip time savings. Additional benefits of NEP are also significant for this mission. First, the direct trajectory allowed by electric propulsion eliminates all Delta $V$ gravity assist maneuvers and removes the 1995-1997 launch window constraint. Second, and of major significance, is the fact that upon arrival at Saturn the electric propulsion system can be shut down and all reactor power system generated electricity is available for payload science. Thus, for the first time, power levels far in excess of the usual $200 \mathrm{~W}$ could be available for science on a planetary spacecraft.

As part of this study a preliminary investigation of the potential science applications that could benefit from additional available power was carried out. A previous in-house NASA study investigated science applications of additional available power and identified significant potential science benefits. Table III summarizes the relevant results and lists the benefits and power level requirements identified. Additional efforts carried out for this study were conducted at JPL and provided a more detailed investigation of seven selected science areas to better quantify the benefits of increased science power availability. These science areas are data rate, radio occultation, relativity/gravity wave, sensor cooling, radar, particles and fields, and laser. The complete results of this investigation are included in appendix $C$ of this report. A summary of three selected high payoff areas are presented herein: increased data rate, radio occultation, and relativity.

Since the value of science information, such as resolution and quantity, is often proportional to data rate, a high rate is desirable. Current science data rates for planetary exploration missions range from 8 to $134 \mathrm{kbps}$ for Galileo at Jupiter to 115 to $268 \mathrm{kbps}$ for Magellan at Venus using the 34 or $70 \mathrm{~m}$ DSN receiving antennae. The power required to increase data rates to a desired value of $1000 \mathrm{kbps}$ is dependent on planetary destination or spacecraft to earth range. Typical power requirements for an enhanced data rate of 1000 kbps from Jupiter, Saturn, Uranus, and Neptune are 2, 8, 25, and $60 \mathrm{kWe}$, respectively.

Radio occultation enhancement to provide new and more complete characterization of planetary atmospheres is required for Jupiter and Saturn. RF penetration of ammonia, methane, and water vapor clouds is severely limited by the low power levels currently available. Atmospheric model studies project penetration depths of up to $50 \mathrm{~km}$ for Jupiter, which will require power levels up to $100 \mathrm{kWe}$. Similar models for Saturn predict maximum penetration depths of up to $100 \mathrm{~km}$ requiring RF power levels in excess of $1000 \mathrm{kWe}$. 
The detection ability and resolution of relativity or gravity wave signatures is currently limited by a variety of factors including signature degradation due to planetary medium and spacecraft radio system effects, time delay RF signal path curvature, and red shift frequency variations. A gravity wave detection value function in excess of $0 \mathrm{~dB}$ is desired to overcome these limitations which will require power levels in excess of $10 \mathrm{kWe}$.

\section{ACKNOWLEDGMENTS}

The author wishes to acknowledge the significant contributions of the following individuals: D. Carlson, Los Alamos National Laboratory, who provided specialized shielding performance calculations for small reactors; $R$. Jones, Jet Propulsion Laboratory, who provided leadership of the reactor I spacecraft integration study; A. Klein, Oregon State University, who provided leadership of the small reactor concepts neutronic safety feasibility study; and R. Wallace, Jet Propulsion Laboratory, who provided leadership of the high power science applications investigation. 
BLANK 
A.C. KLEIN, PRINCIPAL INVESTIGATOR, S.R. GEDEON, AND D.C. MOREY

Final Project Report for NASA Lewis Research Center Grant No. NAG-3-752

AN ASSESSMENT AND VALIDATION STUDY

OF NUCLEAR REACTORS FOR

LOW POWER SPACE APPLICATIONS

OSU-NE reports are the result of work performed in the Nuclear Engineering Department of Oregon State University which, in the opinion of the departmental faculty, contain information useful to other researchers. A limited number of copies are available from the Department. The report series includes theses (available from University Microfilms, Ann Arbor, Michigan), documents which may be reissued under another report number by a sponsoring agency, preprints, some student reports, and archival data. 


\section{BLANK}




\title{
An Assessment and Validation Study of Nuclear Reactors for Low Power Space Applications
}

by

\author{
A.C. Klein, Principal Investigator \\ S.R. Gedeon \\ D.C. Morey
Department of Nuclear Engineering
Oregon State University
Corvallis, OR 97331

to

\section{NASA Lewis Research Center 21000 Brookpark Road \\ Cleveland, $\mathrm{OH} \quad 44135$}

Final Project Report for Grant No. NAG-3-752

Grant Period: November 1, 1986 to April 30, 1987

June 26,1987 
BLANK 
Table of Contents

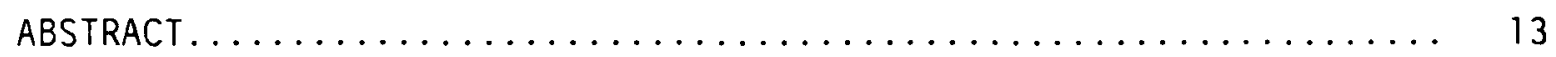

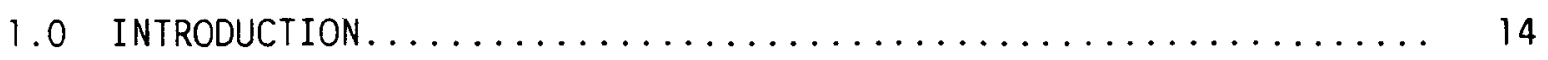

2.0 DESCRIPTION OF MODELING TECHNIQUES USED $\ldots \ldots \ldots \ldots \ldots \ldots \ldots \ldots$

2.1 Nuclear Models......................... 16

2.2 Case Descriptions and Desirable Limits............ 17

2.2.1 Maximum Reactivity................. 17

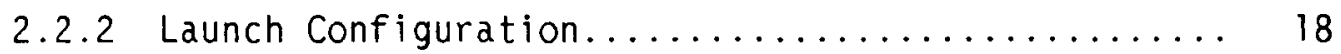

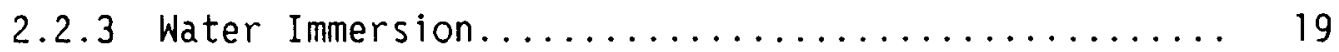

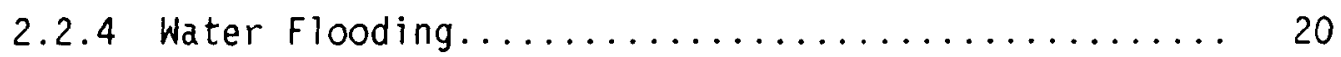

2.3 Concept Models........................ 21

2.3.1 Conceptual Design \#1.................. 21

2.3.2 Conceptual Design \#2.................. 24

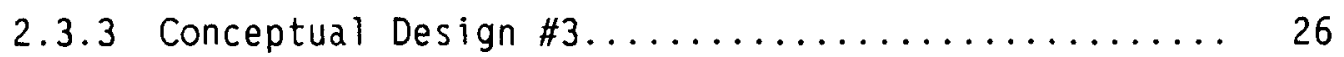

2.3.4 Conceptual Design $\# 4 \ldots \ldots \ldots \ldots \ldots \ldots \ldots \ldots \ldots \ldots \ldots$

2.3.5 Conceptual Design $\# 5 \ldots \ldots \ldots \ldots \ldots \ldots \ldots \ldots \ldots \ldots \ldots$

2.3.6 Conceptual Design $\# 6 \ldots \ldots \ldots \ldots \ldots \ldots \ldots \ldots \ldots \ldots \ldots$

3.0 CRITICALITY FEASIBILITY AND SAFETY EVALUATION........... 39

3.1 Conceptual Design \#1........................ 39

3.2 Conceptual Design $\# 2 \ldots \ldots \ldots \ldots \ldots \ldots \ldots \ldots \ldots \ldots \ldots \ldots \ldots$

3.3 Conceptual Design $\# 3 \ldots \ldots \ldots \ldots \ldots \ldots \ldots \ldots \ldots \ldots \ldots$

3.4 Conceptual Design $\# 4 \ldots \ldots \ldots \ldots \ldots \ldots \ldots \ldots \ldots \ldots \ldots$

3.5 Conceptual Design $\# 5 \ldots \ldots \ldots \ldots \ldots \ldots \ldots \ldots \ldots \ldots \ldots \ldots$

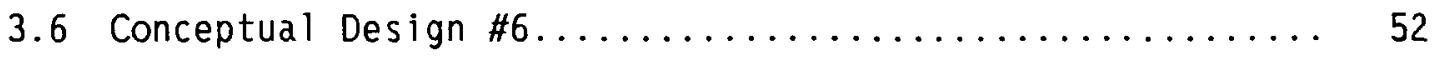

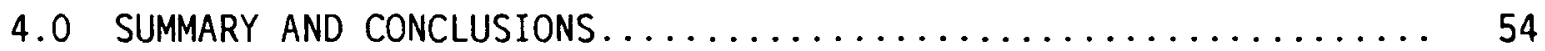

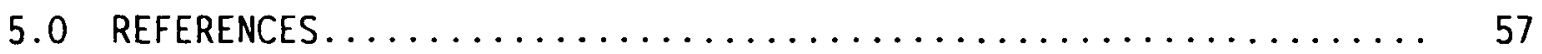

6.0 ACKNOWLEDGMENTS ............................ 58 
Tables

2-1 Regional compositions modeled for conceptual design \#1...... 22

2-2 Regional compositions modeled for conceptual design \#2

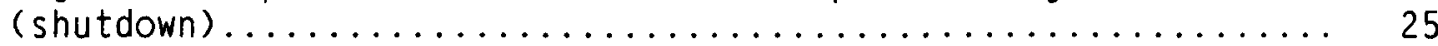

2-3 Regional compositions modeled for conceptual design \#3

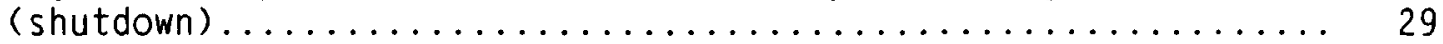

2-4 Regional compositions modeled for conceptual design \#4...... 32

2-5 Regional compositions modeled for conceptual design \#5..... 35

2-6 Regional compositions modeled for conceptual design \#6...... 38

3-1 Criticality feasibility and safety evaluation ( $k_{e f f}$ ) results for conceptual design $\# 1 \ldots \ldots \ldots \ldots \ldots \ldots \ldots \ldots \ldots \ldots \ldots \ldots \ldots$

3-2 Criticality feasibility and safety evaluation (keff) results

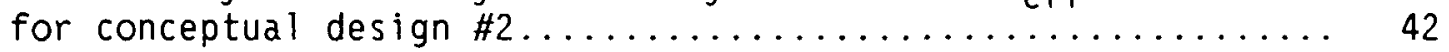

3-3 Criticality feasibility and safety evaluation ( $k_{e f f}$ ) results for conceptual design \#3........................... 45

3-4 Criticality feasibility and safety evaluation ( $k_{e f f}$ ) results

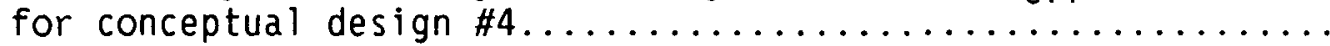

3-5 Criticality feasibility and safety evaluation ( $k_{e f f}$ ) results for conceptual design \#5 and conceptual design \#5/uranium.....

3-6 Criticality feasibility and safety evaluation ( $k_{e f f}$ ) results

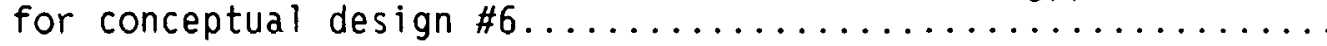

\section{Figures}

2-1 Schematic diagram of conceptual design \#1............. 23

2-2 Schematic diagram of conceptual design $\$ 2 \ldots \ldots \ldots \ldots \ldots \ldots \ldots \ldots$

2-3 Schematic diagram of conceptual design $\# 3 \ldots \ldots \ldots \ldots \ldots \ldots \ldots$

2-4 Schematic diagram of conceptual design $\# 4 \ldots \ldots \ldots \ldots \ldots \ldots \ldots \ldots 32$

2-5 Schematic diagram of conceptual design $\# 5 \ldots \ldots \ldots \ldots \ldots \ldots \ldots \ldots$

2-6 Schematic diagram of conceptual design $\# 6 \ldots \ldots \ldots \ldots \ldots \ldots \ldots \ldots$ 


\section{ABSTRACT}

The feasibility and safety of six conceptual small, low power nuclear reactor designs was evaluated. Feasibility evaluations included the determination of sufficient reactivity margins for seven years of full power operation and safe shutdown as well as handling during pre-launch assembly phases. Safety evaluations were concerned with the potential for maintaining subcritical conditions in the event of launch or transportation accidents. These included water immersion accident scenarios both with and without water flooding the core. Results show that most of the concepts can potentially meet the feasibility and safety requirements; however, due to the preliminary nature of the designs considered, more detailed designs will be necessary to enable these concepts to fully meet the safety requirements. 


\subsection{INTRODUCTION}

This report documents the results of a preliminary small reactor concepts feasibility and safety evaluation study performed by the oregon State University Department of Nuclear Engineering, Dr. Andrew C. Klein, principal investigator. The study was carried out over a seven-month period from November 1986 to May 1987 and is fully compliant with the grant objectives set forth by the NASA Lewis Research Center, Harvey S. Bloomfield, Technical officer. It was designed to provide a first-order validation of the nuclear feasibility and criticality safety assessment of six small reactor concepts provided by five U.S. corporations with interest and expertise in space nuclear power systems. Each concept proposed by industry included an appropriate power conversion and heat rejection subsystem. This study, however, addresses only the proposed reactor subsystems and includes power conversion elements only to the extent that they form an integral part of the reactor design concept. For proprietary and other reasons the six concepts have been disassociated from their industry advocates.

Validation of nuclear feasibility and criticality safety assessments of each concept was based on Monte Carlo three-dimensional model calculations of the effective multiplication factor, keff, for four configurations of each reactor concept. Each configuration represented a specific geometry case to evaluate startup and operational life capability, launch pad and ascent shutdown capability and water immersion criticality and safety for both a normal launch configuration with all shutdown subsystems in place and a post-impact launch abort configuration with all exterior control and shutdown systems removed. Optional concept variations in core poison materials, reflector and control rod/drum geometries, core 
core poison materials, reflector and control rod/drum geometries, core fuel distribution and partial water flooding geometries have also been included where necessary for concept evaluation.

The small reactor concepts evaluated in this study have potential space applications for missions in the nominal 1 to $20 \mathrm{kWe}$ power output range. These electrical power outputs correspond to reactor thermal power levels of from about 5 to $300 \mathrm{kWt}$ depending on power conversion subsystem type and efficiency.

Many small reactor concepts have been proposed for applications in this power range. These include the well known U.S. SNAP series of reactors [1-6] as well as U.S.S.R. reactors [7].

The launch abort water immersion safety philosophy that was acceptable for U.S. space reactors in the 1960 's allowed for a supercritical excursion. Current safety standards will require subcriticality under all water immersion and credible flooding situations. Therefore, low power reactor design concepts that incorporate additional poison control schemes without sacrificing operating reactivity need to be evaluated. 


\subsection{DESCRIPTION OF MODELING TECHNIQUES USED}

\subsection{Nuclear Models}

The nuclear feasibility and criticality safety evaluations were performed using the MCNP Monte Carlo neutron transport code, version 3 [8]. All calculations were performed on the NASA Lewis Research Center's CRAY-XMP computer. First order criticality results are obtained for the proposed reactor concepts utilizing homogeneous, three-dimensional models of each reactor and its associated sub-systems and components as described below. It is felt that greater detail for such scoping studies is unnecessary and would not be warranted considering the level of design detail available. In those cases where more accurate geometrical representations were available, more detail was included. A three dimensional model, such as is available by using MCNP, allows the models to more accurately treat non-symmetric reactor components, such as reflectors, than a one- or two-dimensional model. The cross section set utilized for these calculations was the ENDF/B-IV data set supplied by the Radiation Shielding Information Center, Oak Ridge National Laboratory, Oak Ridge, Tennessee with the MCNP code [9]. The following sections give detailed descriptions of the operational and accident scenarios modeled, and the compositional and geometrical models used for each of the six conceptual designs. 


\subsection{Case Descriptions and Desirable Limits}

\subsubsection{Maximum Reactivity}

In these configurations, the maximum operating reactivity is determined to evaluate the initial criticality of each of the reactor concepts. For this analysis, all control rods are fully withdrawn, all control drums are rotated so that their absorber surfaces are faced away from the core and their reflector surfaces face inward toward the core. For concepts with sliding reflectors which are removed to allow subcriticality, these reflectors are positioned in such a way as to provide for the maximum amount of neutron reflection. In these cases, fixed poisons are assumed to remain in the core and the objective is to estimate the maximum amount of excess reactivity available for normal operation.

The target values for $k_{e f f}$ for these cases was required to fall between 1.05 and 1.09 . These limits were chosen to allow for statistical variances in the calculational techniques, cross section inaccuracies and temperature effects on startup, and to ensure sufficient reactivity margins to provide for reactor operation for a seven year period due to burnup. It is felt for these initial feasibility calculations that if a concept falls within this range, the results should provide sufficient confidence in the startup capability of the reactor. 


\subsubsection{Launch Configuration}

In the launch configuration, all movable poisons are placed in such a manner that a subcritical assembly is maintained prior to and during launch. Control rods are fully inserted into the core, control drums are rotated so that their absorber sections are facing the core, and any movable reflectors used for control are removed and stored in their launch positions. These cases are designed to test the amount of shutdown margin available to the reactor during the fabrication of the concept and the safety of the concept after it is loaded into the launch vehicle. They also give some measure of the capability to shutdown the reactor system after initial criticality in sapce should a problem develop.

The ideal values for $k_{\text {eff }}$ for these cases would be a low as possible; however, a value of less than 0.9 would be acceptable from an initial feasibility standpoint. This would provide sufficient shutdown margin for these concepts and allow for statistical variations, inaccuracies of nuclear data, and other effects. 


\subsubsection{Water Immersion}

In the water immersion cases, an accident in which the reactor system is dropped into water is simulated. This could occur during a launch which is unable to place the reactor into orbit, or during the transportation of the completed reactor system to the launch site, or during the loading of the reactor system into the launch vehicle. In these cases it is assumed that the launch configuration described above is maintained, no water is allowed to enter the reactor system, and the entire reactor system is placed at the center of a 5 meter sphere of water. Here, the water only acts as an additional reflector and external neutron moderator. No neutron moderation, other than from designed core materials, is included within the reactor system. Also, it is assumed that no physical damage to the reactor core occurs and that there is no redistribution of core or reflector materials (i.e., no compaction).

For water immersion accident scenarios, an acceptable upper limit for $k_{\text {eff }}$ was chosen to be 0.95 . This value includes allowances for statistical and data uncertainties, and possible small amounts of re-distribution of reactor components due to impact damage. 


\subsubsection{Water Flooding}

Water flooding cases model the water immersion accident with no allowances for active shutdown systems external to the core. In these cases, all movable components exterior to the core are assumed to have been removed on impact. This includes any movable reflectors and any control drums. It is further assumed that the core itself and any fixed reflector sections will remain intact on impact. Also, for these cases, water is allowed to fill any and all of the voids within the reactor system, including coolant flow channels inside the core, heat pipes, reflector cooling tubes, etc. This includes the assumption that all coolant volume fractions in those concepts which utilize a liquid coolant (even if it is frozen solid for launch) are replaced with water and that any core heat pipes are filled with water. In addition, the resulting configuration is then submersed at the center of a 5 meter sphere of water as in the water immersion cases. No allowances for the compaction of the reactor core and reflectors are made in this modeling effort, however, since such an accident scenario would be highly design and impact dependent.

Acceptable levels of subcriticality could be assumed for such cases if $k_{\text {eff }}$ is found to be less than 0.95. Again, this includes a margin to allow for statistical and data accuracy, but does not leave very much margin in the cases where compaction of the core was possible. 


\subsection{Concept Models}

\subsubsection{Conceptual Design \#1}

This first reactor concept is an SP-100 derivative reactor system with uranium nitride fuel ( $90 \%$ enriched in $\left.U^{235}\right)$. The fuel pin cladding is the refractory metal alloy $\mathrm{Nb}-1 \mathrm{Zr}$, and the reactor coolant is lithium. This coolant is assumed to be enriched to $100 \%$ in the $\mathrm{Li}^{7}$ iosotope to eliminate parasitic thermal captures by $\mathrm{Li}^{6}$ and to reduce the formation of tritium during operation. Another feature of the reactor core is that the fuel elements are arranged in a close packed arrangement with a pitch to diameter ratio of 1.0 . The lithium coolant is pumped through the core by a thermoelectric electromagnetic (TEM) pump and through an annulus outside of the radial reflector where the thermal energy is converted to electricity by an array of thermo electric (TE) conversion elements located on the outside of the reactor vessel.

The neutron economy of the reactor system is enhanced by radial and axial beryllium oxide reflectors, and reactivity control is obtained through the use of a central, fine motion control rod containing boron carbide. This rod is fully inserted for shutdown, and the drive mechanism is to be designed to provide sufficient accuracy to allow for operational reactivity control.

Figure 2-1 shows the nominal $10 \mathrm{kWe}$ model used for the reactivity and safety calculations, including the dimensions of all components. Each region is homogenized for simplicity and the compositions for each region are shown in Table 2-1. Note that both the coolant plena and the TE elements are not modeled in extensive detail; however, this should not have any effect on the calculations. For the maximum reactivity 
case, the control rod channel is assumed to be filled with a fuel region follower; Figure 2-1 represents the shutdown configuration. For the water flooding case, it was assumed that the entire reactor remains intact, including the control rod and the reflectors and all of the lithium coolant was replaced with water. This assumption neglects the fact that lithium will burn when exposed to air/water, and the resulting fire would likely cause damage to the reactor core and reflectors. However, for criticality calculations, it was assumed that the straightforward replacement of lithium with water on a volumetric basis would comprise a worst case accident condition.

Table 2-1. Region compositions modeled for conceptual design \#1.

Region

Core

Control rod channel

Structure

Radial reflector

Axial reflector

Coolant plenum

TE elements
Composition (volume fraction)

UN (90.521), NB $(0.308)$, Li $(0.093)$

Boron carbide (shutdown); UN (operatinq)

$\mathrm{Nb}$

BeO

$\mathrm{BeO}(0.521), \mathrm{Nb}(0.308), \mathrm{Li}(0.093)$

Li

Si 


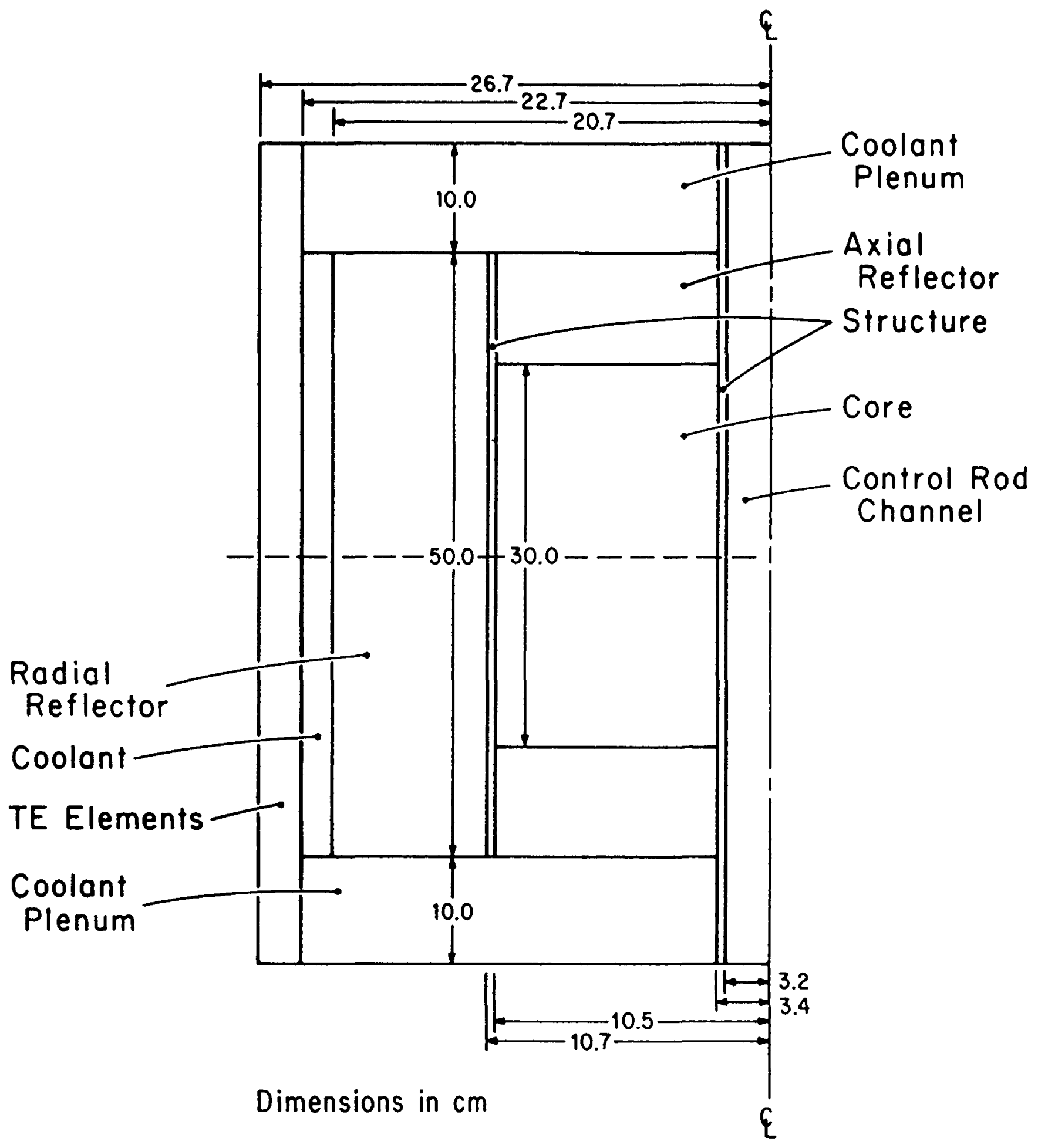

Figure 2-1. Schematic diagram of conceptual design \#1. 


\subsubsection{Conceptual Design \#2}

This reactor concept is a SNAP derivative system utilizing uraniumzirconium-hydride fuel clad with stainless steel. Heat transfer from the core is provided by the forced convection of sodium-potassium (NaK), and thermal to electrical power conversion is provided by an organic Rankine cycle (ORC) heat engine using a Nak-to-organic fluid boiler.

This reactor is controlled by the motion of the radial reflector made of beryllium metal and by the incorporation of a gadolinium burnable poison coating on the fuel pin cladding. The stationary axial reflectors are also constructed of beryllium, and there is a fairly sizable region of the core designed to allow for fuel expansion. This region is constructed of stainless steel springs or collapsible expansion buttons.

The nominal 5 klle model used for these calculations is shown in Figure 2-2, and the compositions of the respective regions are given in Table 2-2. Only the upper portion of the radial reflector is movable for reactivity control, and there is a designed shutter opening of $10.16 \mathrm{~cm}$ which is required for the shutdown of this reactor. The shutdown configuration is modeled in Figure 2-2, and for maximum reactivity cases this gap is completely closed. For the flooded cases, the movable radial reflectors were considered to be dislodged from the outside of the reactor with water filling these regions. Additionally, water replaces the NaK throughout the reactor core on a volumetric basis. 


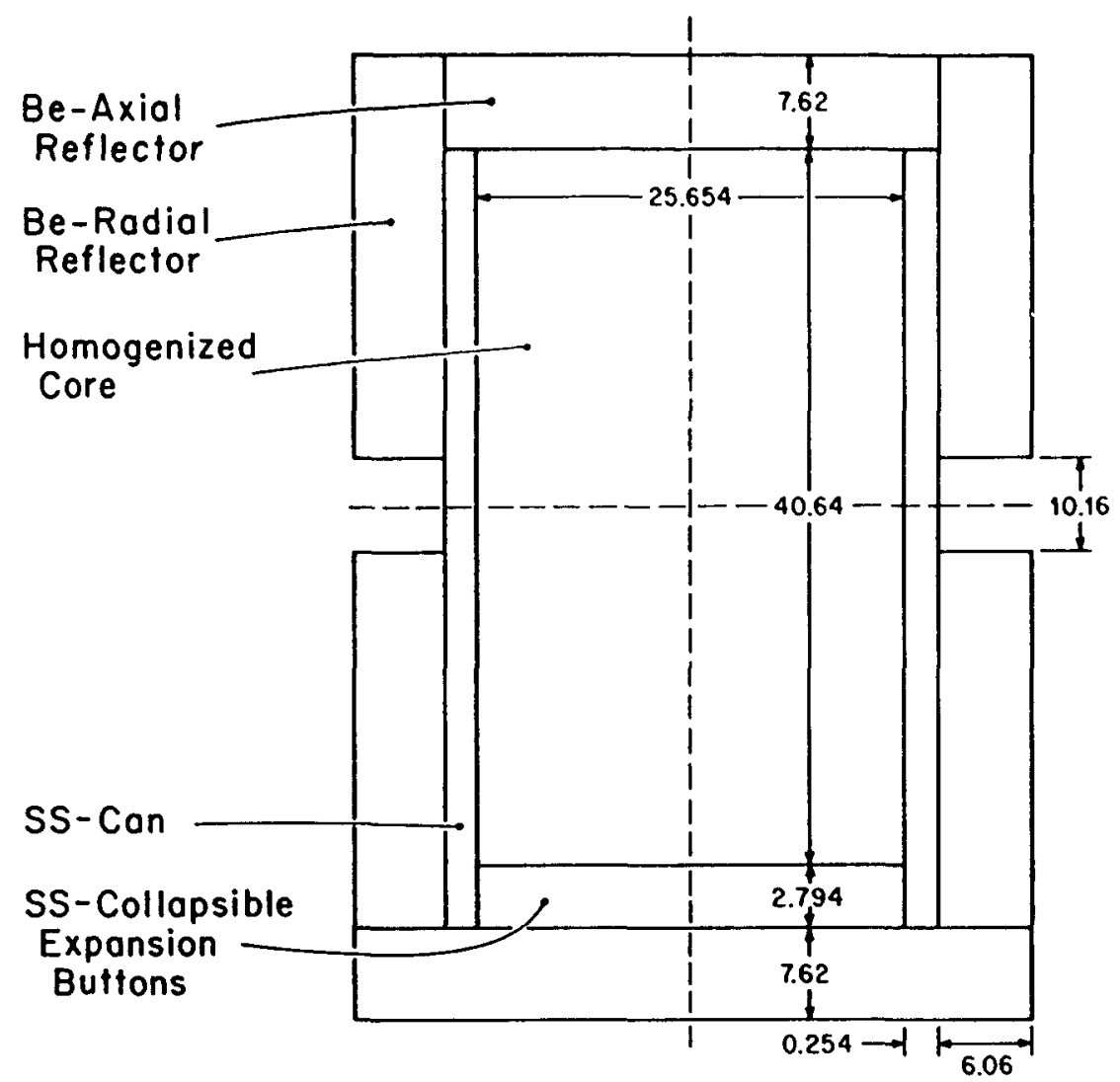

Dimensions in $\mathrm{cm}$

Figure 2-2. Schematic diagram of conceptual design \#2.

Table 2-2. Region compositions modeled for conceptual design \#2 (shutdown)

Region

Core

Can

Axial reflector

Radial reflector

Collapsible expansion buttons
Composition (volume fraction)

U10Zr (U-Zr-H fuel) $0.694, \mathrm{Zr}(0.076)$, NaK $(0.117)$, SS $316(0.088)$

SS 316

Be

$\mathrm{Be}$

SS 316 


\subsubsection{Conceptual Design \#3}

This concept is based on a solid core reactor configuration. In this design, uranium carbide fueled microspheres coated with pyrolytic graphite and zirconium carbide are embedded into graphite matrix fuel disks. These fuel disks are then bonded into poco graphite fuel trays for support. There is no liquid coolant for this concept, and all of the fission heat generated must be conducted to the outside edges of the reactor through the fuel disks and graphite trays. Power conversion is by thermionic convertors fixed into the beryllium metal radial reflector.

Control of this reactor concept is by the use of movable beryllium metal axial reflectors. To obtain sufficient shutdown margin it was proposed that boron carbide plates should be placed on the top and bottom surfaces of the core, underneath the axial reflectors. These shutdown plates must then be removed for operation once the reactor is in space and in position for startup.

Figure 2-3 shows a schematic representation of the nominal 6 klle configuration modeled during these studies. This core is modeled in considerably greater detail than most of the other reactor concepts, primarily because of its relatively simple and heterogeneous design. The core has not been homogenized; rather, ten fuel tray/disk assemblies have been modeled. Table 2-3 gives the representative compositions of the various regions modeled. The configuration shown in Figure 2-3 is the maximum achievable, normal operation reactivity case. The launch configuration is quite similar, with the axial reflectors completely removed to provide sufficient shutdown margin. For the water immersion cases, the shutdown configuration is placed as is into a $5 \mathrm{~m}$ sphere 
of water, and for the water flooding cases, it is assumed that the axial reflectors are displaced and removed on impact, and water fills this region. Since the core itself has no coolant channels, no water is assumed to enter the core during a flooding accident.

A second basic configuration was also modeled to assess the effects of placing boron carbide in close proximity to the core exterior to attempt to reduce the thermalization and reflection of neutrons back to the core in the water immersion and flooding cases. These configurations resulted in the placement of a $0.5 \mathrm{~cm}$ thick $\mathrm{B}_{4} \mathrm{C}$ annulus around the outside of the radial reflectors, outside of the thermionic elements, and a $3 \mathrm{~cm}$ thick disk of $\mathrm{B}_{4} \mathrm{C}$ being placed on the top and bottom surfaces of the core. In addition, a very small hole (on the order of a few millimeters in diameter) is included in the central column of graphite for fission gas collection and removal. In the maximum reactivity case, the $B_{4} C$ disks are removed and the axial reflectors are replaced on the top and bottom of the core. For the shutdown configuration, the disks are placed underneath the axial reflectors and for the water immersion case, this configuration is maintained during immersion. For the flooding case, it is assumed that the axial reflectors are displaced and removed on impact, that the boron carbide shutdown plates are dislodged from their positions, and water fills each of these regions. In all cases, however, the radial annulus of boron carbide remains intact. 


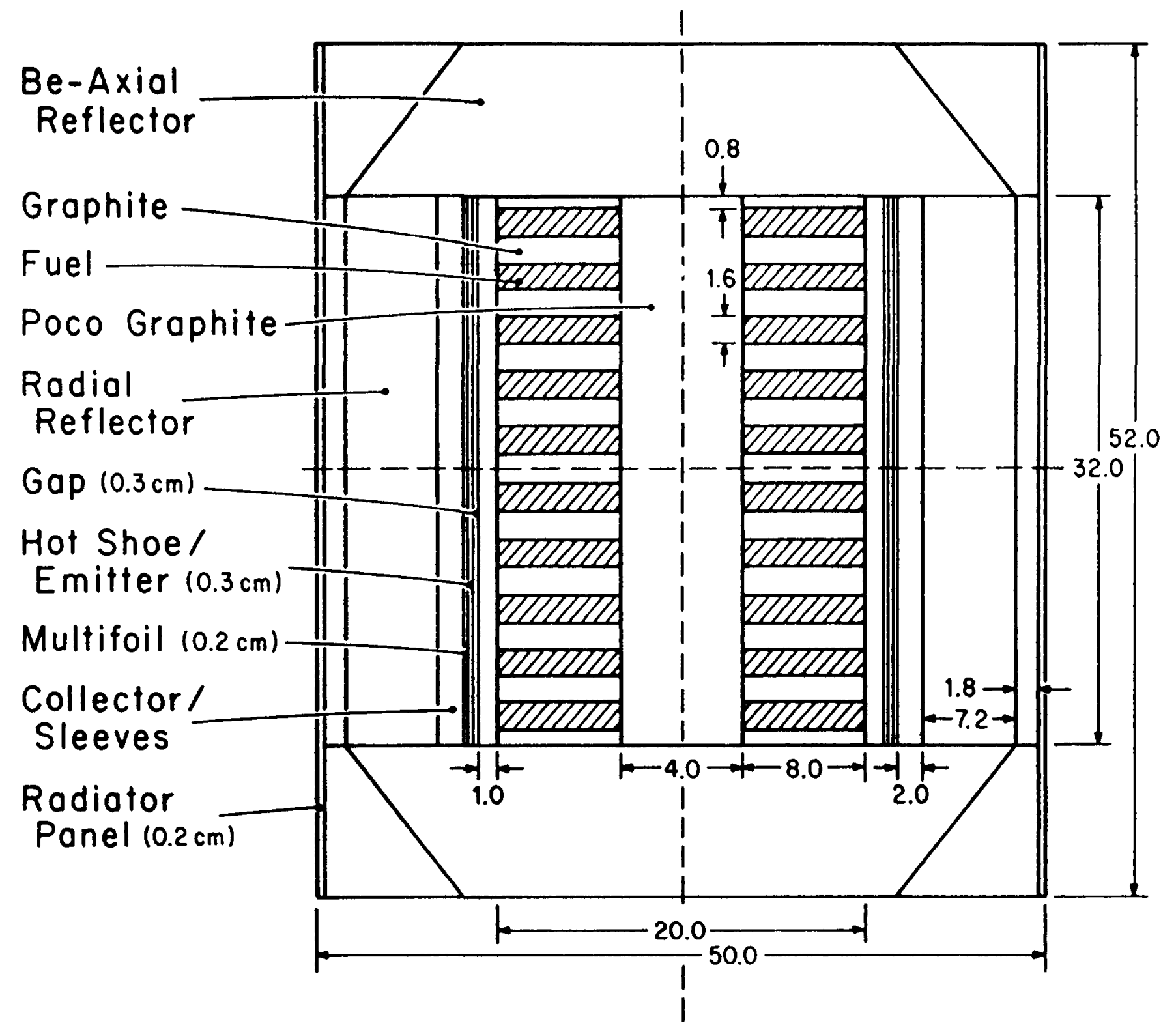

Dimensions in $\mathrm{cm}$

Figure 2-3. Schematic diagram of conceptual design \#3. 
Table 2-3. Region compositions modeled for conceptual design \#3 (operating)

$\begin{array}{ll}\text { Region } & \text { Composition (volume fraction) } \\ \text { Core } & \text { UC }(0.438) \text {, Graphite (0.562) } \\ \text { Hot shoe/emitter } & \mathrm{W} \\ \text { Multifoil insulation } & \mathrm{Nb}-\mathrm{Ta} \\ \text { Collector/sleves } & \mathrm{Be}-\mathrm{Nb}-\mathrm{W} \\ \text { Radiator panel } & \mathrm{Nb} \\ \text { Axial reflector } & \mathrm{Be} \\ \text { Radial reflector } & \mathrm{Be}-\mathrm{Nb}-\mathrm{Al}_{2} \mathrm{O}_{3} \text { mixture }\end{array}$




\subsubsection{Conceptual Design \#4}

This reactor conceptual design utilizes a uranium-yttrium-hydride $(U-Y-H)$ fuel fabricated into plates and clad with stainless steel. The uranium enrichment is $92 \%$. It is primarily a SNAP derivative concept, except that the zirconium used in the SNAP program is replaced with yttrium for the purpose of extending the high temperature range of operation for the reactor. This fuel type may be useful at temperatures up to $1000 \mathrm{~K}$, rather than the $800 \mathrm{~K}$ limit for $\mathrm{U}-\mathrm{Zr}-\mathrm{H}$ based fuels, due to its better high temperature retention of hydrogen [10]. Heat is removed from the core by means of disk shaped heat pipe fuel elements, and power conversion is by thermoelectric convertors attached to the outside surface of the core. Heat pipes are then used on the cold side of the thermoelectrics to radiate the waste heat into space.

Figure 2-4 shows the nominal $1.0 \mathrm{kWe}$ model used for this reactor configuration. The reflector regions are in general treated as homogenized sections, but three core zones are included. There are two fuel zones represented by the plate-type heat pipes. These are shown as the "Central Fuel Zone" and the "Outer Fuel Zone." The third fuel region is part of a reversible fuel plug, made of uranium oxide clad with stainless steel. This fuel plug can be removed, reversed, and replaced for shutdown and launch configurations. The reversed, or shutdown, section of the fuel plug contains boron carbide. Thus, the model shown in Figure 2-4 is the maximum reactivity case. Reactivity is to be controlled during operation through the use of a sliding sleeve radial reflector arrangement. The compositions of the various regions are seen in Table 2-4. Note also that, due to the lack of nuclear data for yttrium, zirconium has 
been substituted for yttrium throughout the core. This could greatly affect the results obtained for this concept since yttrium has a significantly higher thermal absorption cross section than does zirconium. For the launch configuration, the sliding sleeve radial reflector is removed, and the reversible fuel plug is arranged so that the boron carbide end of the plug is inserted into the core region. This configuration was also used for the water immersion cases. For the flooding cases it is assumed that the sliding sleeve reflector is removed and water fills this region as well as all of the void spaces in the plate type heat pipes. It is also assumed that the central reversible fuel plug is dislodged on impact and water fills this region. 


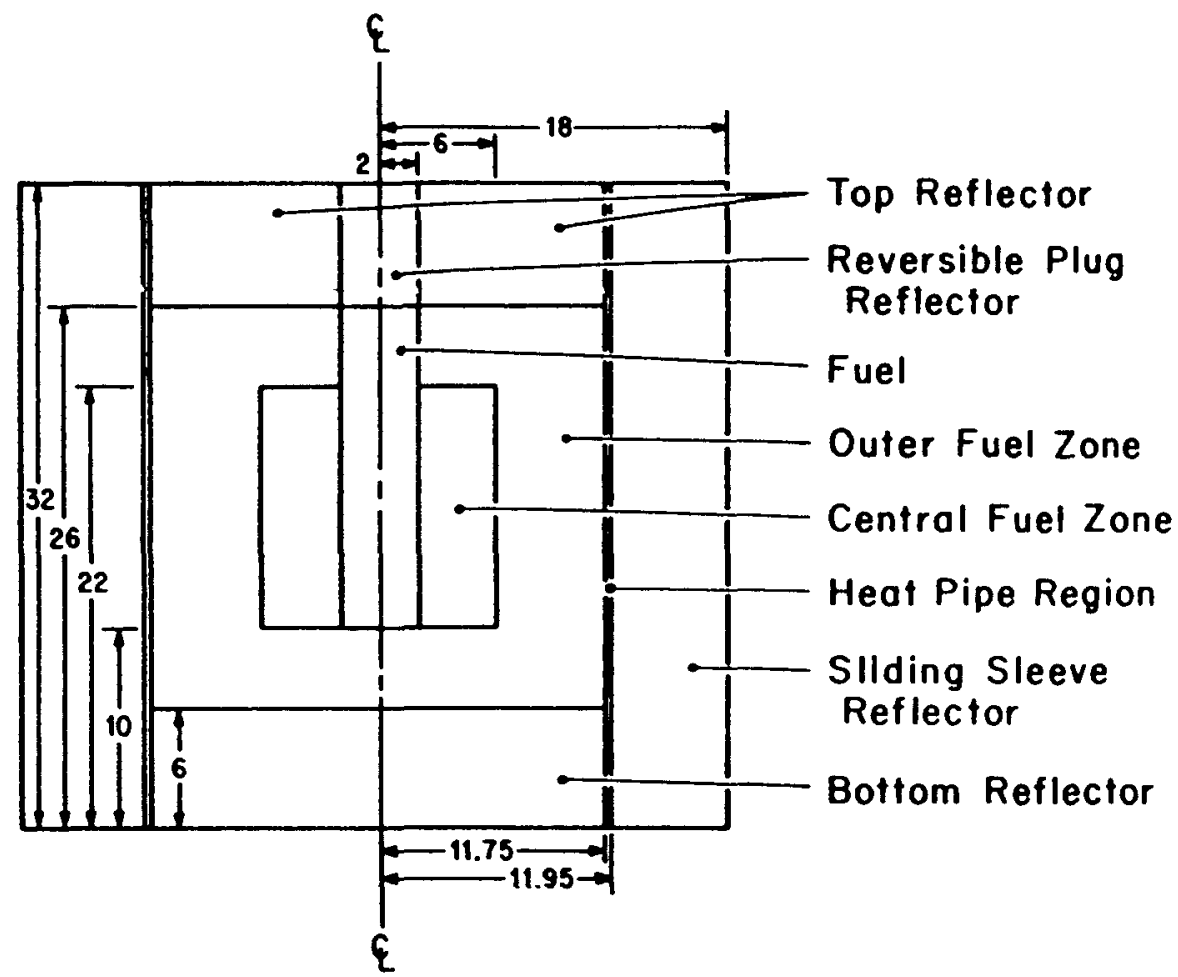

Dimensions in $\mathrm{cm}$

Figure 2-4. Schematic diagram of conceptual design \#4.

Table 2-4. Region compositions modeled for conceptual design \#4

Region

Reversible fuel plug

Central fuel zone

Outer fuel zone

Reflectors

Heat pipes

\section{Composition (volume fraction)}

Uranium oxide (operating), $\mathrm{B}_{4} \mathrm{C}$ (shutdown)

$\mathrm{U}-\mathrm{Y}-\mathrm{H}$ alloy

$U-Y-H$ alloy

Be metal

$\mathrm{Fe}$ 


\subsubsection{Conceptual Design \#5}

This reactor concept is a fast fission, heat pipe cooled core fueled with uranium/plutonium mixed oxide fuel and clad with a molybdenum/rhenium alloy. The uranium enrichment is $100 \%$ and $\mathrm{Pu}^{240}$ is the only plutonium isotope used in the fuel. (Note: Cases were also run with 100\% enriched uranium replacing the $\mathrm{Pu}^{240}$ on an atom per atom basis. These cases will be designated as Conceptual Design \#5/URANIUPi). Heat removal is accomplished by the use of lithium heat pipes constructed from a tungsten/rhenium rhenium alloy, and power conversion is by out of core thermionic convertors.

Control is achieved by boron carbide poison drums integrated with radial reflectors made of beryllium oxide. A central channel is provided for a shutdown control rod of boron carbide. Figure 2-5 shows a nominal $6 \mathrm{kWe}$ reactor configuration for the maximum reactivity cases, and Table 2-5 shows the represented region compositions. For shutdown and launch, the control drums are rotated in order to face their boron carbide surfaces toward the core and the central control rod is inserted. This configuration is then maintained for the water immersion cases. For the flooding accident scenario it is assumed that the control drums remain intact and in their shutdown configuration due to their integration into the radial reflector. It is also assumed that the central control rod remains in place and that all of the heat pipes are sheared off and water allowed to fill their inside volumes. 


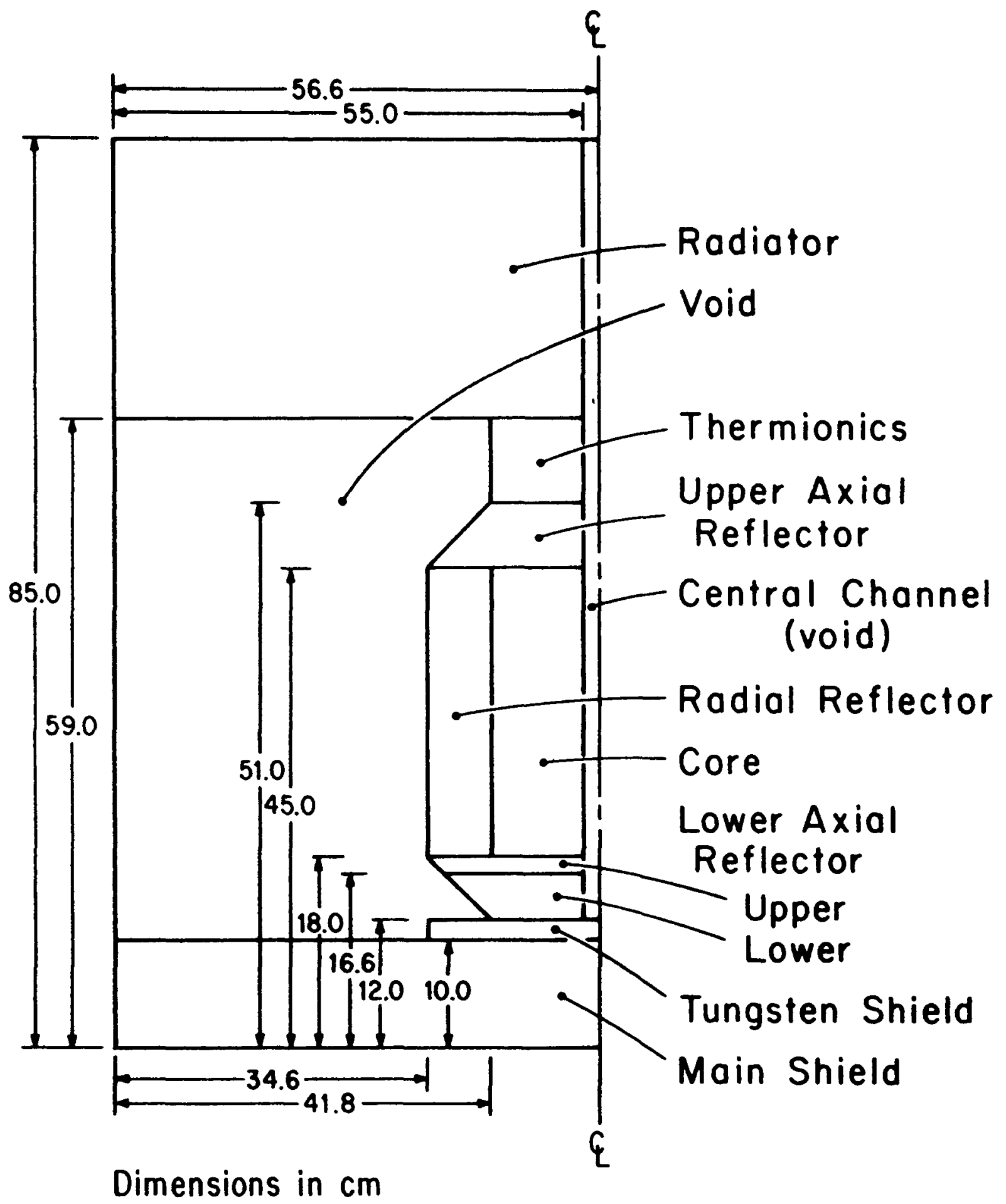

Figure 2-5. Schematic diagram of conceptual design \#5. 
Table 2-5. Region composition modeled for conceptual design \#5

Region

Central channel

Core

Upper reflector

Lower reflector top portion bottom portion

Radial reflector

Tungsten shield

Main shield

Thermionics

Radiator
Composition (volume fraction)

Void (operating); $\mathrm{B}_{4} \mathrm{C}$ (shutdown)

U-Pu oxide $(0.86), W(0.14)$

$\operatorname{Be} 0(0.86), W(0.14)$

$W(0.05), \operatorname{BeO}(0.95)$

$\mathrm{BeO}$

$\operatorname{BeO}(0.5), B_{4} C(0.5)$

W

LiH

W, Mo

Mo 


\subsubsection{Conceptual Design \#6}

This concept is a thermal fission, heat pipe, solid core reactor system. The fueled region consists of uranium carbide microspheres coated with pyrolytic graphite and zirconium carbide uniformly embedded into a beryllium metal matrix. Beryllium metal is utilized for both the axial and radial reflectors. Inert gas controlled, lithium heat pipes constructed of $\mathrm{Nb}-1 \mathrm{Zr}$ are placed within the core to remove the heat which is generated during operation. Heat is transferred through the fuel to the heat pipes by conduction and then to an AMTEC energy conversion system. The nominal power of the reactor modeled was $1 \mathrm{klW}$.

This reactor is controlled by two independent control systems as seen in Figure 2-6. The first control mechanism is achieved through the use of shutdown control rods which penetrate the core, and the second consists of rotating control drums embedded into the radial reflector. The compositions of the regions modeled is shown in Table 2-5. Figure 2-6 represents a maximum reactivity case in which the internal control rods are fully removed and the control drums are rotated outwardly. For shutdown and launch configurations, the control drums are rotated inward and the shutdown rods are inserted. The water immersion cases also utilize this configuration. For the flooding cases the control drums are removed, the central control rod is assumed to remain intact, and all of the heat pipes are filled with water. 


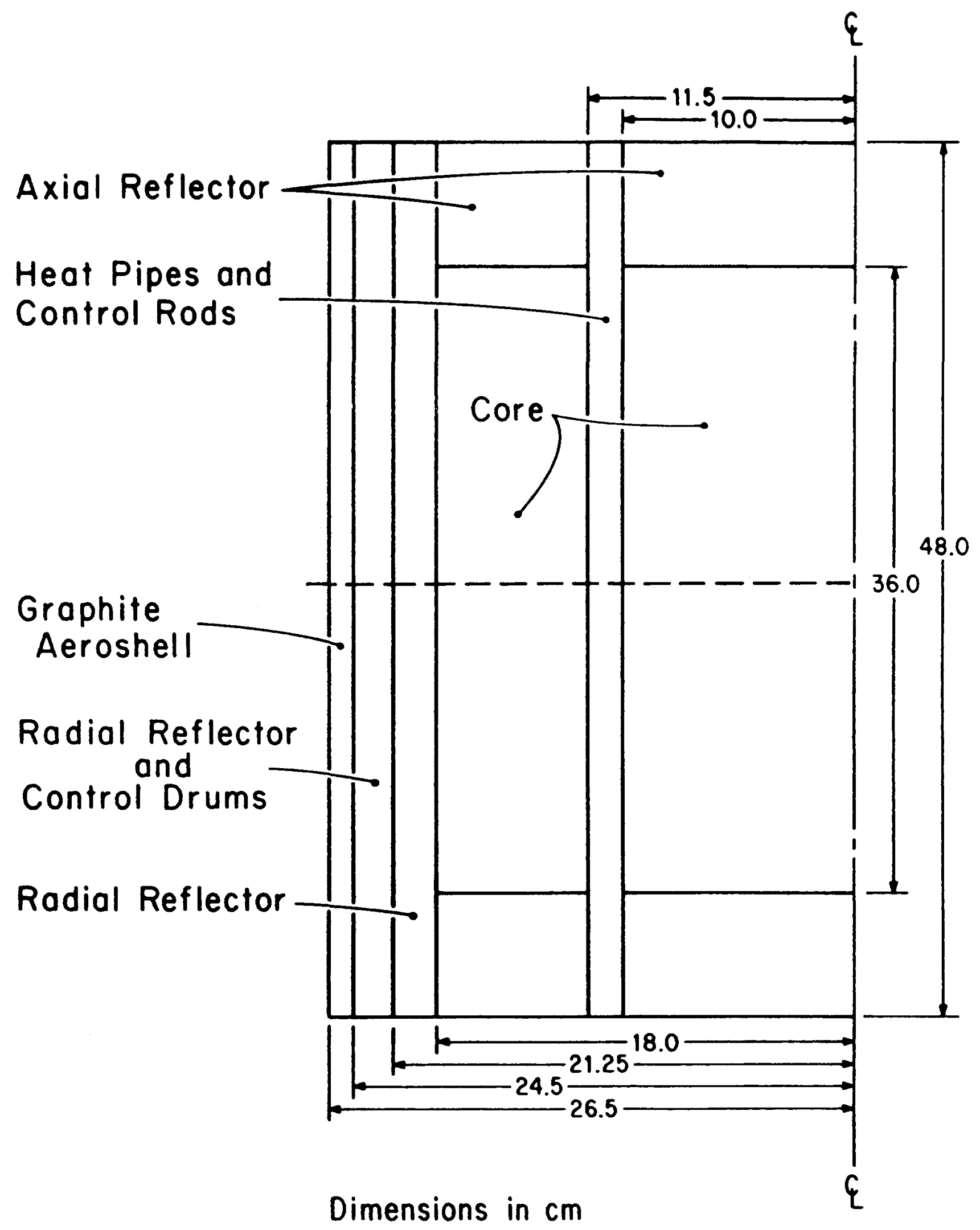

Figure 2-6. Schematic diagram of conceptual design \#6. 
Table 2-6. Region compositions modeled for conceptual design \#6

Region

Core

Heat pipes and control rods

Radial reflector*

Radial reflector and control drums*

Axial reflector

Graphite aeroshell
Composition (volume fraction)

Uranium carbide $(0.24)$, $\operatorname{ZrC}(0.08), C(0.08)$, Be $(0.60)$

Uranium carbide (0.223), $\operatorname{ZrC}(0.074), C(0.074)$, Nb $(0.156)$, Li $(0.158)$, Boron carbide $(0.314)$ (shutdown), without $\mathrm{B}_{4} \mathrm{C}$ for operating case

$\mathrm{Be}$

Boron carbide $(0.36)$, Be $(0.64)$

$\mathrm{Be}$

Graphite

* Operating case shown; for shutdown case the radial reflector and control drums region is reversed with the radial reflector region. 


\subsection{CRITICALITY FEASIBILITY AND SAFETY EVALUATION}

\subsection{Conceptual Design 11}

The initial feasibility results for this reactor concept are quite encouraging. In the first three cases shown in Table 3-1 (maximum reactivity, launch configuration, and water immersion) this reactor concept nearly meets the criticality objectives. The launch configuration case only slightly exceeds the objective of 0.90 , and the addition of a small amount of boron carbide would easily help reach that goal. The one case which significantly fails to meet the goal is the water flooding case. This occured because water was assumed to completely replace the lithium coolant while the reactor core configuration was maintained. Since the exposure of lithium to water or air causes a violent fire, it is unlikely that this core configuration could be maintained during such an accident. Also, the addition of extra control rods in the core could be utilized; additional parasitic absorbers, $U^{238}$ for example, could be incorporated directly into the fuel material, or a small fraction of $L i^{6}$ could be included in the coolant to reduce this $k_{e f f}$ value. The last two adjustments are particularly interesting in that small amounts of these materials would serve to insure the launch configuration subcriticality requirement and could then be burned up in the reactor in a rather short time. The U238 addition would be especially helpful in that $\mathrm{Pu}^{239}$ which would be produced could be utilized to reduce the amount of $U^{235}$ necessary at launch to ensure a 7 year reactor lifetime. 
Table 3-1. Criticality feasibility and safety evaluation (keff) results for conceptual design \#l

\author{
MAXIMUM \\ REACTIVITY
}

1.08

\author{
LAUNCH \\ CONFIGURATION
}

0.91

\section{WATER}

IMMERSION

0.95
WATER

FLOODING

1.02 


\subsection{Conceptual Design $\$ 2$}

The results for the second reactor conceptual design are shown in Table 3-2. Due to the homogeneous nature of the calculations, a range of gadolinium burnable poison values, from 0.00 to 0.02 weight percent, are shown. As can be seen, a considerable amount of fine tuning of this burnable poison is still required; however, the optimal value should fall close to 0.01 weight percent. It is obvious that at gadolinium levels less than 0.01 weight percent it is difficult to show that the reactor has sufficient shutdown margin, yet at much above this level it will be difficult to get the reactor to reach criticality. It is also obvious that this reactor concept has a problem for both the water immersion and flooding cases. This can be explained largely by the fact that this concept is based on the old SNAP safety criteria which placed a different emphasis on the direction of reactor criticality during water immersion accidents than is required today. The philosophy at that time was to allow the reactor to go supercritical during such an accident and disperse itself rapidiy, thereby creating few fission products and little environmental concern. Thus, in order for a SNAP based reactor system to meet the requirement for subcriticality under these accident conditions a core re-design is needed.

It is interesting to note that the $k_{\text {eff }}$ values for the water immersion accident scenarios are higher than those for the water flooding cases. This results because the sliding beryllium radial reflector is allowed to fall off during the water flooding accident, and it stays attached for the water immersion case. This shows that the beryllium reflector is a more efficient neutron reflector for this reactor configuration than water. 
Table 3-2. Criticality feasibility and safety evaluation $\left(k_{e f f}\right)$ results for conceptual design $\# 2$

MAXIMUM

REACTIVITY

$1.09^{1}$

$1.06^{2}$

$1.03^{3}$
LAUNCH

CONFIGURATION

1.02

0.97

0.92
WATER

IMMERS I ON

1.15

1.10

1.03

WATER

FLOODING

1.12

1.06

1.01

1. No gadolinium internal poison.

2. Internal gadolinium poison in fuel zone, 0.01 weight percent.

3. Internal gadolinium poison in fuel zone, 0.02 weight percent. 


\subsection{Conceptual Design 13}

Table 3-3 shows the criticality results for the third reactor concept. The initial data input for this concept resulted in the keff values given on the first line of the table. The maximum reactivity case is close to the required value and the launch configuration, without the shutdown disk and with the axial reflectors (which are to be used for control) completely removed, lies slightly above the target value of 0.90. The original configuration for the water immersion case is only slightly subcritical and greatly exceeds the limiting criterion. This occurs because of the reflection and moderation of neutrons escaping through the ends of the reactor. In order to exclude water from the core/reflector regions in the water immersion case, a void region is assumed in this case where the axial reflectors would be placed for normal operation. This accident scenario assumes that there is a solid container around the reactor, acting as a water barrier. In the flooding case, water is allowed to fill all of these spaces, and, due to its proximity to the core, acts as a significantly better neutron moderator and reflector than in the immersion case, causing an increase in $k$ eff to 1.07 .

The second line of Table 3-3 contains the $k$ eff values for a modified configuration of conceptual design \#3. In this configuration, $3 \mathrm{~cm}$ thick disks of $\mathrm{B}_{4} \mathrm{C}$ are provided on the top and bottom of the core during launch to reduce the possibility of a criticality accident due to water immersion. In addition, a $0.5 \mathrm{~cm}$ thick annulus of $\mathrm{B}_{4} \mathrm{C}$ surrounding the radial reflectors is provided. A small increase in the maximum reactivity is observed over the original configuration. This is apparently due 
to the imperfect absorption of the $B_{4} C$ radial strips and a slight amount of reflection from these strips. In the original case, any neutron leaking into this region is assumed to have escaped from the system, but the inclusion of any material, even a very good absorber like $B_{4} C$ slightly increases the possibility of reflection. This conclusion can also be reached in comparing the two launch configuration results. In the original configuration, any neutron which crosses the top or botion surfaces of the core is assumed to be removed. In the modified configuration, a small amount of reflection is possible from the combined shutdown disk and axial reflector.

The addition of the $B_{4} C$ to this configuration shows its benefit in the water immersion and flooding cases. There is very little increase in the amount of reflection achieved by adding a $5 \mathrm{~m}$ sphere of water around the shutdown configuration. This shows how effective the boron carbide is in cutting off the return of neutrons to the core once they have leaked out of the reactor vessel. Any neutron which escapes the reactor and enters the water has very little possibility of becoming thermalized and being reflected into the core. The $B_{4} C$ is very useful in absorbing these returning neutrons, especially in the water immersion case. The effect is also important in the flooding case in reducing the value of keff from 1.07 to 1.03 . However, this is still an unacceptable result since it allows supercriticality. A reactor re-design that prevents removal of the $3 \mathrm{~cm} \mathrm{~B}_{4} C$ shutdown disks, or prevents water flooding is required. 
Table 3-3. Criticality feasibility and safety evaluation ( $k_{e f f}$ ) results for conceptual design \#3.

$\begin{array}{cccc}\text { MAXIMUM } & \text { LAUNCH } & \text { WATER } & \text { WATER } \\ \text { REACTIVITY } & \text { CONFIGURATION } & \text { IMMERSION } & \text { FLOODING }\end{array}$

$\begin{array}{lcccc}\text { ORIGINAL } \\ \text { CONFIGURATION } & 1.04 & 0.93^{1} & 0.99 & 1.07 \\ \begin{array}{l}\text { MODIFIED } \\ \text { CONFIGURATION }\end{array} & 1.05^{2} & 0.95^{3} & 0.95 & 1.03^{4}\end{array}$

1. Boron carbide launch shutdown disk removed from proposer's configuration. Axial reflectors removed completely for launch.

2. Small central hole for fission gas collection and $B_{4} C$ radial strips $(1.5 \mathrm{~cm})$.

3. Axial shutdown disks $\left(B_{4} C\right)$ on top and bottom and axial reflectors placed on top of shutdown disks.

4. Axial reflectors and $B_{4} C$ axial shutdown disks removed prior to flooding. Radial $B_{4} C$ strips remain intact. 


\subsection{Conceptual Design 14}

A large number of cases were required for conceptual design \#4, since this reactor could not achieve initial criticality as shown in the first line of Table 3-4. A variety of design changes were attempted in order to achieve the desirable range of criticality values for maximum reactivity. The initial changes which were made involved adjusting the location of the uranium fuel within the inner and outer fuel zones of the heat pipe plates. It was found that varying the location of the fuel had an effect on the keff values, and that criticality was approached when only $1 / 4$ to $1 / 3$ of the uranium was placed in the inner fuel plate region and $2 / 3$ to $3 / 4$ in the outer region. The initially proposed concept had $2 / 3$ of the uranium in the inner fuel region. However, this adjustment by itself was insufficient to provide enough available reactivity for reactor start up, and in order to achieve criticality, the core was made larger as shown on the bottom line on Table 3-4. In all of the cases on this line, the inner core region shown in Figure 2-4 was increased by $3.75 \mathrm{~cm}$ in radius and $4 \mathrm{~cm}$ in height. The inner fuel region was increased from $6 \mathrm{~cm}$ to $9.75 \mathrm{~cm}$ in radius, the outer fuel region increased from $11.75 \mathrm{~cm}$ in radius to $13.75 \mathrm{~cm}$, and the overall radius of the reactor system was increased from $18 \mathrm{~cm}$ to $20 \mathrm{~cm}$. Also, the overall height of the reactor was increased from $32 \mathrm{~cm}$ to $36 \mathrm{~cm}$, and the central fuel zone height was changed from $12 \mathrm{~cm}$ to $16 \mathrm{~cm}$. The resulting configuration shows quite satisfactory results for the maximum reactivity, launch configuration (achieved by inserting the boron carbide end of the reversible fuel plug and removing the sliding radial reflector 
sleeve), and the water immersion cases. This is due to the large amount of negative reactivity from the reversible fuel/shutdown $\mathrm{plug}$ and from the effectiveness of the sliding radial reflector. (Note: The use of such a reversible fuel/shutdown plug requires an in-space operation that would allow for the removal, rotation, and replacement of this fuel plug. This concept feature needs further study.)

A significant problem exists for the water flooding case which results in supercriticality. This occurs for two reascins. The first is that on impact, the reversible fuel/shutdown plug is assumed to be dislodged. However, should the shutdown plug remain in place, the keff value would more closely approach the 0.93 value for the water immersion case. The second reason is that water is assumed to enter the shutdown plug region, the sliding radial reflector spaces, and displace the coolant in the heat pipe plates. This considerable amount of water provides a significant amount of neutron moderation, thus increasing keff. A re-design of the shutdown plug hold-down scheme to assure intact re-entry and impact is required. 
Table 3-4. Criticality feasibility and safety evaluation (keff) results for conceptual design \#4

MAXIMUM
REACTIVITY

$0.87^{1}$

$0.98^{2}$

$0.99^{3}$

$0.95^{4}$

$0.84^{5}$
LAUNCH

CONFIGURATION

0.57

0.83
WATER

IMMERSION

WATER

FLOODING
$1.07^{6}$

$0.75^{6}$

$0.93^{6}$

$1.07^{6}$

1. Cases run as received from proposer.

2. 1/4 of the uranium in the inner fuel region, remainder in outer region.

3. 1/3 of the uranium in the inner fuel region, remainder in outer region.

4. 1/2 of the uranium in the inner fuel region, remainder in outer region.

5. $3 / 4$ of the uranium in the inner fuel region, remainder in outer region.

6. 1/4 of the uranium in the inner fuel region, remainder in outer region, and core inner region increased in radius by $2 \mathrm{~cm}$ and $4 \mathrm{~cm}$ in height. Thickness of all other regions maintained. 


\subsection{Conceptual Design $\$ 5$}

A variety of cases were also considered for conceptual design \#5. Table 3-5 and the accompanying footnotes present the results for two slightly different reactor concepts. As stated earlier, the difference between the two is the replacement of the $\mathrm{Pu}^{240}$ in the conceptual design

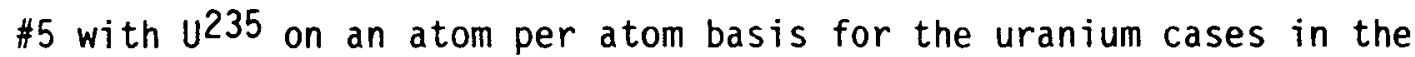
lower half of the table. The top line of the table contains the results of the calculations using the detailed geometry provided by the concept's proposer. However, a flaw was found in the data describing the geometry of the concept, and when corrected, the result was a small increase in $k_{\text {eff }}$ for the maximum reactivity cases. The third line of the table (footnote 3 ) contains an even more appropriate reactor configuration in which the control drums are more adequately treated. This configuration then is utilized as the "base case" for the subsequent calculations.

The launch configuration result $\left(k_{e f f}=0.94\right)$ shows that additional negative reactivity is needed in this concept to provide adequate $(0.90)$ shutdown prior to launch. The addition of the central control rod is insufficient $\left(k_{\text {eff }}=0.93\right)$ to accomplish this and some other method is required. The water immersion case, however, does meet the requirements. This is caused by the already efficient reflectors which were used in this design.

A variety of accident scenarios were modeled for the water flooding cases. In all of these cases the control drums remain intact and in their shutdown configuration. The first case assumed that the heat pipes and core void spaces were flooded with water and the central control 
rod was removed. In this case, as well as for all of these cases, keff exceeds the limit of 0.95 . The second configuration shows the effects of adding the central control rod, and while keff is less than 1.00 it does not meet the 0.95 criterion. The final two cases show the effects of flooding the heat pipes. In the first case it is seen that not flooding these spaces with water has very little effect on keff. There is a larger control rod effect in the final case without the water inside the heat pipes.

The uranium results are seen in the lower half of the table. Similar results and trends are seen as just presented for the $\mathrm{Pu} 240$ cases. The one major difference is the increase in all of the keff values across the table. While the maximum reactivity values now fall within the acceptable range, all of the other results either now move out of the acceptable range or move farther outside the range. It is obvious that a considerable amount of re-design is necessary, especially for control and launch safety, if the $\mathrm{Pu}^{240}$ is to be replaced by $\mathrm{U}^{235}$. 
Table 3-5. Criticality feasibility and safety evaluation (keff) results for conceptual design $\# 5$ and conceptual design $\# 5 /$ uranium.

$\begin{array}{lcccc} & \begin{array}{c}\text { MAXIMUM } \\ \text { REACTIVITY }\end{array} & \begin{array}{c}\text { LAUNCH } \\ \text { CONFIGURATION }\end{array} & \begin{array}{c}\text { WATER } \\ \text { IMMERSION }\end{array} & \begin{array}{c}\text { WATER } \\ \text { FLOODING }\end{array} \\ \text { CONCEPTUAL } & 1.04^{1} & 0.94 & 0.99 & 1.13 \\ \text { DESIGN \#5 } & 1.05^{2} & & & \\ & 1.04^{3} & 0.94^{4} & 0.94 & 1.00^{6} \\ & & 0.93^{5} & & 0.98^{7} \\ & & & & 1.00^{8} \\ \text { CONCEPTUAL } & 1.06^{2} & & & 0.96^{9} \\ \text { DESIGN \#5/URANIUM10 } & 1.07^{11} & 0.96^{12} & 0.97 & 1.09^{14} \\ & & 0.93^{13} & & 1.04^{15} \\ & & & & 1.06^{16} \\ & & & & \end{array}$

1. Cases run as received from proposer.

2. Corrected symmetrical geometry--upper reflector and upper core $3 \mathrm{~cm}$ higher.

3. Footnote 2 with control drums simulated in operational configuration.

4. Footnote 2 with control drums simulated in shutdown configuration and wi thout shutdown rod.

5. Additional shutdown margin provided by insertion of shutdown rod.

6. Heat pipes flooded, core flooded, and without control rod inserted.

7. Heat pipes flooded, core flooded, and control rod inserted.

8. Heat pipes not flooded, core flooded, and without control rod inserted.

9. Heat pipes not flooded, core flooded, and control rod inserted.

10. Replace $\mathrm{Pu}^{240}$ with $\mathbf{U}^{235}$ on an atom per atom basis.

11. Footnote 3 with control drums in operational configuration.

12. Footnote 7 with control drums in shutdown configuration.

13. Additional shutdown margin provided by insertion of shutdown rod.

14. Heat pipes flooded, core flooded, and without control rod inserted.

15. Heat pipes flooded, core flooded, and control rod inserted.

16. Heat pipes not flooded, core flooded, and without control rod inserted.

17. Heat pipes not flooded, core flooded, and control rod inserted. 


\subsection{Conceptual Design 16}

The final reactor concept considered shows the most favorable criticality feasibility and safety results. As seen in Table 3-6 for the primary cases, all of the reactivity values fall within the desirable limits. The maximum reactivity of 1.07 is in the middle of the acceptable range. The launch configuration and water immersion cases show a considerable amount of available negative reactivity for shutdown and immersion accident considerations. Even with the removal of the control drums on impact and the flooding of the core heat pipes, the keff value for the water flooding case is less than 0.95 .

A few extra cases were run to determine the relative shutdown capabilities of the control rods and drums. As can be seen in Table 3-6, the rotation of the control drums to their operational configuration while the control rods are inserted has only a small effect on $k_{e f f}$. The reverse situation is not true, however. If the control drums are placed in their shutdown configuration and the control rods are removed, then criticality will be approached. Thus, a small re-design of the effectiveness of the control drums is suggested in order that by themselves they are capable of providing sufficient negative reactivity to maintain subcriticality.

A highly unlikely water flooding accident was also considered in which the core remains intact, all the control rods and control drums are removed, and the reactor is filled with water. In this case the reactor would go super critical. 
Table 3-6. Criticality feasibility and safety evaluation (keff) results for conceptual design \#6

MAXIMUM
REACTIVITY

1.07

\author{
LAUNCH \\ CONFIGURATION
}

$0.78^{1}$

$0.83^{2}$

$$
1.00^{3}
$$

WATER
IMMERSION

0.78

$0.93^{4}$

$1.16^{5}$
WATER FLOODING

1. Control rods inserted and drums turned to shutdown configuration.

2. Control rods inserted and drums turned to operational configuration.

3. Control rods removed and drums turned to shutdown configuration.

4. Control rods remain in core and control drums removed during flooding.

5. All control rods and drums removed during flooding. 


\subsection{SUIMARY AND CONCLUSIONS}

There are two general conclusions reached by this study concerning small space reactors and also specific conclusions concerning each of the six small reactor conceptual designs.

1. Small reactor concepts are available from the U.S. nuclear industry which have the potential to meet both the operational and launch safety missions requirements.

2. Each of the concepts studied has the potential for useful space application; however, each design has its uncertainties and failures. All of the design concepts studied require further efforts to enable a more positive conclusion to be reached. Specific conclusions on the six conceptual designs studied are: Conceptual Design \#1

This design appears to be quite satisfactory for all cases considered, except for the water flooding case. Considerable re-design will be necessary to ensure subcriticality during such an accident scenario. Small amounts of burnable poisons for launch, or increasing the number and worth of the internal control rods are two possible adjustments. However, the unlikely possibility of replacing the lithium in the core with water without seriously dispersing the fuel into a sub-critical configuration needs to be considered. Conceptual Design \#2

This design, because it is based on the SNAP1OA launch criticality philosophy, fails both the water immersion and water flooding tests. A re-design of this reactor is necessary to incorporate more negative 
reactivity. The inclusion of poison control rods may be sufficient to provide the necessary negative reactivity.

Conceptual Design \#3

This concept includes a number of interesting features. Unfortunately, control of this reactor will be a significant problem since it utilizes only the end surfaces of the cylindrical core for reflector control. This greatly limits the amounts of positive and negative reactivity available, especially during water immersion and flooding. A proposed solution to this problem, i.e., the inclusion of boron carbide shutdown disks on the top and bottom surfaces of the core, helps matters only slightly. This is because (1) these disks must be removed in space for reactor operation, (2) even though they are very good absorbers, they still reflect a small fraction of neutrons back into the core, and (3) the disks are not likely to remain on the top and bottom core surfaces on impact during a launch accident.

\section{Conceptual Design \#4}

This concept required quite a bit of effort even to reach a critical configuration. This design also fails to meet the water flooding criteria, primarily because it is not clear how the central fuel shutdown plug can remain in place on impact in a launch accident. During such an accident a significant amount of water enters the core causing neutron thermalization and supercriticality. Considerable re-design is necessary to ensure that this cannot happen.

Conceptual Design \#5

This design also had trouble meeting the accident criteria; however, there were instances in which subcriticality was achieved, but not below 
the requirements stated. In this case, only a small amount of re-design may be needed to reach the objectives. Suggested improvements include burnable poisons in the core, and/or increased worth of the reactor shutdown and control rods. One problem associated with this design is the use of $\mathrm{Pu}^{240}$ as a fuel in the core. Switching fuel from $\mathrm{Pu}^{240}$ to U235 will require a considerable amount of core re-design since this modified concept cannot meet the safety requirements.

Conceptual Design \#6

This reactor conceptual design, as modeled, is the only concept to meet all of the requirements. It has sufficient negative reactivity included to enable it to remain subcritical during all of the accident cases modeled. Since the reactor modeled was based on an output power of only $1 \mathrm{kWe}$, scale-up to higher power levels must include the consideration that more control rods will be needed to ensure subcriticality for the water flooding case since a greater amount of water will have access to the center of the core if all of the heat pipes become flooded. 


\subsection{REFERENCES}

1. Voss, S.S., "SNAP Reactor Overview," AFWL-TN-84-14, Air Force Weapons Laboratory, Kirtland AFB, NM, August 1984.

2. Jarrett, A.A., "SNAP 2 Summary Report," AI-AEC-13068, Atomics International, Canoga Park, CA, July 1973.

3. Mason, D.G., "SNAP 8 Design Description," NAA-SR-MEM0-8740, Atomics International, Canoga Park, CA, August 1963.

4. Susnir, T. and Harncon, T., ed., "SNAP 10A Reactor Design Summary, NAA-SR-NEM0-8679, Atomics International, Canoga Park, CA, October 1964.

5. 2KW SNAP 10A Developmental Program," NAA-SR-HEM0-8818, Atomics International, Canoga Park, CA, August 1963.

6. Staub, D.W., "SNAP 10A Summary Report," NAA-SR-12073, Atomics International, Canoga Park, CA, March 1967.

7. Reese, R.T., and Vick, C.P., "Soviet Nuclear Powered Satellites," Journal of the British Interplanetary Society, Vol. 36, p. 457, 1983.

8. LANL Radiation Transport Group, "MCNP-A General Honte Carlo Code for Neutron and Photon Transport," LA-7396-11, revised, Los Alamos National Laboratory, NM, 1985.

9. Radiation Shielding Information Center, "MCNP Code Package," CCC-200, Oak Ridge National Laboratory, Oak Ridge, TN, December 1983.

10. Burdi, G.F., ed., "SNAP Technology Handbook--Volume II, Hydride Fuels and Claddings", NAA-SR-8617, Atomics International, Canoga Park, CA, November 15, 1964. 


\subsection{ACKNONLEDEEMENTS}

This study would have been difficult to perform without the assistance of quite a few individuals and corporations, especially the General Electric Company, Rockwell International, GA Technologies Inc., Space Power Inc., and Hestinghouse Electric Inc., for providing details on their design concepts. H. Bloomfield, NASA Lewis Research Center, M. Shirbacheh, Jet Propulsion Laboratory, D. Carlson, Los Alamos National Laboratory, D. Gallup, Sandia National Laboratory, E. Kennel, Wright Patterson Air Force Base, and M. Schuller, Kirtland Air Force Base, have all provided useful comments and information to this study. 
JPL D.4575

\section{Reactor/Spacecraft Integration Study}

Ross M. Jones

October 10, 1987

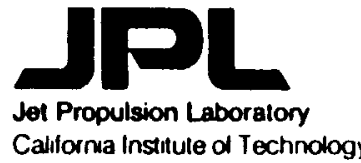


BLANK 
AGENDA

PAGE

INTRODUCTION

63

TASK \#1

67

TASK \#2

92

STUDY SUMMARY

102

RECOMMEMDATIONS

104 
BLANK 


\section{INTRODUCTION}

This study is part of a broad-scope assessment of nuclear reactor power feasibility for NASA and civil applications undertaken at the request of NASA HQ code RP. The study took place between about February 1 and June 30 1987. Selected members of the MMII spacecraft and mission design teams at JPL provided support and review of the results. Technology inputs for electric propulsion and small reactor power systems (RPS) were received from the Jet propulsion Laboratory (JPL) and the NASA Lewis Research Center (LeRC) respectively.

At the start of this study it was anticipated that the characteristics (primarily mass versus power) of the RPS would be provided. However as the study progressed it became clear that there was no consistent definition of a small RPS. Therefore the study took the approach of defining the relationship between flight time and the allowable mass and power of the RPS. In this manner the RPS technologists are given technology goals for this class of NASA deep space missions.

The participants of this study were as follows. Unless otherwise noted all participants are JPL employees.

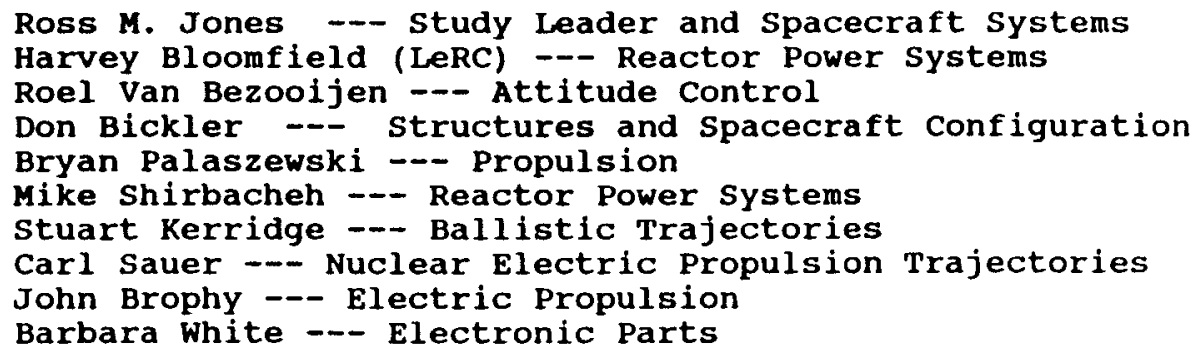

A complete package of the detailed technical inputs and results of this study is contained in the appendix to this document. The appendix, while not included with this document, is available from the study leader.

REACTOR/SPACECRAFT INTEGRATION STUDY

DESCRIPTION

- LEADER/RESOURCES: ROSS JONES / \$40K

- SCHEDULE: FEBRUARY THROUGH JULY 1987

- Deliverable: final presentation tO H.Q.

- OBJECTIVE: INVESTIGATE THE COMPATIBILITY BETWEEN SMALL REACTORS AND THE CASSINI SPACECRAFT AND MISSION.

- APPROACH: UTILIZE MMII SPACECRAFT AND MISSION DESIGN TEAMS

AND "REFERENCE" CASSINI DESCRIPTION ALONG WITH

TECHNOLOGY INPUTS FROM LERC AND JPL. 
STUDY OBJECTIVES

There were two basic objectives of this study: 1) investigate the compatibility between a small Reactor Power system (RPS) and the Mariner Mark (MM) II Cassini spacecraft and mission and 2) determine the utility of a low power Nuclear Electric Propulsion NEP system for the Cassini mission.

In the context of this study, mission compatibility was investigated only to the extent of understanding the flight time impacts of a small RPS and a low power NEP system.

The MMII program was chosen as the example application for this study because MMII is the next generation deep space spacecraft being proposed for development by JPL and the Cassini mission would be the first MMII mission to require a power source that is independent of the sun.

The second objective came from the first by the following path. It was anticipated that a small RPS would create a trip time penalty for the Cassini mission relative to the reference case. The second objective was to determine whether an increase in the power of the RPS and the use of an electric propulsion subsystem could eliminate the trip time penalty. Once the spacecraft has reached its destination and the electric propulsion subsystem was no longer required, the additional electric power could be used to enhance the science investigations.

JPL

\author{
STUDY OBJECTIVES
}

OBJECTIVE 1: DETERMINE HHETHER A SMALL REACTOR POWER SYSTEM (RPS) CAN BE SUCCESSFULLY INTEGRATED ONTO THE MARINER MARK II CASSINI SPACECRAFT/MISSION.

APPROACH: 1) RTG "REPLACEMENT"

II) PERFORM THE SAME SCIENCE WITH THE SAME LAUNCH VEHICLE USING THE SAME SPACECRAFT

(II) MAINTAIN THE BASELINE SPACECRAFT AS MUCH AS POSSIBLE AND THE "SPIRIT" OF THE MMII PROGRAM

OBJECTIVE 2: ASSESS THE UTILITY OF A "LOW POWER" NEP SYSTEM FOR THE MARINER MARK II CASSINI, MISSION.

APPROACH: I) USE MEP SPACECRAFT CONFIGURATION DEVELOPED IN 1986 SP-100 STUDY*

11) USE JPL ION ENGINE SYSTEM PROJECTIONS "JONES, R. M- "SP-100 PLANETARY MISSION/SYSTEM PRELIMINARY DESIGN STUDY, FINAL REPORT",
JPL-D-2544, JUNE 1986. 


\section{MARINER MARK I I BACKGROUND}

The Mariner Mark II (MMII) program (reference 1) has been recommended for development by the Solar System Exploration Committee of the NASA Advisory Council. The MMII program would continue the exploration of the solar system beyond the Earth. The MMII program is envisioned as a series of projects that would use the same basic spacecraft in order to reduce the costs. The cost goal of a MMII mission is $\$ 300 M$ in FY' 84 , project start through launch plus 30 days. The first MMI mission has been proposed to be the comet Rendezvous and Asteroid Flyby (CRAF) project. CRAF has been proposed to be launched in February 1993. The second MMII mission is proposed to be the Cassini project that would send an orbiter to Saturn which would deploy a probe to Saturn's large moon, Titan. Cassini is proposed to be launched in March 1995.

The MMII spacecraft is being designed to be modular and inexpensively reconfigured for a series of missions. MMII will be a class "A" spacecraft that will use the Galileo class of fault detection and correction. No single spacecraft failure shall cause the loss of science data from more than one instrument or the loss of more than 50 of the spacecraft engineering telemetry. The spacecraft is being designed to be compatible with the Titan IV/Centaur $G^{\prime}$ launch vehicle combination. The spacecraft components are being designed for a broad range of performance requirements with standardized interfaces to maximize the similarity among spacecraft in the MMI mission set. Spacecraft design costs are being minimized by: 1) using residual hardware/components from previous projects, 2) using proven design approaches, 3) maintaining large margins, 4) providing data processing on board the spacecraft to reduce downlink requirements and 5 ) using new technology where it provides a cost savings.

Some of the items of new technology that are being used in the MMII spacecraft design for CRAF are: 1) $4 \mathrm{~N}$ bipropellant thrusters and a high performance bipropellant engine (Isp=326 sec.) in the propulsion subsystem, 2) fiber optics rotation sensor and a momentum compensated actuator in the attitude and articulation control subsystem, 3) a common flight computer design with a 32 bit microprocessor and a 16 bit data bus in the command and data subsystem, 4) an $X$ band solid-state amplifier in the telecommunications subsystem, 5) solid state power switches in the power subsystem and 6) a central heating system utilizing waste heat from the RTGs supplied to the spacecraft via heat pipes in the temperature control subsystem.

1) Draper, R., "Comet Rendezvous Asteroid Flyby, First Mariner Mark II", American Astronautical Society Paper 86-333, Presented at the 33 rd AAS Annual Meeting, Boulder Colorado; October 26-29, 1986. 
- recommended by solar system exploration cOMmittee of the nasa advisory council

- MISSION CHARACTERISTICS

- beyond the inNER solar system

- LONg DURATION

- highly cost constrained

- no close sun or jupiter flybys

- large maximum earth and sun ranges

- high SCIENCE RETURN

- spacecraft characteristics

- INHERITANCE fROM PAST SPACECRAFt

- "Forhard" INHERItance to later mMil spacecraft

- utilization of nen technology

- INTERFACE STANDARDIZATION

- modularity 


\author{
REFERENCE CASSINI MISSION
}

The reference cassini mission (reference 2) is proposed to be launched in March of 1995 on a Titan IV/Centaur G' launch vehicle combination. The total injected mass requirement is $4310 \mathrm{~kg}$ which includes $230 \mathrm{~kg}$ for the adapter which connects the spacecraft to the centaur. The launch vehicle has the capability to inject $102 \mathrm{~kg}$ more than the required $4310 \mathrm{~kg}$. The spacecraft mass of $4080 \mathrm{~kg}$ contains $2496 \mathrm{~kg}$ of bipropellants, $30 \mathrm{~kg}$ of hydrazine, a Titan probe of $192 \mathrm{~kg}$ and associated probe interface equipment of $61 \mathrm{~kg}$. The basic dry MMII spacecraft has a mass of $1301 \mathrm{~kg}$ which includes $154 \mathrm{~kg}$ of science instruments and $156 \mathrm{~kg}$ of contingency.

The mission scenario is as follows. Launch and injection takes place on March 15, 1995 followed by a deep space delta V burn (568 m/sec) on March 17, 1996. After the deep space delta $V$ burn and just prior to the Earth flyby, the spacecraft is at its closest approach to the Sun at $0.89 \mathrm{~A}$. U. The spacecraft gets a gravity assist from the Earth on April 29, 1997 during an Earth flyby and another gravity assist from Jupiter on May 25 , 1999. Arrival and insertion into Saturn orbit takes place on January 5, 2002. The magnitude of the insertion delta $\mathrm{V}$ burn is $1436 \mathrm{~m} / \mathrm{sec}$. The Titan probe is released when the spacecraft is in orbit around saturn about 80 days after Saturn insertion. The spacecraft remains in orbit around Saturn for about another four years during which time it uses $393 \mathrm{~m} / \mathrm{sec}$ worth of delta $V$ in order to adjust the orbit to meet the science requirements and to have about 35 flybys with the various moons of saturn.

The current spacecraft design includes two RTGs, one GPHS and one MHW. Together these RTGs produce 433 We at the beginning of the mission, 371 we after 7 years and 347 We after 10 years. The power requirements are generally below the capability of the RTG except during the Titan encounters when the present project design shows a negative power margin.

REFERENCE CASSINI MISSION

- launch 3/15/95 on titan iv + 6' at $28(\mathrm{~km} / \mathrm{SeC})^{2}$

- DRY S/C = $1301 \mathrm{Kg}(154 \mathrm{SCI})+192$ PROBE + 61 PROBE IMTERFACE EQUIPMENT

- delta $V=2374 \mathrm{~m} / \mathrm{sec}$ (PRe probe releAse), delta $V=393$ (POSt probe Release)

- 6.8 yr trip to Saturn + 4 yrs IN orbit, 11 yr total mission length

- BaSELIME MISSION USES A DELTA V EJGa (EARTH AND JUPITER gRAVITY aSSIST) TRAJECTORY AND HAS A 100 KG LAUNCH VEHICLE MARGIN

- RT6 POWER: 433W BOH, 37IW AT 7 YRS, 347W AT 10 YRS

2) Sergeyevsky, A. B., Kerridge, S. J. and Stetson, D. S., "Cassini - A Mission to the Saturnian System", American Astronautical Society Paper \# 87-423, presented at the AAS/AIAA Astrodynamics Special ist Conference, Kalispell Montana; August $10-13,1987$. 


\section{REFERENCE MOI CASSINI SPACECRAFT}

This vugraph presents the reference MMII Cassini spacecraft, its components and its size. The main engine $(400 \mathrm{~N})$ is aligned along the $Z$ axis. The RTG boom is aligned with the $x$ axis and the high precision scan platform and turntable booms are aligned with the $Y$ axis of the spacecraft coordinate system. The high gain antenna has a diameter of 3.67 meters and is mounted such that its field of view is in the $-z$ direction. The Titan probe is the large circular object mounted on the $x$ side of the spacecraft. The high precision scan platform has two degrees of freedom i.e., rotation about the boom axis ( $Y$ axis) and rotation about an axis perpendicular to the $Y$ axis. The cameras and many other sensitive science instruments are mounted on the high precision scan platform. During flight, the orientation of the spacecraft is such that the $-z$ axis points toward the Earth to enable communications via the high gain antenna. Due to the distance that the spacecraft will be from the Earth during most of the mission, the Earth and the Sun are in the same area of the sky.

Basically the entire spacecraft must be shielded from the reactor radiation. Leaving aside the magnetometer boom, the largest dimension that must be shielded is the distance between the high precision scan platform and the turntable, 8.56 meters. The magnetometer boom may not need to be within the shielded volume because the magnetometer is probably not sensitive to radiation and it may be possible to locally spot shield its electronics. 


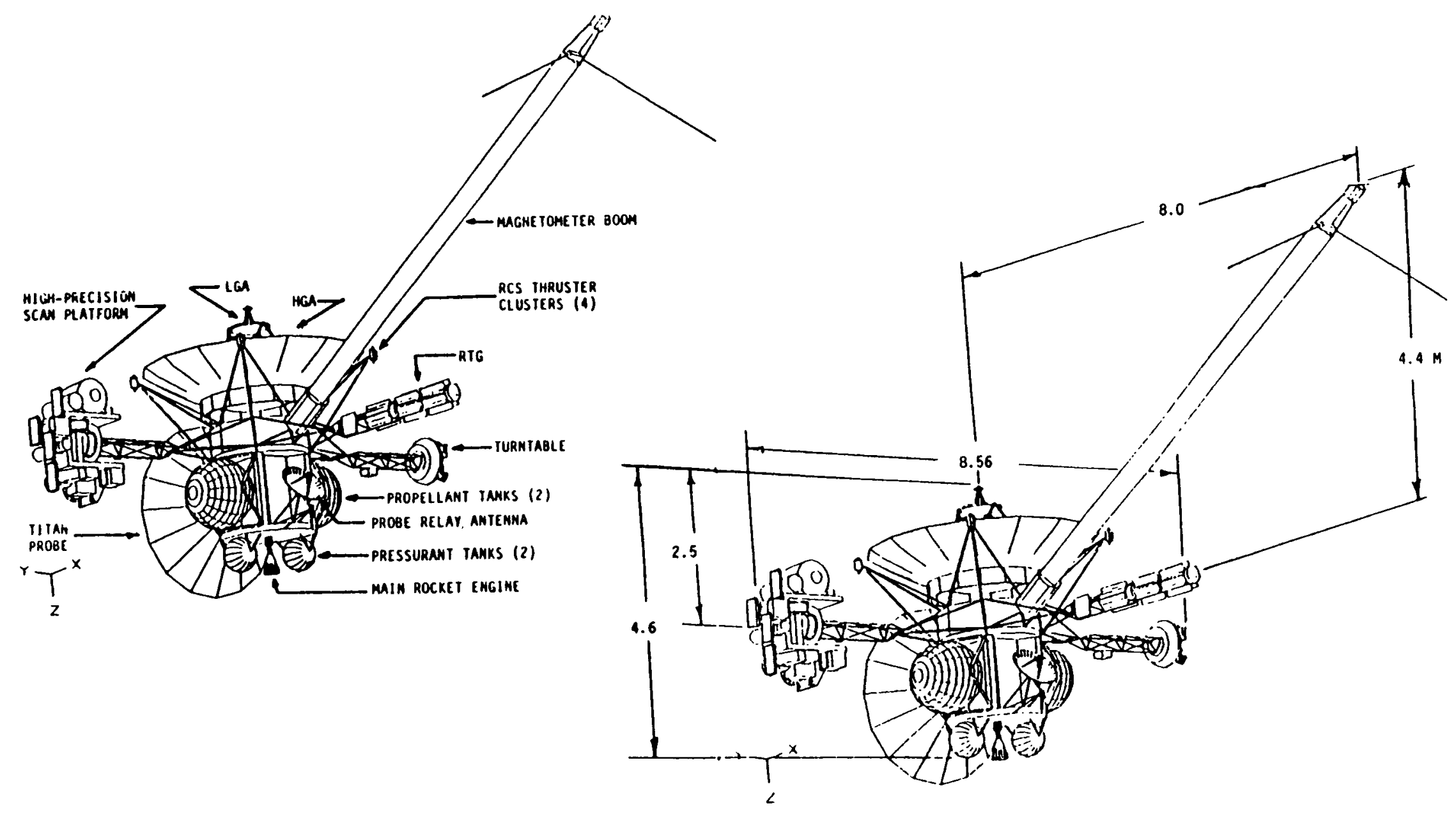




\section{COMPARISON OF DEPLOYED CONFIGURATIONS}

This chart presents a comparison of the reference, and modified configuration of the MII Cassini spacecraft. The drawings on the vugraph are very nearly the same scale. The shape and size of the RPS shown on the facing page is generic and is not meant to specifically represent a 1 kwe RPS for the Cassini mission.

The approach taken in the spacecraft reconfiguration activity was to replace the RTGs with the Reactor Power System (RPS) and make no other changes to the baseline spacecraft except those that were required to accommodate the RPS or made possible by the increase in power available from the RPS.

The RPS was assumed to have a mass of less than $1000 \mathrm{~kg}$ and an EOL power of at least $1 \mathrm{kwe}$ which is approximately double the power required for the baseline spacecraft. This larger power was chosen in order to provide "power to burn" which conceptually simplifies the temperature control design for the spacecraft and also eliminates the need for the central heating system and the RHUs. In a qualitative sense, the major changes are as follows.

1) The RTGs are removed and the Reactor Power System (RPS) is added. The RPS is placed on a boom which is attached to the spacecraft in the position that is currently occupied by the high gain antenna (HGA).

2) A smaller HGA is attached to a boom of similar size and attached to the spacecraft in a similar position as the RTG boom which was deleted. The HGA is articulated on the end of the boom by a one (possibly two) DOF gimbal and is pointed in a direction similar to that in which the original HGA pointed.

3) Two additional $X$-band solid state amplifiers (XSSA) are added to the RF subsystem in order to increase the $R F$ power to retain the same effective isotropic radiated power (EIRP) and compensate for the smaller HGA.

4) The power subsystem control and distribution equipment is enlarged in order to handle the additional power demand from the RF subsystem and temperature control subsystem and the larger capability of the RPS.

5) All the radio-isotope heater units (RHUs) and the central heating system are replaced by electric heaters. 
JL COMPARISON OF DEPLOYED CONFIgURATIONS
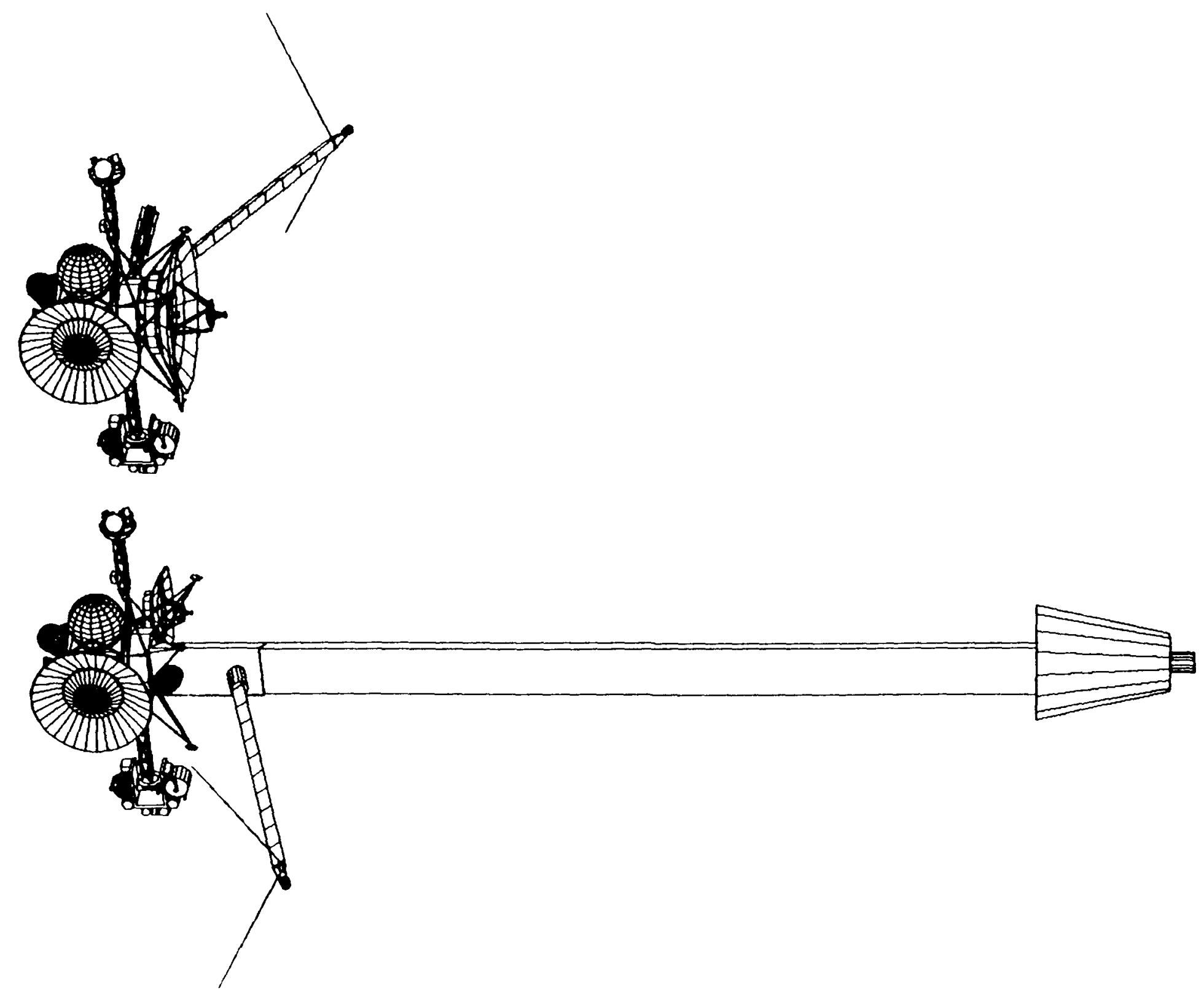
The boom concept used for this study was a scaled down version of a concept developed by the Lockheed Missiles and Space Company (reference 3). The concept uses longerons that fold for storage and that snap into place during deployment. The boom is not designed to be stowed once it has been deployed. The basic truss structure uses a bay that has equal dimensions, 50 inches. The battens and longerons that make up the bay are made from aluminum tubes that are 50 inches long, 0.02 inch in wall thickness and 1.3 inches in diameter. The total mass estimate for a 16 bay, 20 meter boom is $31.5 \mathrm{~kg}$, which includes the longerons, battens, fittings and Kevlar diagonal cables. The mass estimate for the deployment mechanism is $13.15 \mathrm{~kg}$, which includes a dual drive motor. The stowed length of the $20 \mathrm{~m}$ boom is $3.81 \mathrm{~m}$. The lateral and torsional first modes of the boom/RPS/spacecraft system were estimated. Further details of the boom concept can be found in the appendix to this report.

\section{RPS BOOM CONCEPT}

- aluminum

- 20 m BOOM PLUS DEPLOYMENT

EQUIPRENT: $45 \mathrm{KG}$

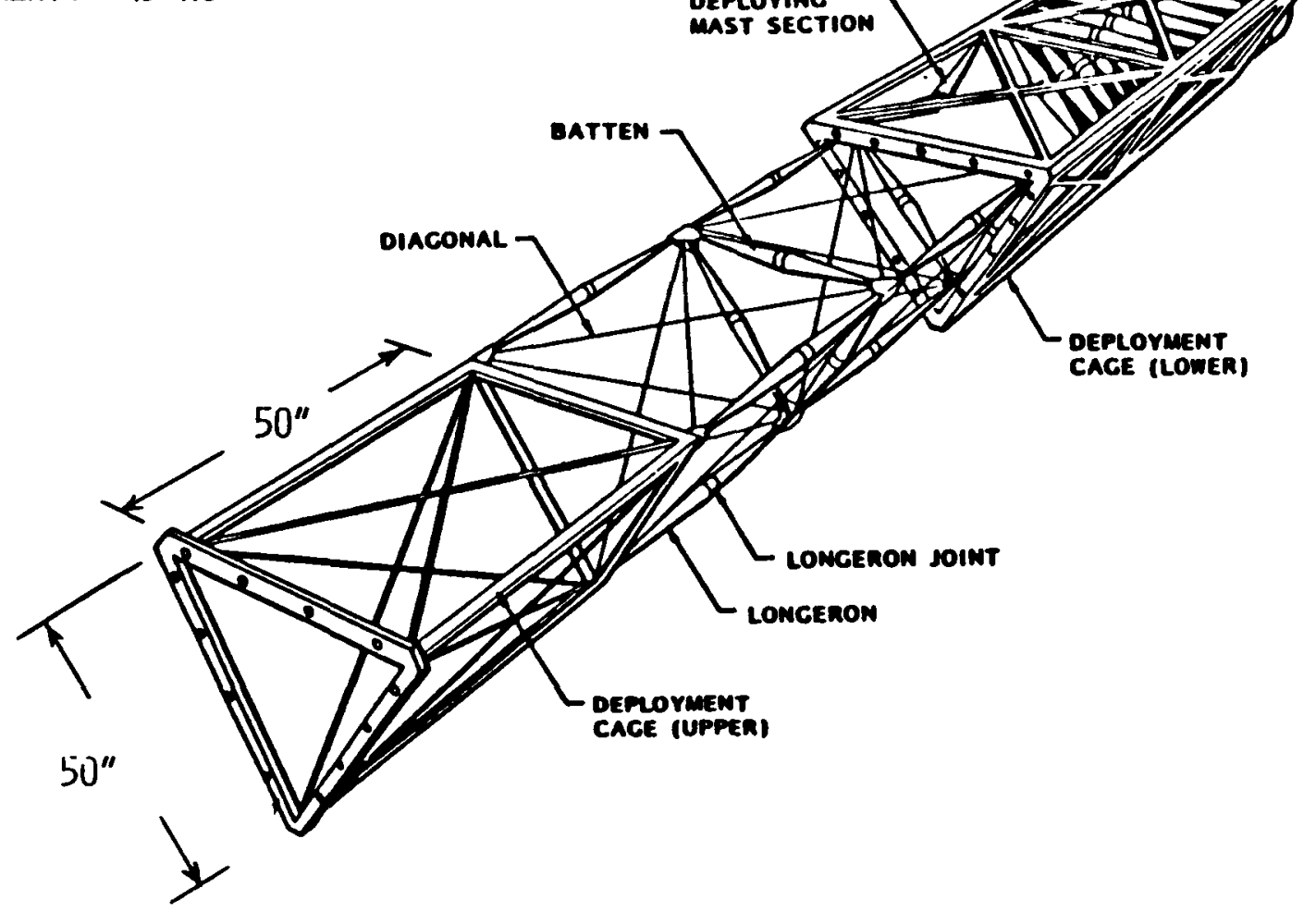

3) "Interim Report for the Study for a Wrap-Rib Antenna Design", IMSC Report D-714653 for JPL Contract $955345,7 / 17 / 81$. 
The net mass change in the spacecraft (before the addition of contingency) is a $72.26 \mathrm{~kg}$ reduction. The spacecraft mass reduction $(-173.06 \mathrm{~kg})$ is dominated by the deletion of the two RTGs and the central heating system and the smaller HGA. The largest item added to accommodate the RPS (not counting the RPS) is a $44.6 \mathrm{~kg}$ increase in the structure to handle the launch loads. Smaller additions include another hydrazine tank, electric heaters and controllers, HGA gimbal and driver, more power control and processing equipment and the two additional $x$ band amplifiers. The total added spacecraft mass (not including the RPS) is $100.8 \mathrm{~kg}$. The detailed changes to the spacecraft subsystems are 1 isted in the appendix.

The changes to the adapter are dominated by the addition of structure to handle the expected increase in launch loads and the deletion of equipment required to support the RTGs.

SPACECRAFT AND ADAPIER CHANGES

SPACECRAFT ADDITIONS:

BOOM EQUIPMENT

HGA GIMBAL \& DRIVER HEATERS AND CONTROLLERS HYDRAZINE TANK \& LINES

RF AMPLIFIERS

PC \& C EQUIPMENT

STRUCTURE

$12 \cdot 3$

8.9

4.0

7.0

12.0

12.0

44.6

$100.8 \mathrm{KG}$

ADAPTER ADDITIONS: STRUCTURE HGA SUPPORT

26.8

2.3

$29.1 \mathrm{KG}$

SPACECRAFT DELETIONS: RTG BOOM EQUIPMENT RTGS (MHW + GPHS)

CENTRAL HEATING SYSTEM 58 RHUS HGA DECREASE

MISC
$12 \cdot 3$

93.28

32.46

4.12

28.60

2.30

$173.06 \mathrm{KG}$

ADAPTER DELETIONS: RTG SUPPORT

RTG SHIELD

RTG COOLING

2.3

15.0

1.0 
This chart presents a view of the MMI Cassini spacecraft with the RPS from the point of view of the RPS 1 .e., looking down the boom at the spacecraft. The small concentric circles that cover most of the propellant tanks represent the assumed size of the RPS. The dark circles are 6 and 10 meters in diameter and represent the coverage of dose planes relative to the spacecraft equipment. It is clear that to completely shield the spacecraft, including the magnetometer, using circular dose planes (shields with circular cross sections), would require a dose plane between 16 and 18 meters in diameter. It is also clear that circular dose planes (shields) are not required. A shield that was shaped to shield only the required outline of the spacecraft can be smaller and presumably much lighter than a full shield with a circular cross section.

For this example, it appears that the shield geometry that would provide a 6 in circular dose plane could be re-arranged to shield the two instrument platforms, and that a $10 \mathrm{~m}$ dose plane may not be required. The magnetometer and magnetometer boom is a difficult case due to its length. However, it is not clear that the magnetometer is sensitive to radiation. Even if the magnetometer and its boom need to be shielded, a shaped shield at the reactor may be feasible or the magnetometer may be able to be relocated so that it does not extend out so far in a direction perpendicular to the RPS boom.

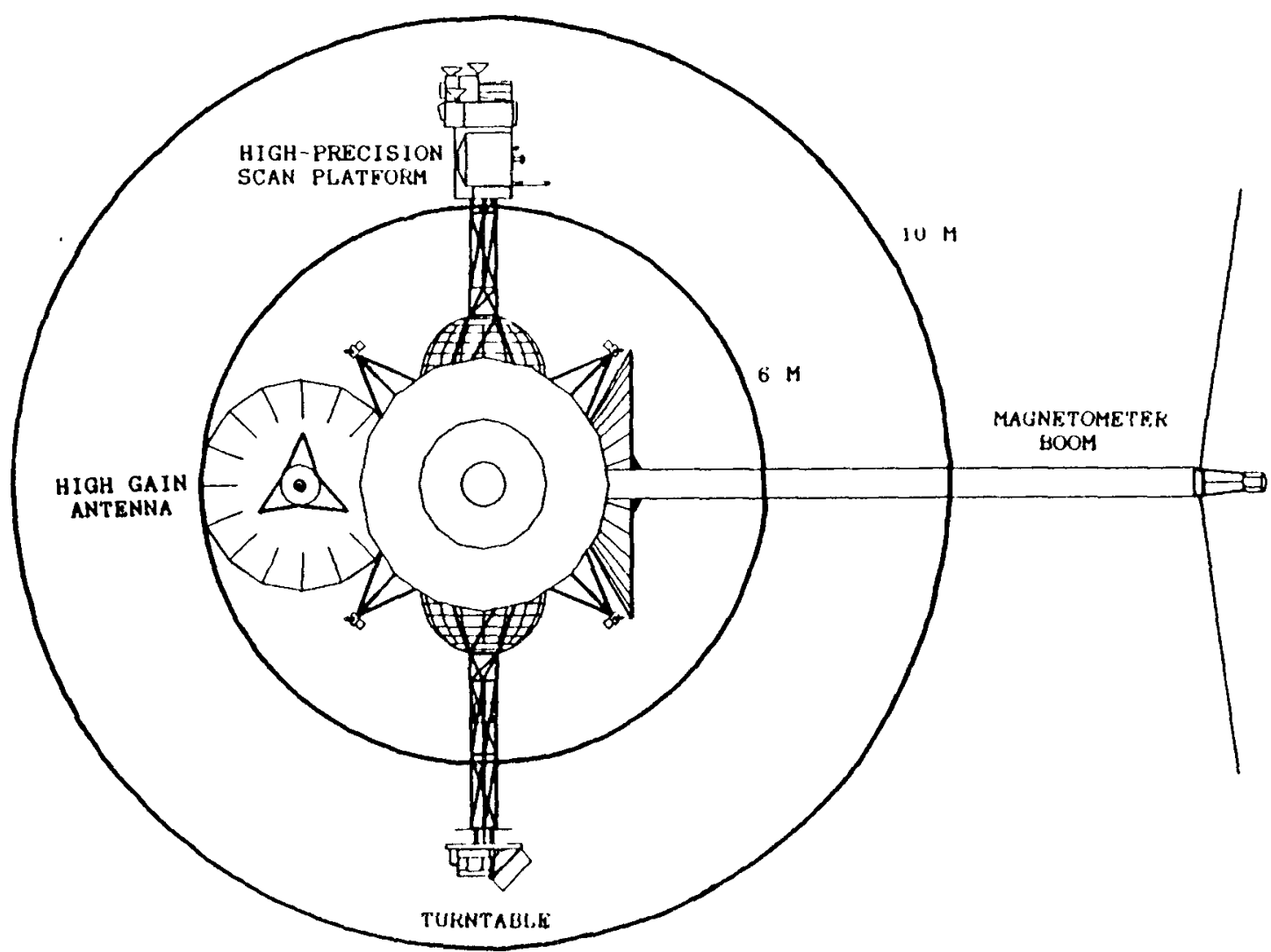


This chart compares the reference and the modified launch configuration for the MMII Cassini spacecraft. The drawings are to the same scale. The launch vehicle is the Titan IV and a centaur $G^{\prime}$ upper stage. The spacecraft is mounted on the adapter which is connected to the centaur. The Titan launch shroud comes in standard $10 \mathrm{ft}$ sections. One additional $10 \mathrm{ft}$. section has been added in order to accommodate the spacecraft with the RPS. The launch vehicle performance decrease, due to the addition of this extra shroud section, was not taken into account. The adapter mass has been increased by $26.8 \mathrm{~kg}$ relative to the reference case in order to handle the larger bending moments expected during launch. Larger bending moments are expected due to the RPS being very massive and being several meters removed from the adapter, which must accommodate the loads caused by the bending moments.

The Cassini spacecraft with the RPS may be close to the structural capability of the Titan IV/Centaur $G^{\prime}$ combination and may require the launch vehicle structure to be strengthened. However, only an assessment by the launch vehicle contractors can determine the changes (if any) that are required. Such an assessment was outside the scope of this study. 
JPL COMPARISON OF STOWED CONFIGLIRATIONS
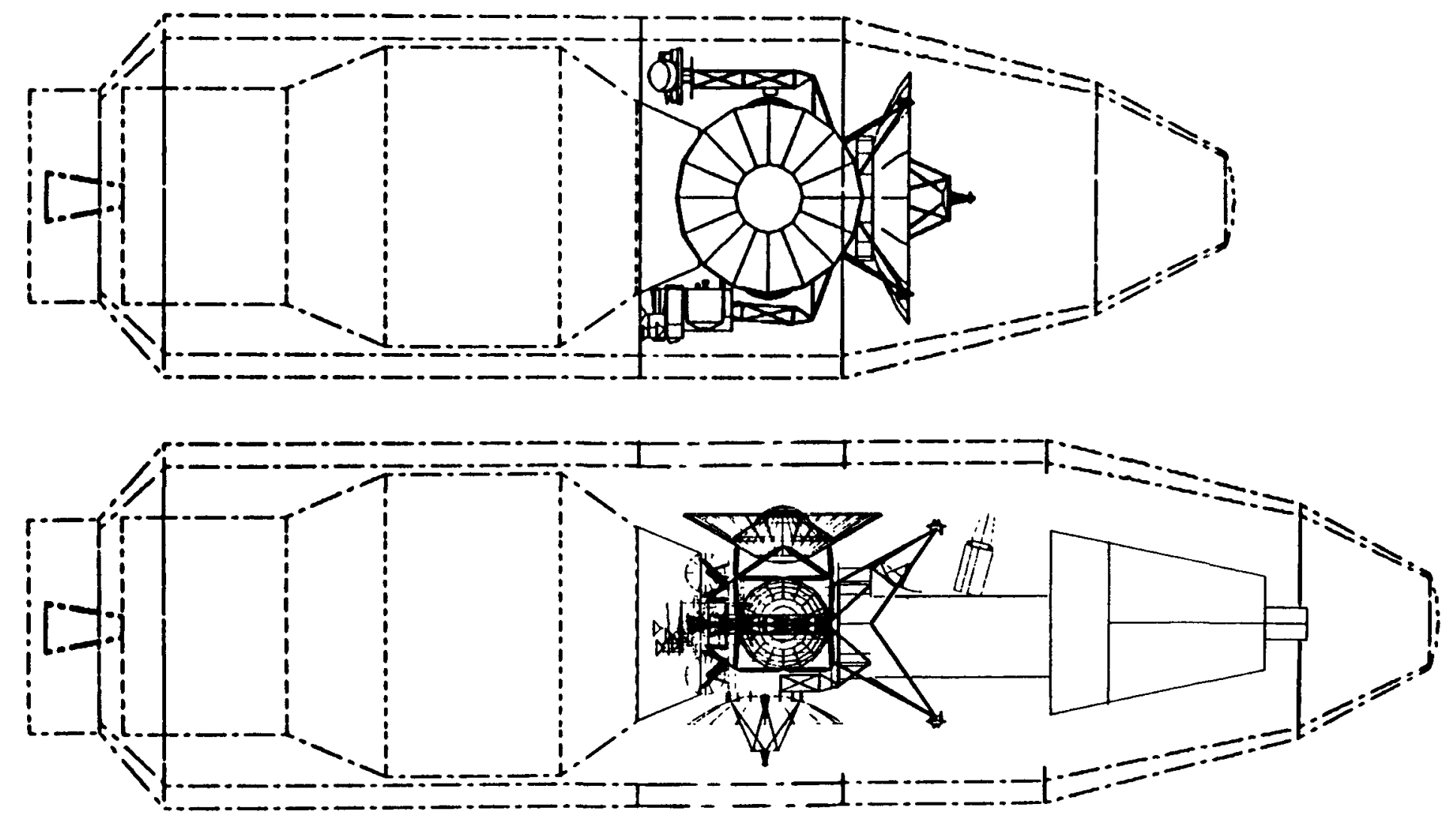
This chart presents the dry mass summary for both the reference and the modified MMII Cassini spacecraft. The reference spacecraft mass summary was taken from the MMII mass and power report $\$ 14,2 / 29 / 87$. The addition of the RPS allowed a $72.26 \mathrm{~kg}$ reduction in the spacecraft mass before the addition of the RPS. The RPS shall include the boom that connects to the spacecraft.

The modified spacecraft mass contingency was increased to 258 to accommodate items that have not been identified as being necessary to the RPS integration. Note that the modified spacecraft does not have an RTG shield but does have double the capacity for hydrazine compared to the reference design. The RTG shield shown is meant to be a blast shield to reduce the risk of plutonium contamination in the event of a launch accident. The RTG shield has been eliminated from the most recent cassini baseline and was not carried to the injection energy in any case.

\section{DRY SPACECRAFT MASS COMPARISOIN}

TOTAL SPACECRAFT REFERENCE

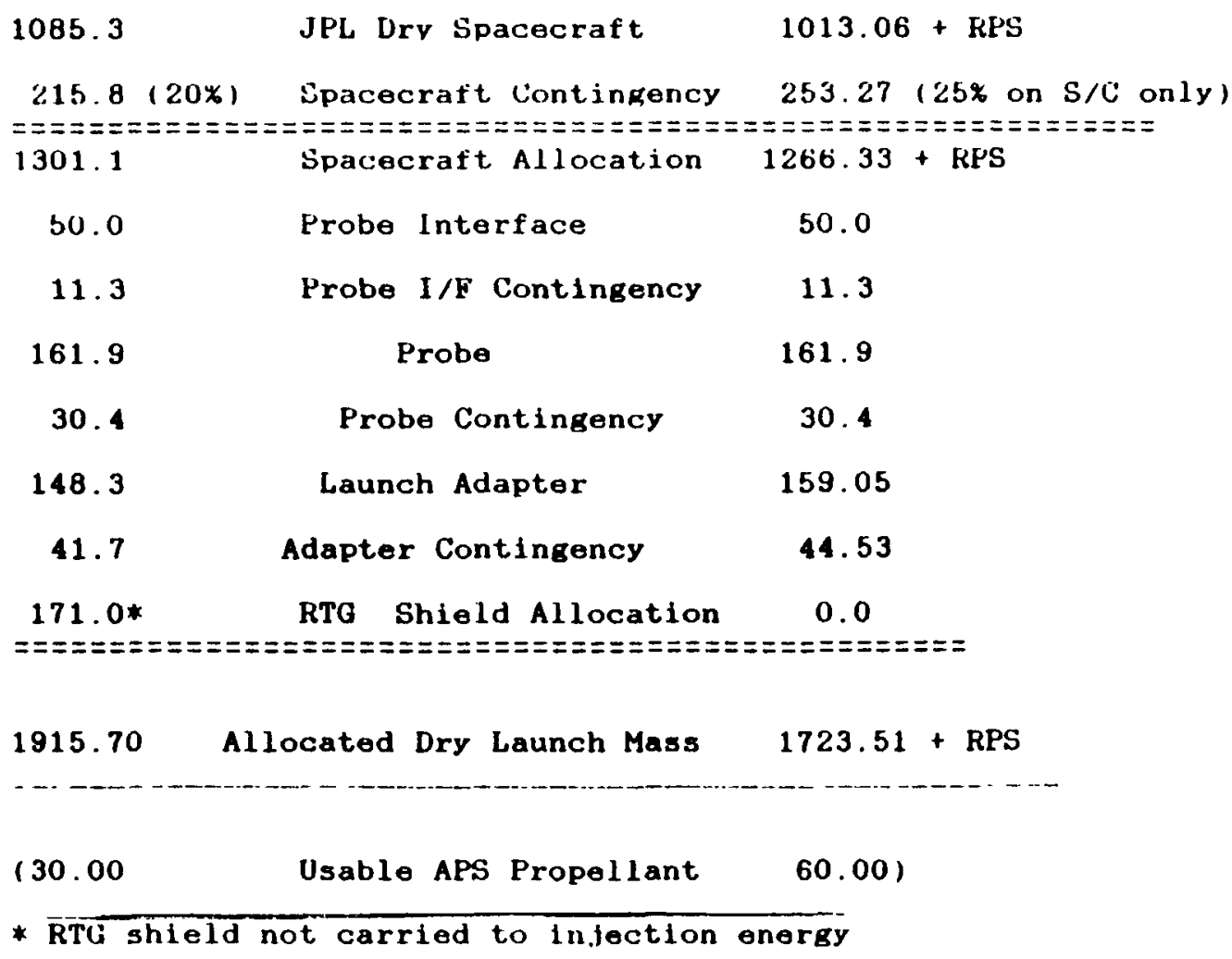

TOTAL SPACECRAFT WITH RPS

$1013.06+\mathrm{kPS}$ 


\section{RPS POWER REOUIREMENTS}

This chart presents the power requirements that the RPS must meet for the Cassini mission using a MMI spacecraft modified to include a small RPS. The power for heaters has been separately defined since it was provided by the central heating system (waste RTG heat) in the reference case and was assumed to be supplied by electric power from the RPS. The duration of the cruise phase is dependent on the mass of the RPS, where the reference is 6.8 years. The two science states bound the power requirements while in orbit around Saturn. In actuality, the spacecraft would be in many more power states for much shorter durations that shown on the chart. However, in terms of energy consumption the chart is quite conservative.

This information was used in determining the radiation dose from the RPS under the assumption that the RPS would not operate at 1 kwe continuously, but rather would throttle down to more nearly match the power requirement of the spacecraft. Since radiation dose is directly related to the reactor operating power, by throttling the reactor the radiation dose is reduced. A 1 KWe RPS always has the capability of meeting the peak power demands of the spacecraft and the RPS does detailed load following via power shunts not by reactor throttling.

The power profile shown on this chart will reduce the radiation dose for a 7,8 , and 9 year cruise duration missions to 70,76 and 82 r respectively of the dose that would have been accumulated if the RPS would have operated at 1 kWe continuously for 10 years.

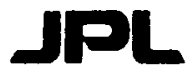

RPS POWER REQUIREMENTS

MISSION PHASE

CRUISE

7-10 YRS
SCIENCE \#1

2 YRS
SCIENCE \#2

2 YRS

SPACECRAFT

LOADS

ENGINEERING

218

351

259

SCIENCE

68

156

104

HEATERS

298

298

298

$584 W_{E}$

805

661 
This chart lists the three primary technical challenges that must be overcome in order to successfully integrate a RPS onto the cassini spacecraft and mission. Each of these challenges will be addressed on subsequent vugraphs.

All of these issues can, and must, be considered separately but they are also all interrelated. First is controllability. Can the spacecraft meet its pointing, stability and turning requirements with the RPS on a long boom? Second, will the mass of the RPS be such that the trip time penalty is acceptable? Last, will the spacecraft be able to accommodate the radiation environment that the RPS will impose?

1) CONTROLABILITY:

2) MASS:

3) RADIATION: 


\section{CONTRQLLABILITY}

This chart summarizes what was a thorough analysis at the conceptual level. The basis conclusion is that, given the level of depth that the resources of this study allowed, no show stoppers were identified in the controllability area. Several concerns were identified that could be serious, but further analysis is required before the concerns can be quantified.

The controllability analysis used two RPS/spacecraft configurations: 1) a $1000 \mathrm{~kg}$ RPS on a 20 boom and 2) a $500 \mathrm{~kg}$ RPS on a 5 boor. The spacecraft capabilities, requirements and the mission duration were the same as the reference. Moments of inertias and the center of mass were calculated. The $20 \mathrm{~m}$ boom had an estinated mass of $45 \mathrm{~kg}$ and a first beam bending mode frequency $0.2 \mathrm{~Hz}$.

Solar pressure disturbance torques were estimated at 1 AU (Earth) and 9.5 AU (Saturn). Gravity gradient disturbance torques were estimated at both 6 and 50 saturn radil. The possible disturbance torque generated by a RPS radiator imbalance was estimated. The radiator torque can be generated by having more radiant flux being emitted from one "side" of the radiator than other sides. This torque can be as large as other disturbance torques, and its agnitude was estimated by assuming that there was a 1 to 53 radial imbalance of the heat radiated by the radiator.

Spacecraft turns were analyzed by assuming that there would be 15 turns during crules and 100 while in orblt about Saturn. The turn angle was assumed to follow a uniform distribution between 0 and 180 degrees. Assuming that the turn rate was 1 imited to 1 mrad/sec, the time to turn 90 and 180 clegrees was 40 and 80 minutes respectively. The specific impulse of the stitude control system thrusters was 200 secs.

The calculated hydrazine propellant requirements for the $1000 \mathrm{~kg}$ RPS on a 20 boom are as follows. Solar pressure, gravity gradient and RPS radistor imbalance (assuming a 1 imbalance) torques require 18,4 and 3.7 $\mathrm{kg}$ Nespectively. Llmit cycling with a 0.2 degree deadband and a rate of 0.115 micro-radian per sec requires $3.9 \mathrm{~kg}$. The spacecraft turns described abesve require $19 \mathrm{~kg}$. The total hydrazine propellant requirement plus a 50 . contingency is $73 \mathrm{~kg}$ and $33.7 \mathrm{~kg}$ for the $500 \mathrm{~kg}$ RPS on a $5 \mathrm{~m}$ boow.

The RPS confuguration 18 expected to degrade the pointing stability of the high precision scan platform by about one microradian over 0.5 seconds, which is negligible compared to the 12 microradian over 0.5 seconds requirement.

The two areas of concern that require further study are as follows. Because the main engine gimbal controller bandwidth $1 \mathrm{~s}$ about $1.0 \mathrm{~Hz}$ and the first boom bending frequency is about $0.2 \mathrm{~Hz}$, the boom flexibility may drive the main engine thrust vector control unstable. slosh in the propellant tanks may be more of a problem because the distance from the propellant tanks to the center of mass is greater than with the reference configuration.

A complete report of this analysie le included in the appendix to this document. 
ASSUMPTIONS:

- 1000 KG RPS ON A $20 \mathrm{M}$ BOOM (BOOM MASS $45 \mathrm{KG}$ )

- "VERY STIFF" bOOM

- baseline cassini spacecraft CAPABILITIES and REQUIREMENTS

ANALYSIS:

- DISTURBANCE tORQUES: SOLAR PRESSURE, GRAVITY GRADIENT AND REACTOR hEAT REJECTION

- SPACECRAFT TURNS AND DELTA $Y$ MANEUVERS CONSIDERED

RESULTS:

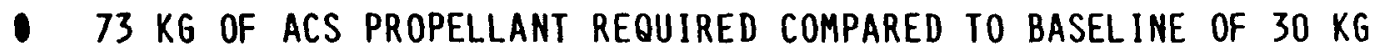

- all baseline requirements conceptually met

- LARGEST CONCERN IS BOOM FLEXIBILITY DURING MAIN ENGINE BURN (POTENTIAL tO DRIVE S/C UNSTABLE) 


\section{CASSINI NEP TRAJECTORY PARAMETERS}

This chart presents a list of the parameters that were involved in the calculation of NEP trajectories for this study. With only about 15 of the study resources available, this subtask could not thoroughly analyze all of these parameters.

The launch vehicle was constrained to the Titan IV and centaur G'. A 200 $\mathrm{kg}$ adapter was assumed and trajectories were run assuming a zero launch vehicle margin. The goal was to duplicate the reference trajectory i.e., Earth-Jupiter gravity assist and also look at other types of trajectories i.e., EGA (Earth gravity assist), VEEGA (Venus-Earth-Earth gravity assist), VEJGA (Venus-Earth-Jupiter gravity assist) and VEEJGA (VenusEarth-Earth-Jupiter gravity assist). However it proved impractical to study trajectories other than the simplest, Direct. Direct trajectories go "direct" from Earth to saturn without any intermediate gravity assists. Direct trajectories require more energy but are preferable because they are not constrained to a certain arrangement of planets which may occur infrequently. Direct trajectories to Saturn are available every year while delta $V$ EJGAs are available only 3 years out of 20 . All other parameters being equal, a direct trajectory would be selected for a mission. A direct trajectory was not selected for the reference mission because the launch vehicle combination has insufficient energy. However, with NEP, direct trajectories are possible.

The modified Cassini spacecraft mass of $1013 \mathrm{~kg}$ was used as the starting point. The bi-propellant propulsion subsystem $(170 \mathrm{~kg})$ was subtracted and a $25 \%$ contingency was added. The probe and probe interface equipment and contingencies were added as was done for task \#1. Sixty kilograms of hydrazine and $40 \mathrm{~kg}$ of Xenon were assumed to be carried into saturn orbit. The spacecraft mass that was inserted into saturn orbit was $1407 \mathrm{~kg}$, not including the NEP subsystem. It was assumed that the NEP system would manuever the spacecraft in orbit around Saturn. Forty kilograms of Xenon were allocated for these manuevers $(400 \mathrm{~m} / \mathrm{sec})$.

The inputs to the trajectory calculations were the flight time, the launch vehicle characteristics and the "jet power" of the NEP system. Flight time is measured form the end of the centaur injection burn at Earth until the spacecraft is placed into a 90 day orbit at saturn via a spiral capture orbit. The trajectory software optimized the specific impulse and the injected mass to give the largest final mass in orbit at saturn. The "burn time" of the NEP system and the mass of Xenon propellant were results of the calculations. The spacecraft final mass of $1407 \mathrm{~kg}$, the projections for the mass of the electric propulsion subsystem and the Xenon mass were subtracted from the final mass calculated from the trajectory analysis to determine the allowable mass for the RPS.

MMII CASSIMI DELTA V EJGA TRAJECTORY PARAMETERS

- LaUnCh year --- Three ANHUAL OPPORTUnities eVEry 20 years, i.e., '75, '76, '77

- launch vehicle -.- titan iv and centaur 6'

- SPACECRAFt MASS --- RPS MASS (PARAMETER)

- SPACECRAFT PROPULSION ISP --- RECENT CHANGE OF MMII BASELINE FROM 308 TO 326 SEC

- Flight time -.- (Independent variable)

- Launch yehicle margin --- (Dependent variable must be positive) 


\section{SAMPLE RESULTS}

This chart presents a sample of the results of the trajectory analysis. The RPS mass for this chart is $600 \mathrm{~kg}$. The chart presents flight time versus launch vehicle margin for four combinations of launch year and propulsion system specific impulse i.e., 1) 1996 and $308 \mathrm{sec}$, 2) 1997 and $308 \mathrm{sec}, 3) 1996$ and $326 \mathrm{sec}$ and 4) 1995 and $326 \mathrm{sec}$. The chart shows that '96 is better than '95 which is better than '97, although, after the launch vehicle margin goes positive, the difference between '95 and '96 becomes small. The advantage of the $326 \mathrm{sec}$. Isp compared to the $308 \mathrm{sec}$. is clear and continuous over flight time. Finally, this chart demonstrates the trip time penalty created by the addition of a heavy RPS compared to the reference. Even the best case from this chart ('96, 326 sec) has a trip time of 7.6 years $(100 \mathrm{~kg}$ launch vehicle margin) compared to the reference of 6.8 years $(0.8$ year trip time penalty). The '95 and 308 case requires 8.4 years, a 1.6 year trip time penalty.

The results shown on this chart and on the charts to follow show small variations about a clear trend. These small variations are due to "noise" in the trajectory calculations and no significance should be attached to them. The "noise" is caused in part by the nature of the calculations, which is a search for a local optimum in a large multi-dimensional parameter space.

The complete set of trajectory calculations can be found in the appendix to this report.

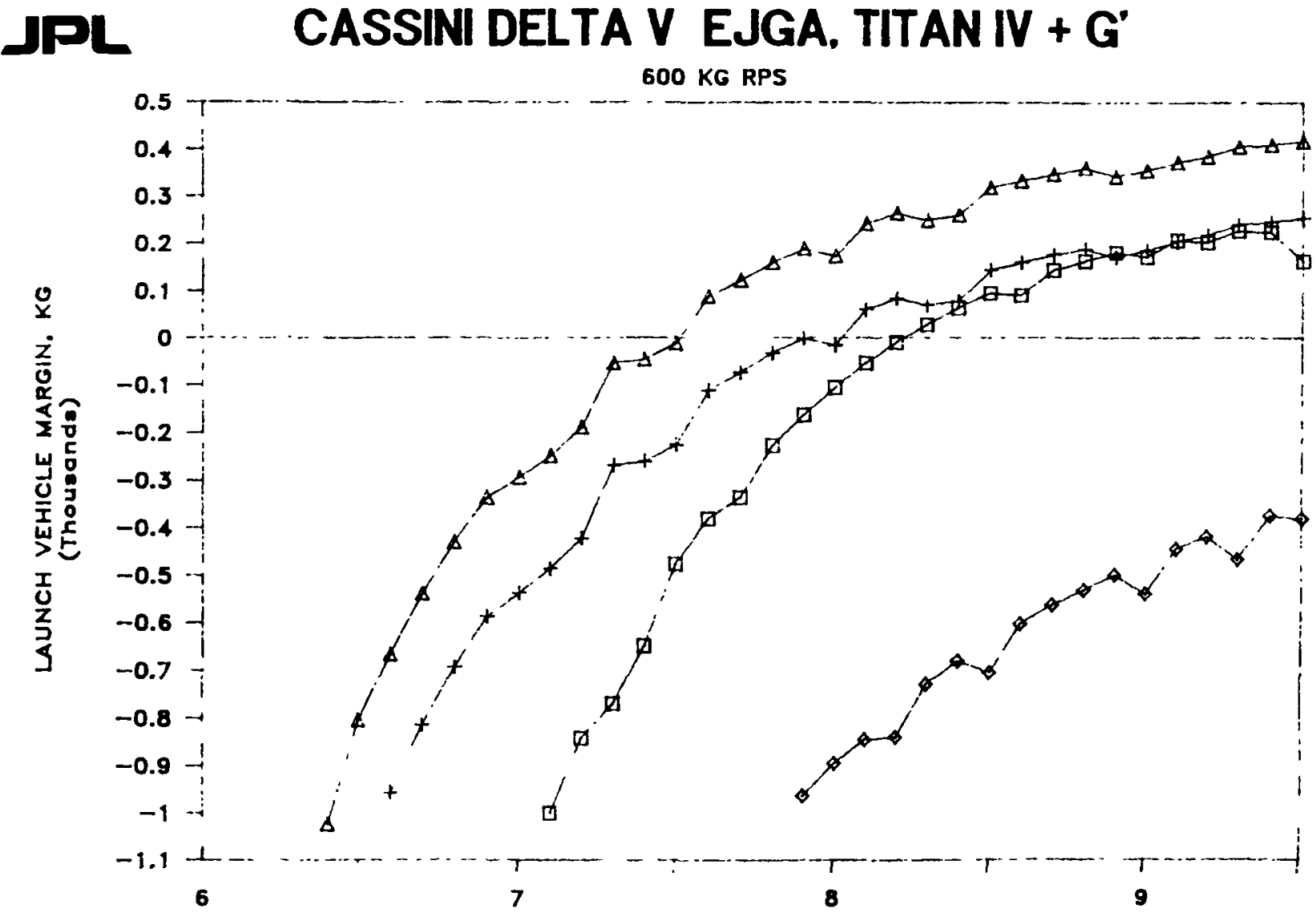

FLIGHT TIME, YEARS
$\Delta 1996,326 \mathrm{~s}$
$+1996,308 \mathrm{~s}$
$1995,308 \mathrm{~s}$
$\diamond 1997,308 \mathrm{~s}$ 


\section{BEST RESULTS}

This chart presents the best case results i.e., for a propulsion system Isp of $326 \mathrm{sec}$. and a launch in 1996. Three values of RPS mass are shown. It is important to remember that the RPS masses shown are ALLOCATIONS. The mission flight time will be as shown if the RPS mass is as allocated.

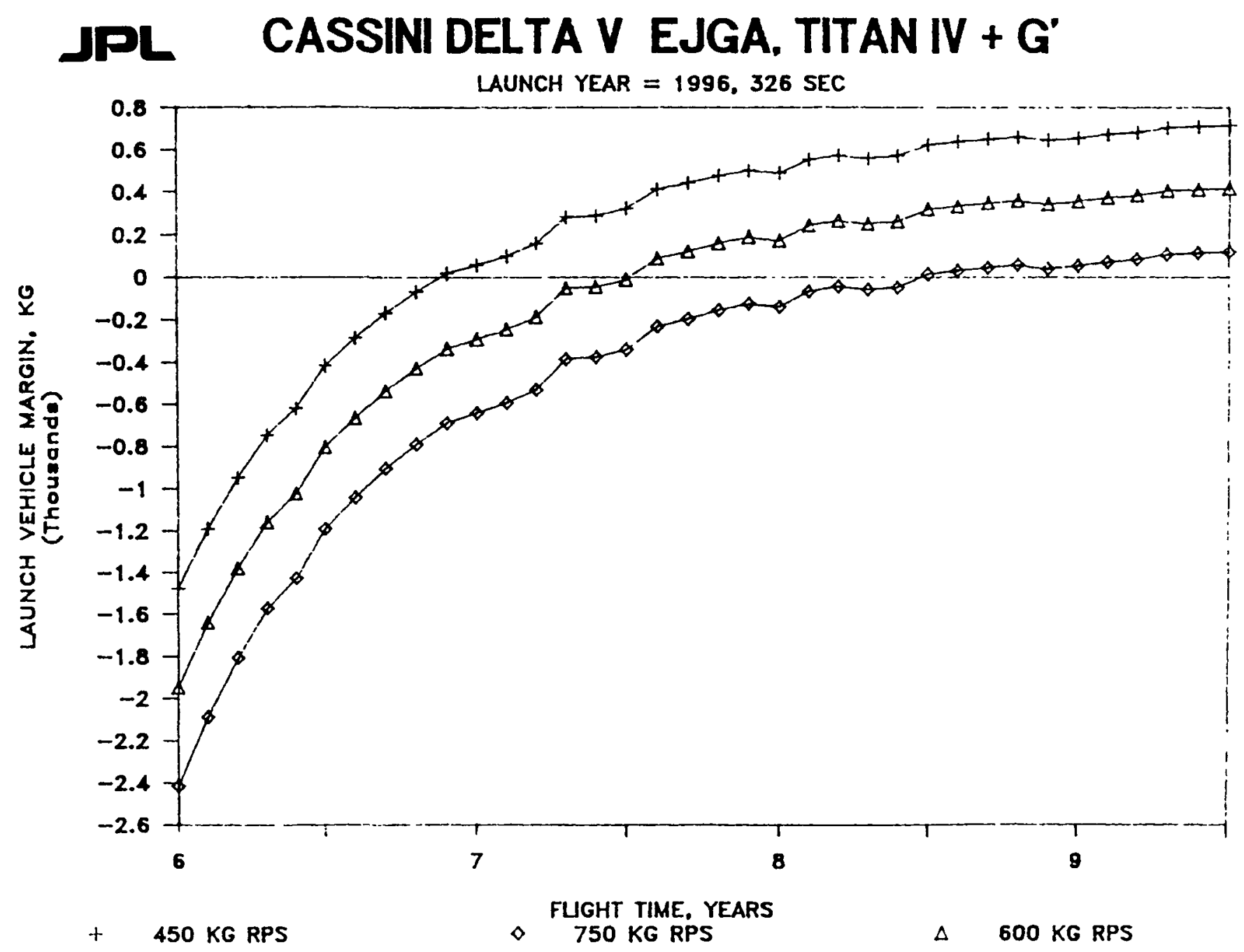


This chart presents a summary of all the results. The trip times for the Cassini mission with a RPS added to the spacecraft are shown for all launch years and both values of specific impulse. Note that the launch vehicle margin is $100 \mathrm{~kg}$ in all cases. For some cases the flight time was longer than 9.5 years which is where the trajectory calculations ended.

JPL

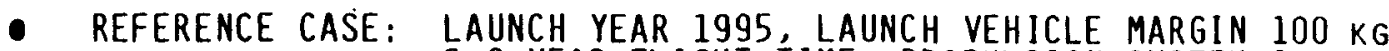
6.8 YEAR FLIGHT TIME, PROPULSION SYSTEM ISP $=308 \mathrm{~S}$

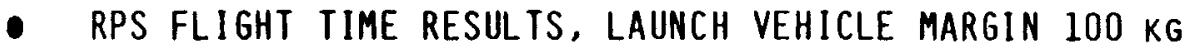

\begin{tabular}{|c|c|c|c|c|}
\hline \multicolumn{5}{|c|}{ PROPULSION SYSTEM ISP $=308$} \\
\hline $\begin{array}{c}\text { LAUNCH } \\
\text { YEAR }\end{array}$ & $\begin{array}{l}\text { RPS } \\
\text { MASS }\end{array}$ & $450 K G$ & 600 & 750 \\
\hline 95 & & 7.7 YEARS & 8.4 & $>9.5$ \\
\hline 96 & & $7 \cdot 5$ & $8 \cdot 1$ & $>9.5$ \\
\hline 97 & & $>9.5$ & $>9.5$ & $>9.5$ \\
\hline \multicolumn{5}{|c|}{ PROPULSION SYSTEM ISP $=326$} \\
\hline & & 450 & 600 & 750 \\
\hline 95 & & 7.5 & 8.0 & $9 \cdot 1$ \\
\hline 96 & & $7 \cdot 1$ & 7.6 & $9 \cdot 1$ \\
\hline 97 & & 8.8 & $>9.5$ & $>9.5$ \\
\hline
\end{tabular}


This chart presents a summary of the trajectory results in the form of flight time versus RPS mass for the only launch years of interest and for both values of specific impulse. Note that these results are for a $100 \mathrm{~kg}$ launch vehicle margin i.e., the same as the reference case.

Reduction in the mass of the RPS below the 400 to $500 \mathrm{~kg}$ range has little effect on the flight time, although a RPS with zero mass should provide the same flight time as the reference case. It appears that the minimum flight time penalty for the reference conditions i.e., 1995 and 308 seconds, is about one year ( 7.8 year flight time). A 7.8 year flight time ( 1 Yr penalty), allows a RPS mass of between about 450 and $650 \mathrm{~kg}$. A 8.8 year flight time ( 2 yr penalty), allows a RPS mass of between about 630 and $730 \mathrm{~kg}$.

\section{JPL CASSINI + RPS, FLIGHT TIME SUMMARY}

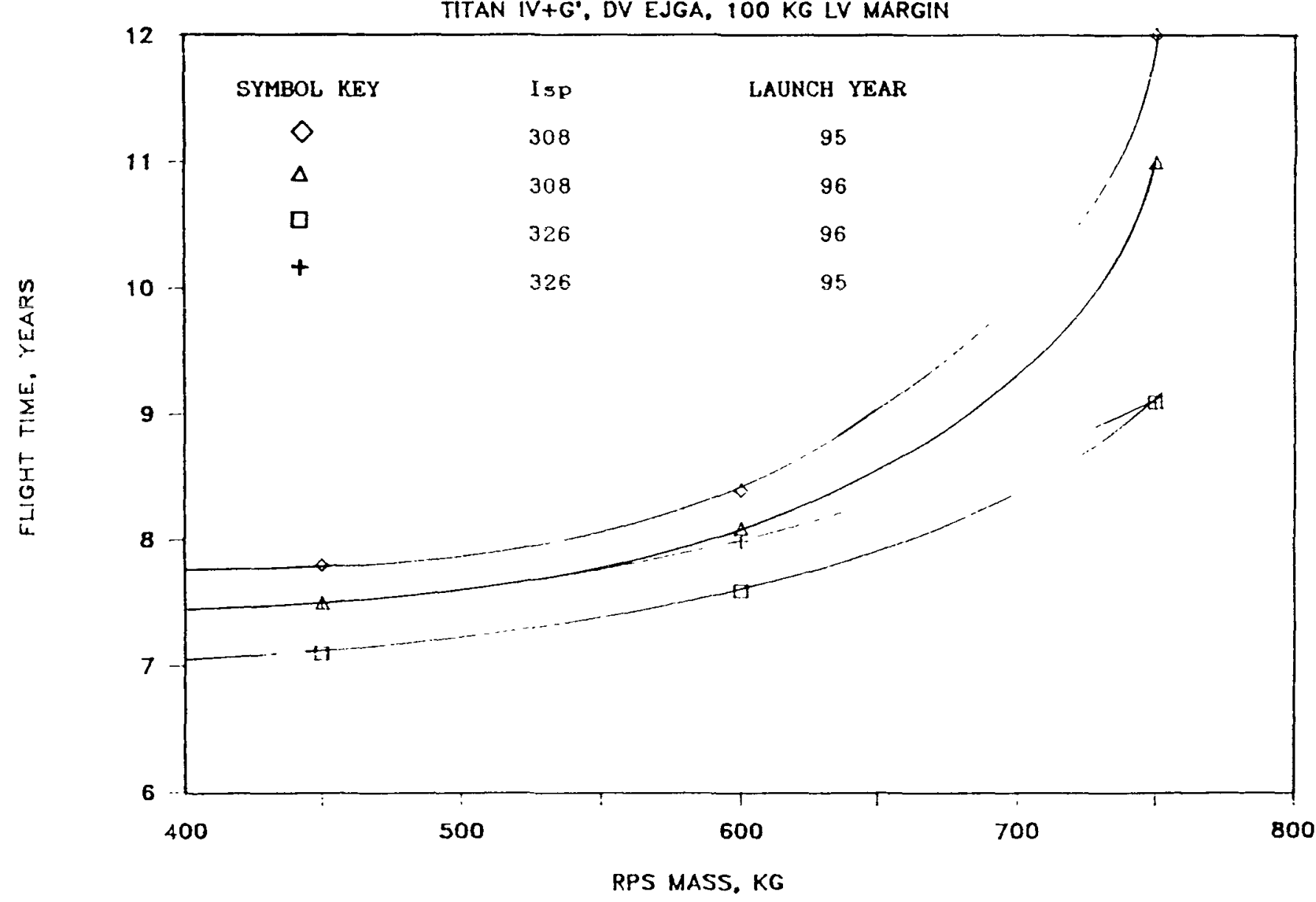




\section{RADIATION}

Because the MMI spacecraft radiation specification has been estimated on the basis of ONLY the natural environment and because the radiation dose imposed by the RPS cannot practically be made zero; the MMII spacecraft could not accommodate a RPS unless its radiation specification was changed to allow some contribution from the RPS. The same could be said for any planetary spacecraft, or for that matter, any spacecraft that has had its radiation specification created only on the basis of the natural environment.

The magnitude of the increase in the spacecraft radiation specification is dependent on the margin in the original specification, the mass vs. dose vs. distance relationship of the RPS and finally on the mass allocation that the mission can give to the RPS.

Any increase in the radiation specification for the spacecraft will have an adverse cost, schedule and performance impact. The magnitudes of these impacts will depend on how far along in the design cycle the spacecraft is when the increase in radiation specification is made and the magnitude of the change relative to the original specification.

- A RPS IS NOT COMPATIBLE WITH THE MMII SPACECRAFT WITHOUT AN INCREASE IN THE MMII RADIATION SPEC

- THE MAGNITUDE OF THE REQUIRED INCREASE IS DEPENDENT UPON THE MASS VS DOSE RELATIONSHIP OF THE RPS AND THE SEPARATION DISTANCE BETWEEN THE RPS AND THE S/C 
This chart presents the RPS mass projections provided by Harvey Bloomfield of NASA LeRC. The projections include the mass of the reactor, shield, heat transport, conversion, power conditioning, structure and radiator subsystems. The mass of the 5,10 or $20 \mathrm{~m}$ boom to connect the RPS to the spacecraft is NOT included in these projections. The projections shown on this chart are for a RPS that produces 1 kWe for 10 years using thermoelectric converters at an overall efficiency of 5 t. The mass of a $20 \mathrm{kWth}$ reactor was $220 \mathrm{~kg}$. The shield is made of tungsten (for the gammas) and Lithium-Hydride (for the neutrons). The projections were made for three dose levels: 1) $7.5 \mathrm{krad}$ and $1.5 \mathrm{E} 11 \mathrm{NVT}, 75 \mathrm{krad}$ and $1.5 \mathrm{E} 12 \mathrm{NVT}$ and 300 $\mathrm{krad}$ and 6 E12 NVT.

All the projections, including those for $a$ m boom as well as other details, can be found in the appendix to this report.

\section{JPL PROJECTED REACTOR POWER SYSTEM MASS}

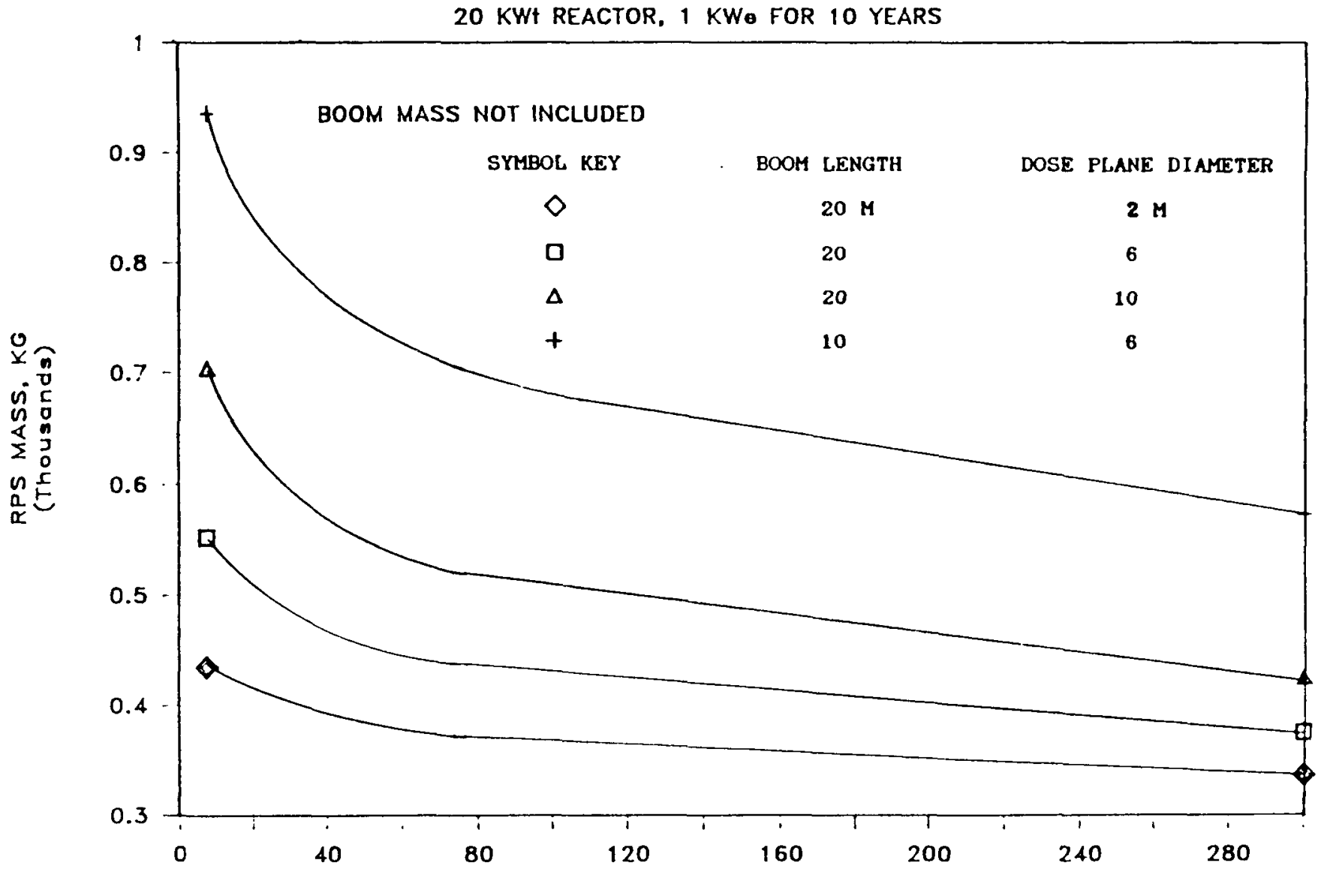

10 YEAR GAMMA DOSE. KRAD 
This chart compares the results of the trajectory calculation in terms of the allowable RPS as a function of flight time, to the 1 kWe RPS mass projections as a function of boom length, dose plane diameter and dose. For a given RPS mass there is a range of flight times due to the dependence of flight time on the launch year where the shortest flight time is for a mission launched in 1996. Fundamentally, this chart shows that the allocations for RPS mass for a "short" flight time penalty (about 1 year) trajectory are consistent with the RPS mass projections in the 400 to $500 \mathrm{~kg}$ range. This situation is made possible by a $20 \mathrm{~m}$ boom and a $6 \mathrm{~m}$ dose plane and a radiation dose around $75 \mathrm{krad}$ and $1.5 \mathrm{E} 12$ NVT. Note, that with reactor throttling, the dose can be reduced to between 70 and $80 \%$ of the values mentioned in the previous sentence. Shaped shields and local spot shielding may also be able to reduce the mass of the RPS.

$20 \mathrm{KWH}$ REACTOR, $1 \mathrm{KW}$ FOR 10 YEARS

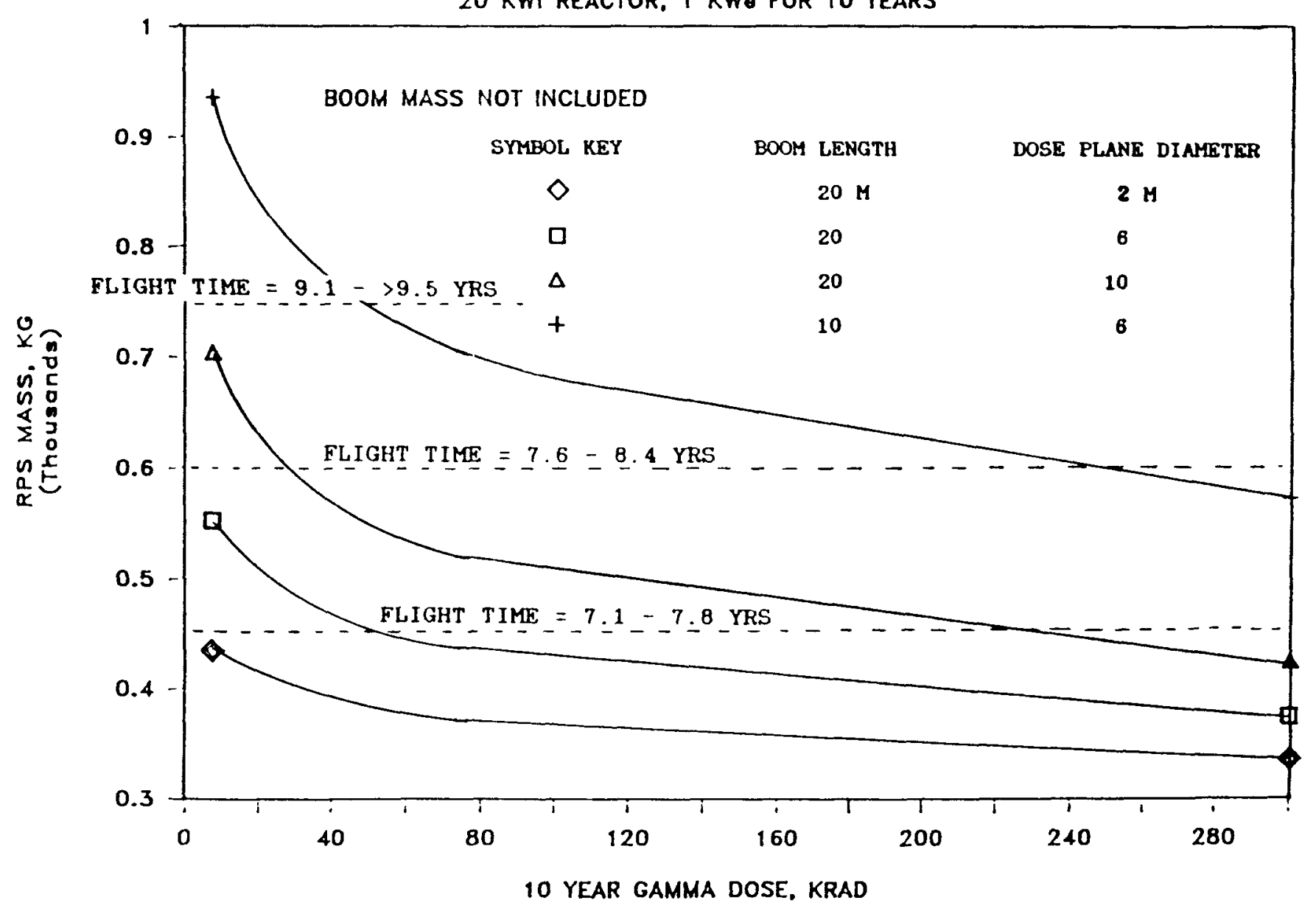


TO THE EXTENT THAT THE RESOURCES OF THIS STUDY ALLOWED, no "show stoppers" were found. Further analysis, especially in the areas of controllability and the accommodation of the RPS radiation dose, is required in order to verify the compatibility of an RPS and a planetary spacecraft.

Several of the spacecraft subsystems are impacted by the addition of the RPS. A heavier spacecraft structure is required to support the RPS for the launch loads. The telecommunications subsystem was required to be changed to use a smaller high gain antenna. The same data rate was supported by increasing the RF output power of the subsystem. While almost two thirds of the power subsystem mass were eliminated (the RTGs), the power control and distribution equipment was doubled in order to handle the increase in power demand from the telecommunications and temperature control subsystems. The attitude and articulation subsystem requires the addition of the gimbal and gimbal drivers for the HGA. AACS also will have the largest and least well defined changes to the software of any subsystem. AACS is also the subsystem where further study may identify "show stoppers" or at least reasons why a $20 \mathrm{~m}$ boom is not acceptable. The temperature control subsystem design philosophy will be changed from one of trying at all costs to minimize heat leaks to conserve power, to one of designing a "leaky" spacecraft and using the large excess of power from the RPS to make up heat losses.

The reliability of the spacecraft will be more costly to ensure due to the longer flight time and the additional radiation dose created by the addition of the RPS. While most of the impact to the spacecraft is negative, the philosophy change in the temperature control subsystem, the elimination of all the plutonium isotope and the excess power provided by the addition of the RPS will make the spacecraft design and operation easier.

\section{JPL}

SUBTASK \#1 SUMMARY

CAN A SMALL RPS BE COMPATIBLE WITH THE MMII CASSINI SPACECRAFT AND MISSION?

- ALTHOUGH NO "SHOW STOPPERS" WERE FOUND IN THE AREAS OF SPACECRAFT CONFIGURATION AND CONTROLLABILITY, FURTHER STUDY IS REQUIRED TO VERIFY COMPATIBILITY. THE AREAS OF CONTROLLABILITY AND RADIATION DOSE ACCOMMODATION SHOULD BE STRESSED IN FUTURE STUDIES.

- generally, the LONGER fLIGHT time AND tHE INCREASE IN RADIATION DOSE AND TYPE WILL MAKE THE RELIABILITY OF THE SPACECRAFT MORE DIFFICULT TO ENSURE

- the elimination OF the PLUTONIUM ISOTOPE AND the ADDITION OF "POWER tO BURN" WILL MAKE THE SPACECRAFT DESIGN AND OPERATION EASIER 
While no configuration or controllability "show stoppers" were found, the integration of a RPS onto the MMII spacecraft will cause a trip time penalty. The figures on previous pages of this package have quantified the trip time penalty as a function of the mass of the RPS. Relative to the reference Cassini mission with a 6.8 year flight time, launched in ' 95 using a propulsion system with 308 seconds, a $500 \mathrm{~kg}$ RPS causes a trip time penalty of about 1.1 years. If launched in 1996 using a 326 sec. propulsion system, a $500 \mathrm{~kg}$ RPS causes a trip time penalty of only about 0.5 year.

The natural environment on the Cassini mission uses most if not all of the MMII radiation specification allocation. Therefore the RPS can not be compatible with the MMII spacecraft unless an allocation for RPS radiation is added. The current MMI radiation specification is for $7.5 \mathrm{krad}$ and $2.7 E 10$ NVT. The RPS mass projections show that the mass of a 1 KWe RPS producing $75 \mathrm{krad}$ and $1.5 \mathrm{E} 12 \mathrm{NVT}$ on $\mathrm{a} 20 \mathrm{~m}$ boom can be in the 450 to 600 $\mathrm{kg}$ range. The Galileo spacecraft radiation specification was for 75 krad and 2.5E10 NVT. Therefore, if the MMII radiation specification was changed to accommodate about $75 \mathrm{krad}$ and $1.5 \mathrm{E} 12 \mathrm{NVT}$ from the RPS, the projected mass of a RPS would be such that the trip time penalty for the cassini mission would be about 1 year. While a 1 year trip time penalty plus an increase in the MMII radiation specification by at least a factor of ten indicates that a RPS is NOT compatible with the reference MMII Cassini mission and spacecraft, it is conceivable that such a spacecraft could be built and the mission could be flown.

JPL SUBTASK \#1 SUMmARY (CONTINUED)

CAN A SMALL RPS BE COMPATIBLE WITH THE MMII CASSINI SPACECRAFT AND MISSION?

- THE ADDITION OF THE RPS CAUSES A TRIP TIME PENALTY. A RPS WITH a MASS OF abOUT OF 500 KG CAUSES A TRIP TIME PENALTY BETWEEN 0.5 AND 1.1 YR

- A RPS IS NOT COMPATIBLE WITH PLANETARY SPACECRAFT UNLESS AN ALLOCATION FOR RPS RADIATION IS ADDED TO THE SPACECRAFT RADIATION SPECIFICATION

- the mass of a 1 kWe rPS producing about 75 krad at 20 m can be close to 500 kg 


\section{TASK \#2}

The objective of this task was to determine the lowest power Nuclear Electric Propulsion system that could eliminate the trip time penalty (imposed by the addition of the RPS) for the Cassini mission. This task was performed in a parametric manner such that the utility of NEP systems above and below the power level needed just to match the reference mission would be described. This task started with a review of the NEP spacecraft configuration that was developed by the SP-100 program in 1985 .

This spacecraft configuration was created during 1984-85 and is discussed in more detail in reference 4. The current study performed a brief review of this configuration. The findings of this review are as follows. The payload module shown in the chart is a generic planetary spacecraft and is not the MMII Cassini spacecraft. The probe is missing from the configuration and would need to be added near to the center of mass of the entire configuration i.e., on the thrust module. An inertial measurement package containing gyros and accelerometers would have to be added to the thrust module. While the concept shown uses hydrazine thrusters as the only control actuators, momentum wheels placed in the thrust module may also be required.
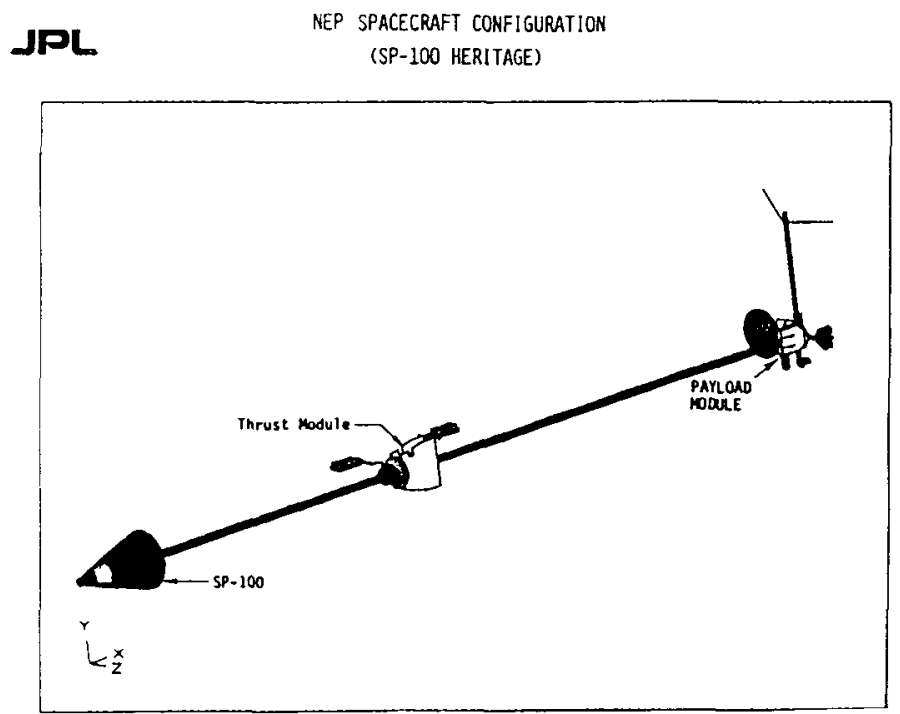

4) Jones, R. M., "SP-100 Planetary Mission/System Preliminary Design Study, Final Report", Jet Propulsion Laborarory Document D-2544, June 1986 . 


\section{ELECTRIC PRQPULSIQN}

The JPL electric propulsion group recommended the use of an Xenon ion thruster system for this study. Ion thrusters were selected on the basis of their long life time, their relatively well developed status and the knowledge that they could meet the mission requirements. Xenon is now the propellant that the ion thruster technologists are working with, having replaced mercury for several reasons including: 1) safety (both during development and for launch), 2) a simpler thruster propellant flow controller compared to mercury and 3) Xenon gives comparable performance to mercury.

A computer model of a Xenon ion thruster propulsion system was used to generate the mass and performance values used in this study. The model uses ion thruster technology that is based upon the circa 78 mercury $\mathrm{J}$ series ion thrusters that were proposed to be used on the SEPS comet rendezvous project. The operation of these thrusters has been demonstrated at higher thrust densities and on Xenon. A typical output of this model is shown below.

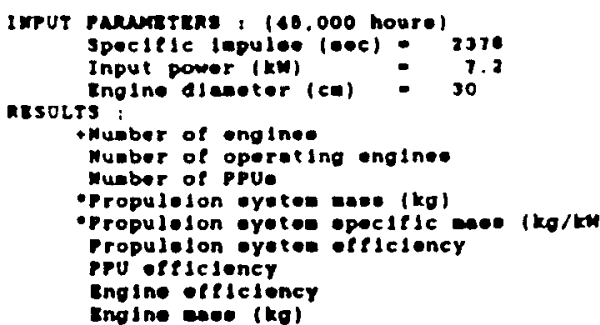

olubel noed (kg)

PPU

pru epeciple maec (kg/kw)

Thereel control wo per pru (kg)

Interfece oodule meese (kg)

Engine input power (kw) , 27

Deace current (a) - 3.60

soan voltege (y) - 454.?

Englno thruet (u)

Dlecherge current (A) - it.4

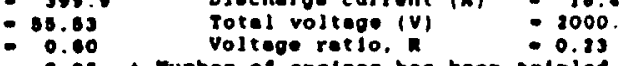

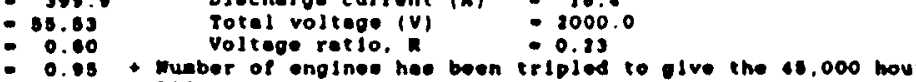

- 0.63 I180 tleo and then Jacreesed 288 for redundency.

- 10.0 - Includea lat contingency.

The input parameters are power, specific impulse and required lifetime (in increments of 15,000 hrs.). The input parameters all come from the trajectory analysis that optimizes specific impulse and flight time or power with respect to final mass for the NEP trajectory. The model includes mass for: 1) thrusters, 2) gimbals, 3) power processor units (PPUs), 4) radiators, 5) structure, 6) etc. A 151 contingency is added to the mass. The number of thrusters required to meet the mission lifetime is increased by 25 as another contingency factor.

This study assumed that the Xenon propellant would be stored as a high supercritical fluid which is the most easily implemented method of storage but also has a high mass penalty. The tankage fraction used in this study was $30 \mathrm{~kg}$ plus $29 \mathrm{t}$ of the propellant mass. This tankage fraction includes a 10 contingency factor. For some of the trajectories where the Xenon mass is on the order of $3000 \mathrm{~kg}$, the Xenon tank can be as massive as the entire remainder of the propulsion subsystem 1.e. $900 \mathrm{~kg}$. This high tankage fraction could be significantly reduced by storing the xenon as a cryogenic liquid at about $165 \mathrm{~K}$. In order to maintain this temperature a refrigerator would be required. The technology for long life cryogenic refrigerators has been demonstrated at JPL using a Joule Thompson cycle and no moving parts.

The complete results of the lon thruster system mass modelling are contained in the appendix to this report. 
- $30 \mathrm{cM}$, XENON ION THRUSTER TECHNOLOGY

- 15000 hr thruster lifetime; Plus 25\% contingency on number of thrusters

- $2270 \leq I S P \leq 6430$ sECS, $9.3 \leq P E \leq 27.6 \mathrm{KWE}$

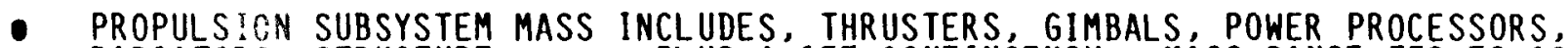
RADIATORS, STRUCTURE, ETC., PLUS A 15\% CONTINGENCY: MASS RANGE 370 TO $1000 \mathrm{KG}$

- xenON stored as a high pRESSURe gas, large tankage fraction, 30 kg + 29\% PLUS 10\% CONTINGENCY; MASS RANGE 500 TO $1050 \mathrm{KG}$ 


\section{CASSINI DELTA V EJGA TRAJECTORY PARAMETERS}

This chart present the parameters that were considered when calculating the trajectories for this study. The trajectories enable the trip time and RPS mass relationship to be quantitatively described. The reference Cassini mission uses a delta v Earth-Jupiter Gravity Assist trajectory where. the spacecraft is launched, performs a deep space delta $v$ burn, returns to the Earth for a gravity assist, then travels past Jupiter for another gravity assist and finally arrives at Saturn. Earth-Jupiter gravity assist trajectories are only available for three years out of approximately every 20. The last opportunities were in 1975-1977 when the Voyager spacecraft were launched. The next set of opportunities is in 1995-1997. Within those years 1996 is the most favorable, followed by 1995 and then 1997.

The launch vehicle for this study was constrained to be the same as the reference mission i.e., the Titan IV and a centaur $G^{\prime}$ upper stage. The Titan $I V+G^{\prime}$ will be the most capable launch vehicle combination in the world except for the new soviet booster. The Titan IV+G' combination is being developed by the USAF.

The injected mass (wet spacecraft plus RPS) is required for the trajectory analysis. The injected mass is a function of the propellant which is a function of the flight time. The flight time was the dependent variable for this analysis, therefore a scaling equation is required to relate propellant mass to injected mass. The scaling equation used in this study is shown below.

Injected Mass $=$ Msc + Mp $+313+$ adapter

Mp = Loaded bi-propellant

MSC $=$ RPS $+978.8+.0653 \star M p u+.1255 \star M p u \star \star 2 / 3+7.272 \star M p u \star \star 1 / 3$

$\mathrm{Mpu}=$ useable bi-propellant ( $97.3 \%$ of loaded bi-propellant)

$313=60$ (hydrazine) +61 (probe $I / F)+192$ (probe)

Adapter $=203.58 \mathrm{~kg}$

The MMII program has recently changed the specific impulse of the spacecraft propulsion system from 308 sec to 326 sec based upon a technology development program that has been going on at JPL for many years. However, the reference cassini mission has not yet been updated to the new Isp; therefore, this study used both values of Isp.

In summary, this study calculated delta $v$ EJGA trajectories for the Cassini mission and spacecraft modified with a RPS. The independent variable was flight time. The dependent variable was the launch vehicle margin (which must be positive for a viable mission). RPS mass, Isp and year of launch were parameters. These trajectories were compared to the reference case that has a 6.8 year flight time, $100 \mathrm{~kg}$ of launch vehicle margin and used a 308 sec propulsion system launched in 1995. 
1) LAUNCH VEHICLE/INJECTED MASS -- TITAN IV AND CENTAUR G'

2) TRAJECTORY -.- DIRECT, EGA, EJGA, VEEGA, VEJGA, VEEJGA

3) PAYLOAD -- CASSINI SPACECRAFT

4) POST INSERTION MISSION --- 4 YEARS IN ORBIT AROUND SATURN

5) INJECTION ENERGY/INJECTED MASS --- OPTIMIZED

6) ELECTRIC POWER LEVEL --- (INDEPENDENT VARIABLE)

7) SPECIFIC IMPULSE --- OPTIMIZED

8) FLIGHT TIME --- (INDEPENDENT VARIABLE)

9) BURN TIME -.- (DEPENDENT VARIABLE)

10) ELECTRIC PROPULSION SYSTEM TYPE, PROPELLANT, TECHNOLOGY LEVEL, EFFICIENCY -.JPL PROJECTIONS

11) RPS MASS -- (DEPENDENT VARIABLE) 
This chart presents the results of the trajectory calculations in terms of the allowable RPS mass as of function of flight $t$ ime for different NEP power levels. The three lines of results are for $6.54,10$ and $20 \mathrm{kw} j e t$ power levels. The electric power levels (in units of kilowatts) are shown above each data point. The electric power levels vary with trip time for a given jet power because the specific impulse optimized at a different value for each trip time. A different specific impulse means a different propulsion system efficiency and required input power for each flight time.

An example data point shows that for a 6 year trip time, the allowable RPS mass is $800 \mathrm{~kg}$ and the required RPS power is $27.59 \mathrm{KWe}$.

The complete set of NEP trajectory results can be found in the appendix to this report.

JPL CASSINI NEP DIRECT, TITAN IV + G'

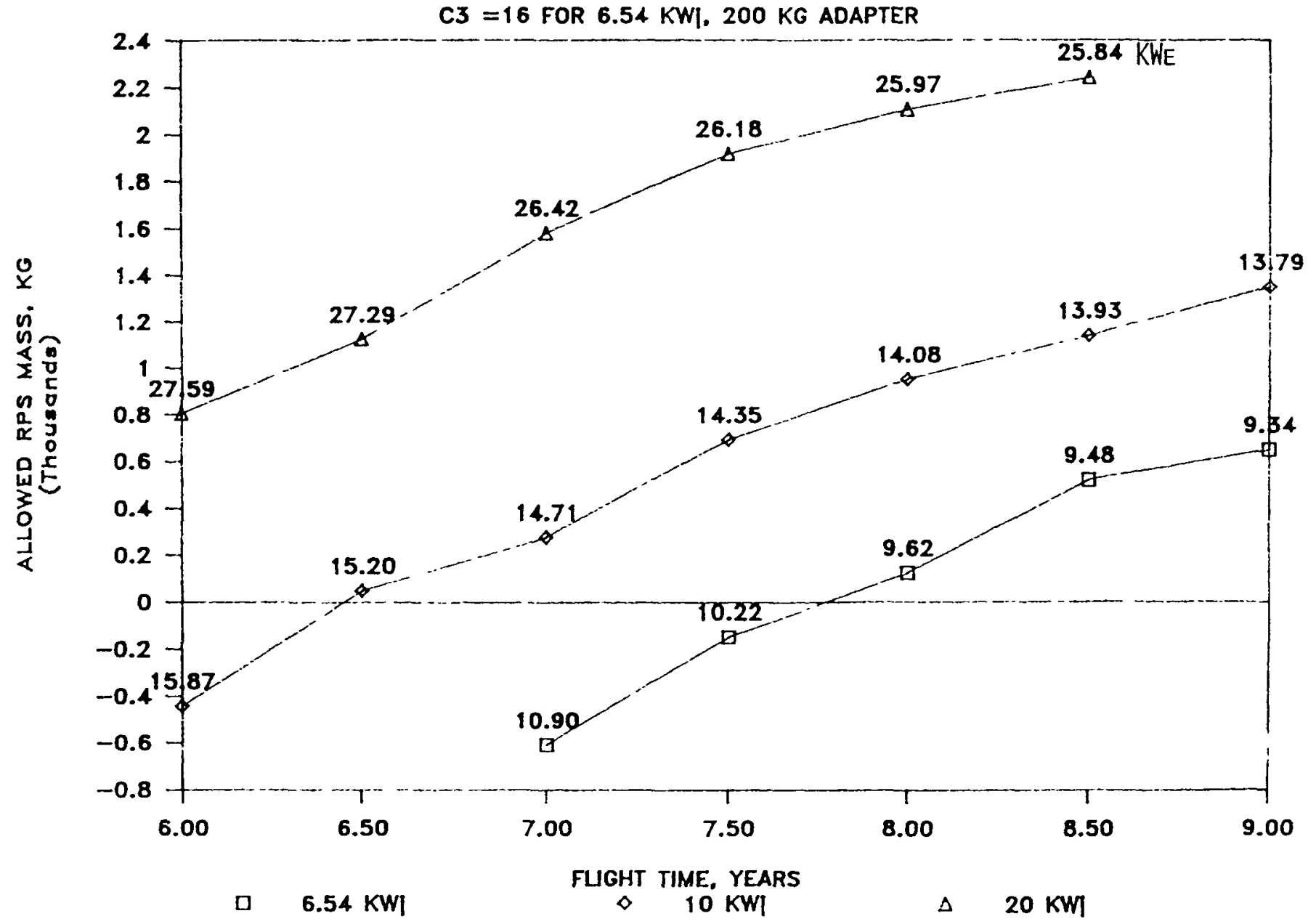


This chart presents the detailed results of the allowable RPS mass as a function of jet power for both 8 and 9 year flight times. The electric power levels are shown next to the 8 yr data points and above the 9 yr data points. An example data point shows that the mission can be performed in 9 years with a 28.06 KWe and $2300 \mathrm{~kg}$ RPS.

Some of the discontinuities shown on this chart and the following chart are due to large increases in the mass of the electric propulsion system. These mass increases are caused by the "burn time" requirement going from one multiple of 15000 hrs to another which causes a significant increase in the number of thrusters and hence system mass.

J2

\section{CASSINI DIRECT WITH NEP, TITAN IV + G'}

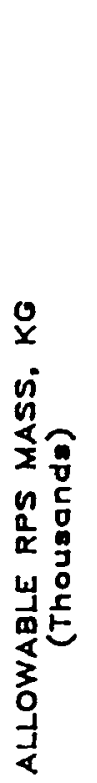

200 KG ADAPTER

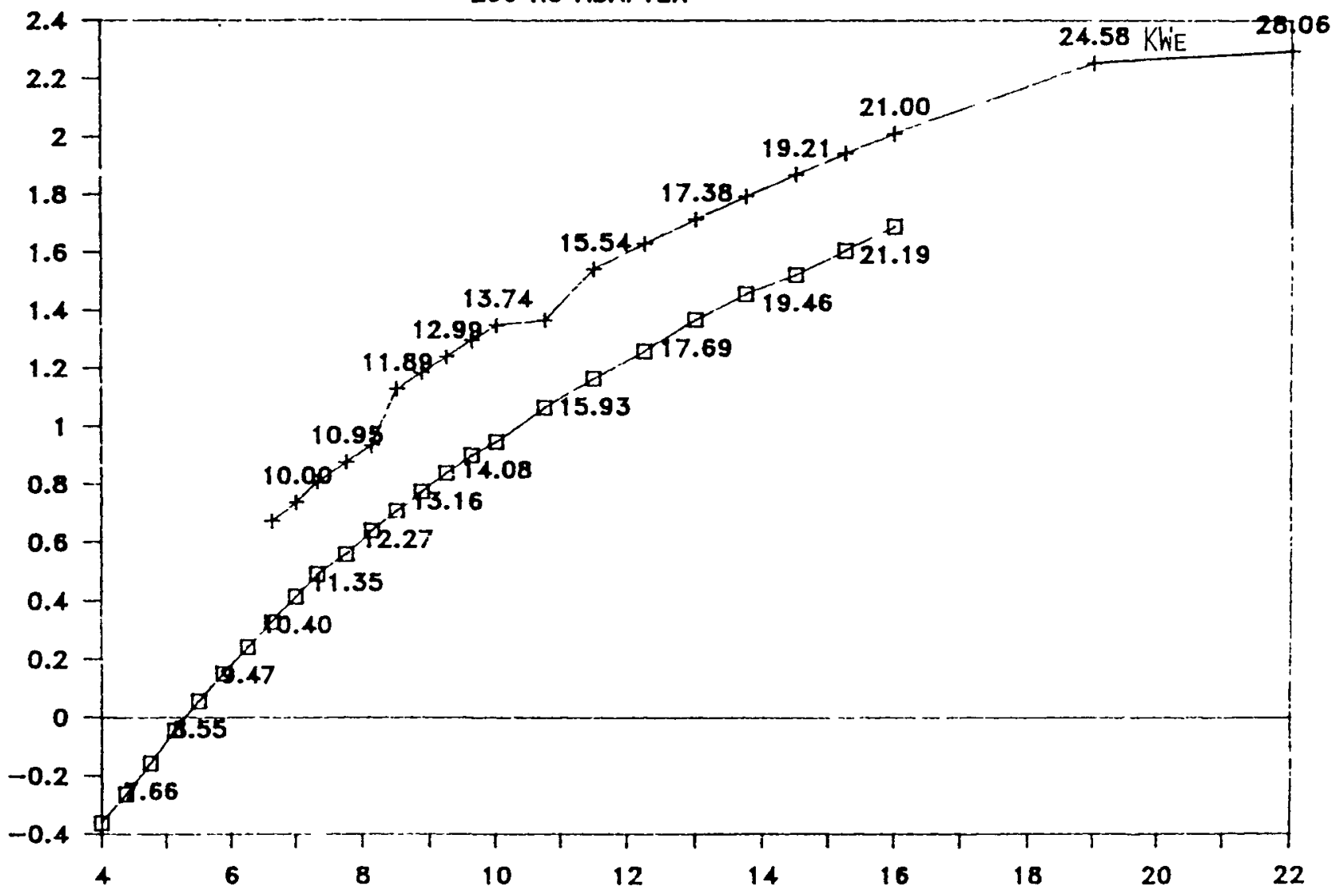

D 8 YEAR FUGHT TIME

JET POWER, KW

$+\quad 9$ YR FUGHT TIME 
This chart presents the same data as on the previous chart but in terms of the allowable RPS specific mass ( $\mathrm{kg} / \mathrm{KWe}$ ) versus jet power for both 8 and 9 year flight $t$ imes. The electric power levels are shown below the 8 yr data points and above the $9 \mathrm{yr}$ data points. The specific mass is largest for the 8 year flight time at the end of the calculations i.e., at 21.19 KWe where the alpha is $79.71 \mathrm{~kg} / \mathrm{KWe}$. For the 9 year flight time, the specific mass is greatest at $15.54 \mathrm{KWe}$ for an alpha of $99.22 \mathrm{~kg} / \mathrm{kWe}$.

\section{NEP CASSINI DIRECT ALLOWABLE RPS ALPHA}

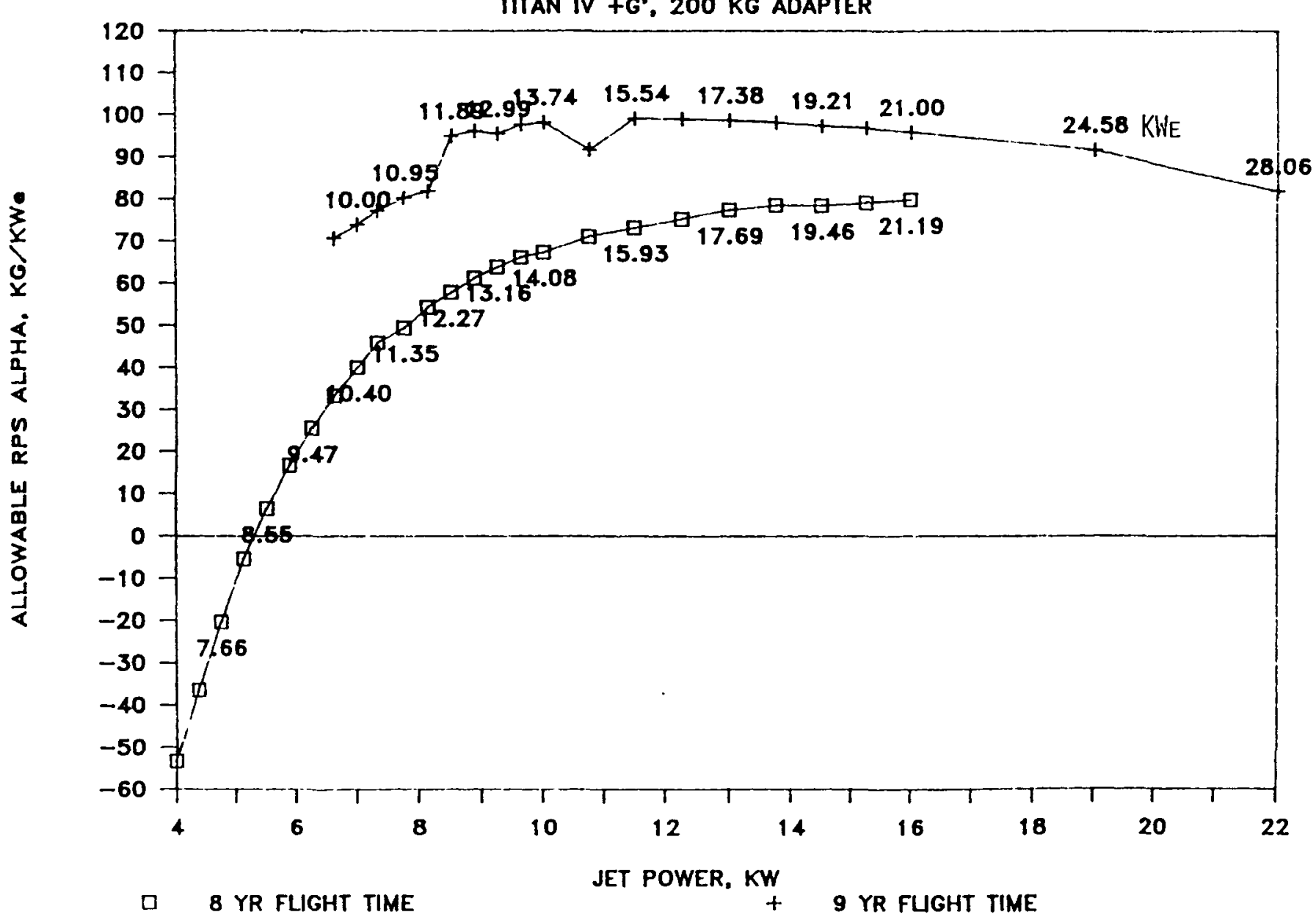


NEP MASS REQUIREMENTS VS PROJECTIONS

This chart presents a comparison between the RPS mass allocations/requirements as results obtained from the trajectory calculations shown on the previous charts, and the RPS mass projections. The RPS profections used for this chart were for a $6 \mathrm{~m}$ dose plane, $40 \mathrm{~m}$ from the reactor. The 10 year radiation dose range is from $7.5 \mathrm{krad}$ and $1.5 \mathrm{E} 11$ NVT to $300 \mathrm{krad}$ and $6 \mathrm{E} 12 \mathrm{NVT}$. The results show that a 7 year flight time mission is just captured by the 300 krad level RPS mass projections at 25 kwe. On the other end of the results, a 9 year flight time mission is captured by the $7.5 \mathrm{krad}$ level RPS mass projections at about 12 KWe.

The RPS mass projections were provided by Harvey Bloomfield of NASA LeRC and the full set of these projections for RPS power levels of $1,5,10$, 15, 20 and 25 kWe can be found in the appendix to this report. The RPS mass projections do NOT contain a mass estimate for the boom to connect the RPS to the thrust module nor the boom to connect the thrust module to the payload module. However, the projections were performed for a RPS operating for 10 years at the stated power level and producing the stated radiation dose. As with task $\$ 1$, the RPS could be throttled down in power when full power is not required in order to reduce the radiation dose or, equivalently, the dose could be maintained and the shield mass could be reduced. For these NEP trajectories, the "burn time" (full power time) was about 5 years. Therefore the radiation doses shown on this chart could be reduced by about 50 .

\section{JPL NEP MASS REQUIREMENTS VS PROJECTIONS}

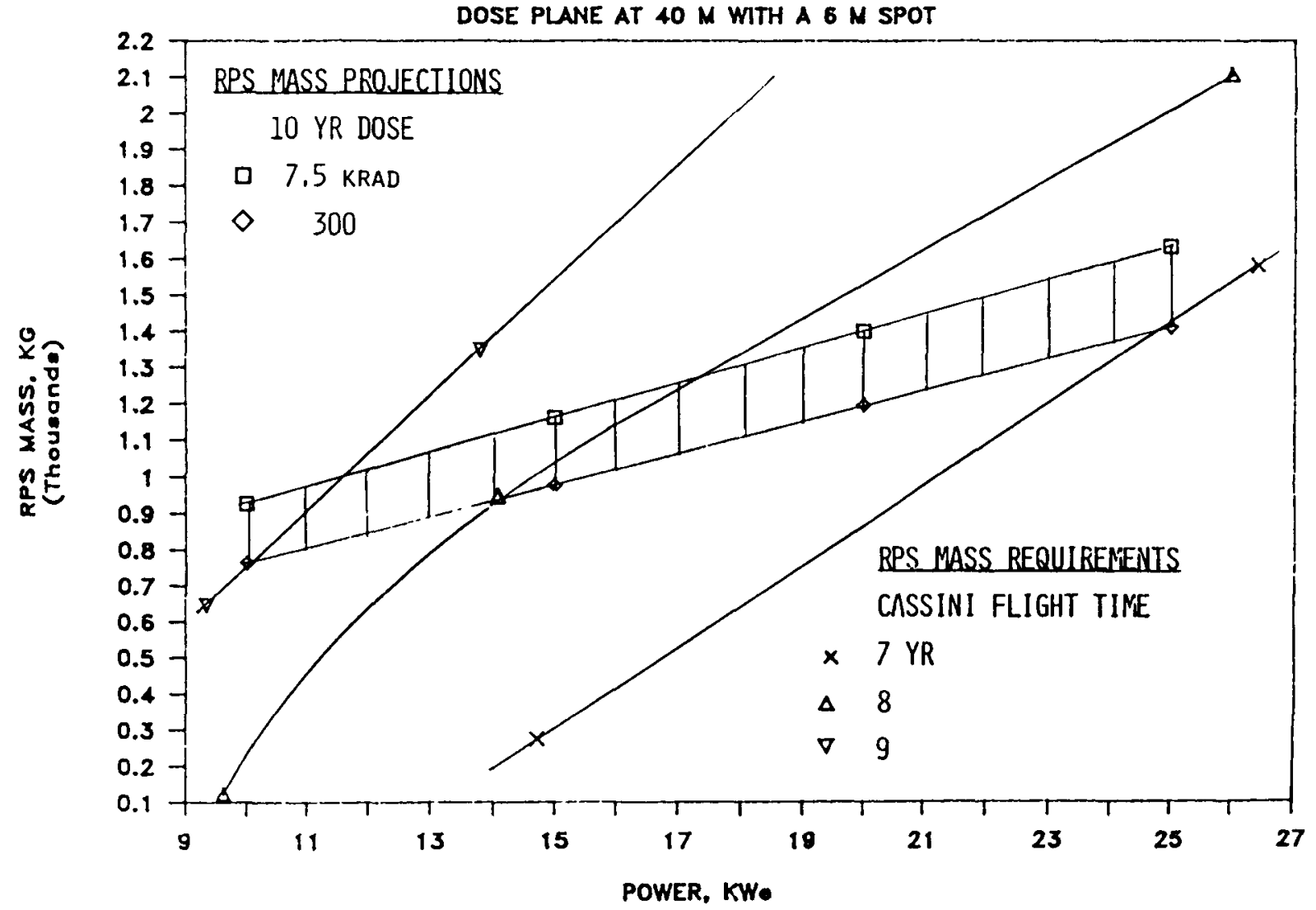


The RPS mass projections show that the mass of a 25 kWe RPS producing 75 krad and 1.5 E12 NVT over 10 years in a $6 \mathrm{~m}$ diameter dose plane $40 \mathrm{~m}$ from the reactor $1 \mathrm{~s} 1500 \mathrm{~kg}$. The trajectory calculations require that the mass of a 26.4 KWe RPS be less than $1581 \mathrm{~kg}$ for the NEP direct cassini flight time to be 7 years. This set of requirements and capabilities is close enough to conclude that a 26.4 KWe NEP system could eliminate the trip time penalty imposed by the addition of the RPS.

Longer flight times enable lower power or more massive RPSs.

These results were for "direct" trajectories, which are preferred over the reference delta $V$ EJGA trajectory.

This task did not attempt to determine specifically whether 75 krad and 1.5 E12 NVT at 40 meters would be compatible with the NEP spacecraft configuration shown on the previous chart, however, no conceptual "show stoppers" are expected.

During the course of this task, it became apparent that the mass of the Xenon tanks was a significant penalty (as much as 1000kg!). Future NEP studies should consider all the system, mission and technology trade offs between Xenon and Mercury propeliant and the ways that are conceptually available to reduce the Xenon tank mass. Future studies should also account for the radiation shielding that can be provided by the Xenon propellant tanks.

- A RPS PRODUCING $26.4 \mathrm{kWE}$ WITH A MASS OF $1580 \mathrm{~kg}(59.8 \mathrm{~kg} / \mathrm{kW})$ CAN DELIVER THE CASSINI SPACECRAFT TO SATURN IN 7.0 YEARS ON A DIRECT

TRAJECTORY USING THE ELECTRIC PROPULSION SYSTEM PROJECTIONS OF THIS STUDY

- the RPS PROJECTIONS ShON that a $26.4 \mathrm{KWE}, 1580 \mathrm{Kg}$ is fEASIBLE WITH A $40 \mathrm{M}$ BOOM FOR A DOSE LEVEL OF 75 KRAD AND 1.5 E12NVT

- allowing an 8.5 year flight time, the fOllowing rps systems COULd perform THE CASSINI MISSION:

$$
\begin{aligned}
9.5 \mathrm{KWE}, \quad 518 \mathrm{KG}, & 55 \mathrm{KG} / \mathrm{KWE} \\
14 \mathrm{KWE}, & 1140 \mathrm{KG}, \quad 82 \mathrm{KG} / \mathrm{KWE} \\
26 \mathrm{KWE}, & 2240 \mathrm{KG}, \quad 87 \mathrm{KG} / \mathrm{KWE}
\end{aligned}
$$

- these results are for D I R E C T trajectories hHICh allon launch in any YEAR COMPARED TO THE BASELINE DELTA V EJGA WHICH CAN BE LAUNCHED ONLY

3 YEARS OUT OF TWENTY 


\section{STUDY SUMMARY}

The objective for task 1 was to determine whether a small reactor power system (RPS) could be successfully integrated onto the MMII Cassini spacecraft/mission. TO THE EXTENT THAT THE RESOURCES OF THIS STUDY ALLOWED, no "show stoppers" were found to the integration of a small RPS onto the MMII spacecraft in the areas of spacecraft configuration and controllability. Further analysis, especially in the areas of controllability and the accommodation of the RPS radiation dose, is required in order to verify the compatibility of an RPS and a planetary spacecraft.

While no configuration or controllability "show stoppers" were found, a RPS and the MMII Cassini spacecraft/mission are not strictly compatible due to the radiation environment and the trip time penalty imposed by the RPS.

Because the MMII spacecraft radiation specification has been estimated on the basis of ONLY the natural environment and because the radiation dose imposed by the RPS cannot practically be made zero: the MMII spacecraft (or any other planetary spacecraft) could not accommodate a RPS unless its radiation specification was changed to allow some contribution from the RPS.

Relative to the reference cassini mission with a 6.8 year flight time, a $500 \mathrm{~kg}$ RPS causes a trip time penalty of about 1.1 years. The RPS mass projections show that the mass of a 1 KWe RPS producing 75 krad and 1.5 E12 NVT on a $20 \mathrm{~m}$ boom, can be in the 450 to $600 \mathrm{~kg}$ range.

Therefore, if the MMI radiation specification was changed to accommodate about $75 \mathrm{krad}$ and $1.5 \mathrm{E} 12$ NVT from the RPS, the projected mass of a RPS would be such that the trip time penalty for the cassini mission would be about 1 year. While a 1 year trip time penalty plus an increase in the MMII radiation specification by at least a factor of ten indicates that a RPS is NOT compatible with the reference MMII cassini mission and spacecraft, it is conceivable that such a spacecraft could be built and the mission could be flown.

The objective of task $\| 2$ was to determine the lowest power Nuclear Electric propulsion system that could eliminate the trip time penalty (imposed by the addition of the RPS) for the Cassini mission.

The RPS projections show that the mass of a 25 KWe RPS producing $75 \mathrm{krad}$ and 1.5 E12 NVT over 10 years in a $6 \mathrm{~m}$ diameter dose plane $40 \mathrm{~m}$ from the reactor is $1500 \mathrm{~kg}$. The trajectory calculations require that the mass of a 26.4 KWe RPS be less than $1581 \mathrm{~kg}$ for the NEP direct cassini flight time to be 7 years. This set of requirements and capabilities is close enough to conclude that a 26.4 KWe NEP system could eliminate the trip time penalty imposed by the addition of the RPS. 
TASK 1:

- a sMall RPS may be cOMpatible with the mMII CASSINI SPACECRAFt and MISSION IF:

1) AN ALLOCATION FOR RPS RADIATION IS INCLUDED IN THE MMII RADIATION SPEC.

2) THE MISSION CAN TOLERATE A TRIP TIME PENALTY OF AT LEAST ONE YEAR

- BASED UPON CURRENT PROJECTIONS, THE MASS OF A 1 KWE RPS PRODUCING 75 KRAD AT 20 METERS WOULD BE CONSISTENT WITH THE ONE YEAR TRIP TIME PENALTY

TASK 11:

- THE MINIMUM SIZE NEP SYSTEM THAT CAN ELIMINATE THE TRIP TIME PENALTY IS A $26.4 \mathrm{kWE}$ NEP SYSTEM WHOSE RPS HAS A MASS OF $1580 \mathrm{~kg}$

- CURRENT PROJECTIONS SHOW THAT A 25 KWE RPS WILL HAVE A MASS OF BETWEEN 1400 TO $1600 \mathrm{KG}$ ( $6 \mathrm{M}$ DOSE PLANE, $40 \mathrm{M}$ SEPARATION) 


\section{RECOMMENDATIONS}

Based upon the work performed during this study, a small RPS technology development program that had planetary spacecraft/missions as one application should include the following areas of work. For relatively near term applications that do NOT include electric propulsion acceptable technology development goals are: 1) a 1 KWe system, 2) a mass of about $500 \mathrm{~kg}$ or less, 3) with a 12 year 1 ife and 4) a total integrated radiation dose of about $75 \mathrm{krad}$ and 1.5 E12 NVT. The radiator slould be designed so that the rejected heat is directionally balanced to within 1 in order to minimize disturbance torques. The analysis tools and the shield technology should be developed for shaped shields. The reactor should be designed to be throttled down in power in order to reduce the radiation dose.

Any small reactor development program should include a continuation of the systems work performed in this study in order to verify and extend the results presented here. This Reactor/Spacecraft Integration study, Phase II, should be at the 2 man year level in order to significantly add to the quality and quantity of the results presented here. Foremost among the issues which this phase II study would address is radiation. The implications of the RPS radiation environment on the design of planetary spacecraft and the sub-issues of electronic parts availability and cost are not now well understood. Other significant issues which would be part of the Phase II study include: 1) controllability, 2) implications of the "power to burn" approach to planetary spacecraft design, 3) the sensitivity of science instruments to RPS radiation and 4) the sensitivity of propeliants to RPS radiation.

RECOMMENDATIONS

- SMall reactor power system technOLOGY deVELOPMENT

- goals for a planetary spacecraft application:

- $1 \mathrm{KWE}, 500 \mathrm{Kg}, 12$ YEAR, < 75 KRAD, 1.5 E12 NVT

- develop analysis tools and technology for shaped shields

- balance heat rejection to within $1 \%$

- design reactor to be throttled to reduce dose

- REACTOR/SPACECRAFT INTEGRATION STUDY, PHASE II

- REFINE REQUIREMENTS VS CAPABILITIES

- StUdy SPACECRAFT/RPS INTEgRation ISSUES IN MORE DETAIL

- IMPLICATIONS OF RPS RADIATION ENVIRONMENT ON S/C DESIGN AND PARTS COST \& AVAILABILITY

- controllability

- implications of "power to burn" approach to s/C design

- SCIENCE INSTRUMENT SENSITIVITY TO RPS RADIATION

- propellant SENSITIVITY to RPS Radiation 
APPENDIX C

JPL

ENHANCED PLANETARY SCIENCE THROUGH

AVAILABILITY OF INCREASED POWER

STATUS REPORT

R. A. WALLACF.

JANUARY 27, 1987 


\section{BLANK}


- INCREASED DATA RATE

O RADIO OCCULTATION (OUTER PLANET

ATMOSPHERES AND RINGS)

- RELATIVITY INVESTIGATIONS

- COOLING (INSTRUMENT SENSORS, ETC)

O RADAR (MAPPING AND COMPOSITION)

O PARTICLES \& FIELDS

- LASER BOMBARDMENT (REMOTE/IN-SITU COMPOSITION)

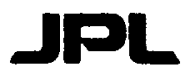

\author{
SCIENCE ENHANCEMENT WITH \\ INCREASED POWER FOK INCREASED DATA RATE
}

- SCIENCE VALUE OFTEN PROPORTIONAL TO DATA RATE

O ENHANCEMENTS IN RESOLUTION/OUANTITY

- SPATIAL (E.G., MAPPING)

- TEMPORAL (E.G., ENCOUNTER TIME)

O TRANSMITTER COOLING REOUIRED AT HIGH POWER

- CURRENT EXAMPLES OF BEST SCIENCE DATA RATES

- MARS OBSERVER ...... 56 kBPS (34M DSN)

- VOYAGER: JUPITER … 115 KBPS (70M DSN)

NEPTUNE $\ldots 22$ KBPS (70M DSN)

- GALILE0 $\ldots \ldots \ldots \ldots \ldots . \quad 8$ kRPS ( $34 M$ DSN)

134 KBPS (70M DSN)

- MAGELLAN ........... 115 KBPS (34M DSN)

268 KBPS (70M DSN) 
ENHANCED DATA RATES* WITH INCREASED POWER

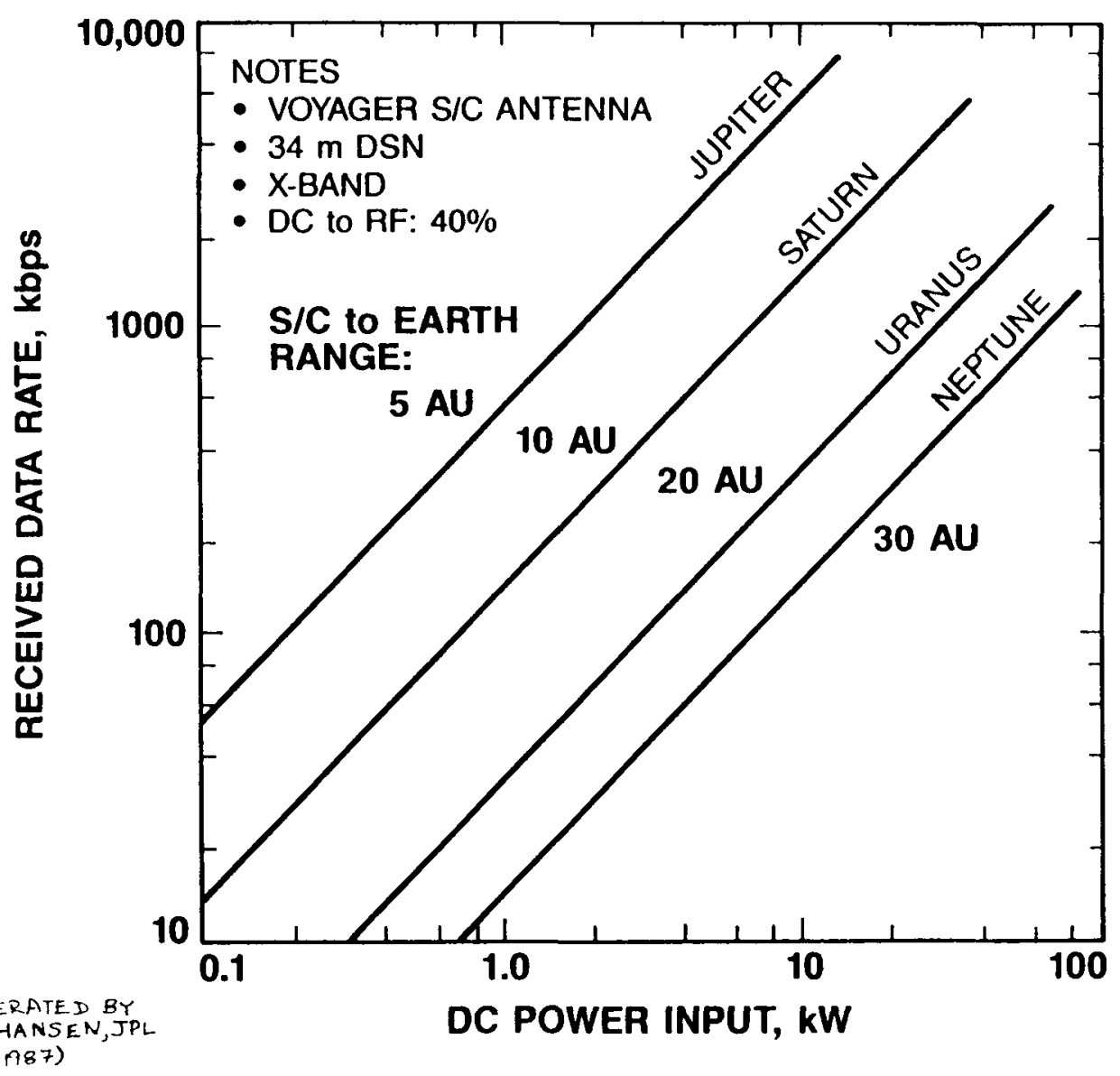
* G.M HANSEN, JPL (JANA87)

- INCREASED POWER USED TO SEND RF SIGNAL UEEPER INTO PLANETARY ATMOSPHERE

- DEEPER ATMOSPHERIC PENETRATION PROVIDES NEW AND MORE COMPLETE CHARACTERIZATION

O LIMITATIONS:

- ammonia saturation level difficult to penetrate

- PERFORMANCE CHART BASEd ON DIAMETRICAL OCCILLTATIONS

(THE IDEAL)-EXCIJRSIONS DIFFICULT TO ANALY7E

- TRANSMIITER COOLING RIOIJIRFO AI HIGII POWWR 
JPL

PLANETARY SCIENCE ENHANCEMENT THROUGH INCREASED POWER

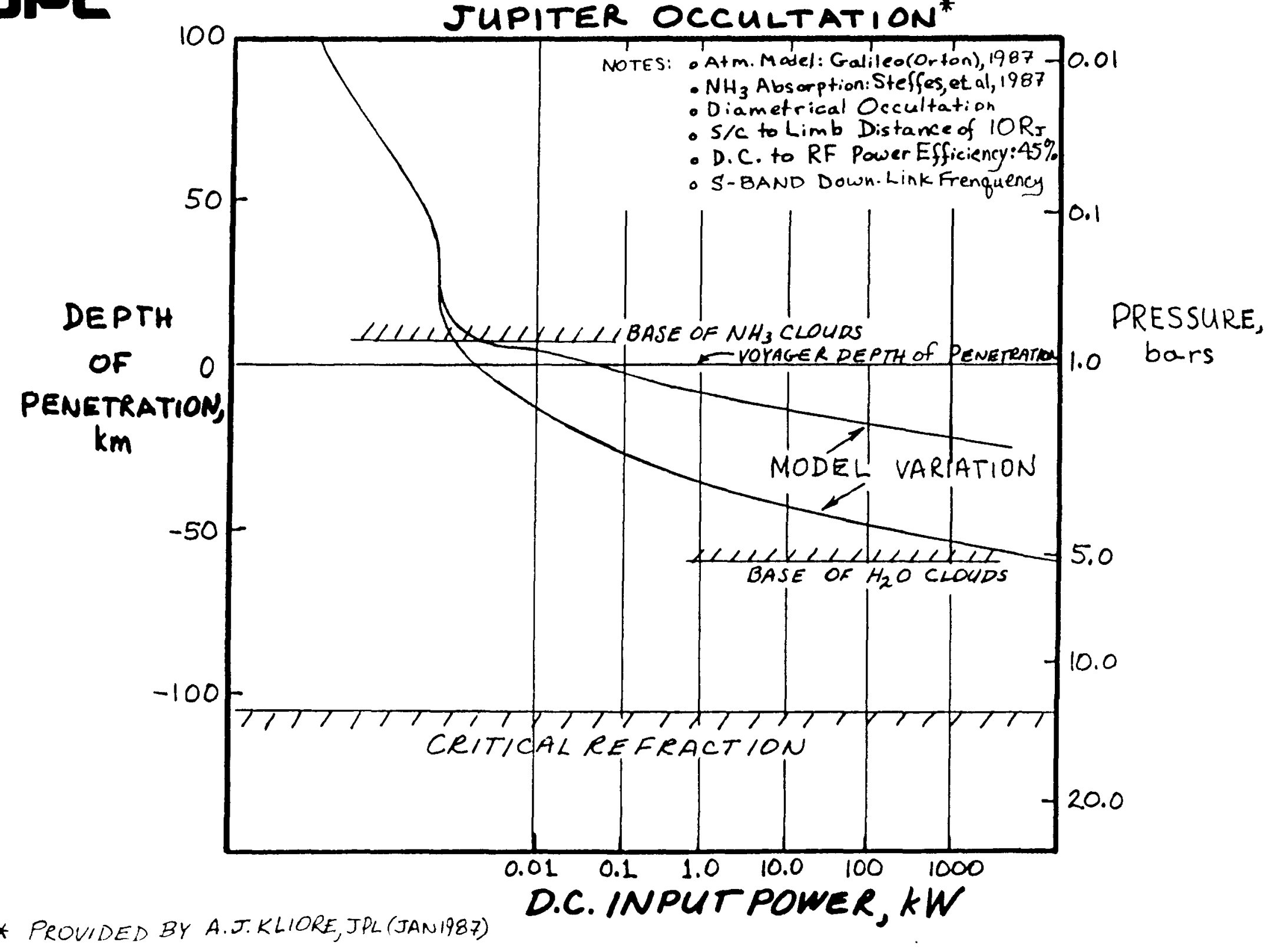




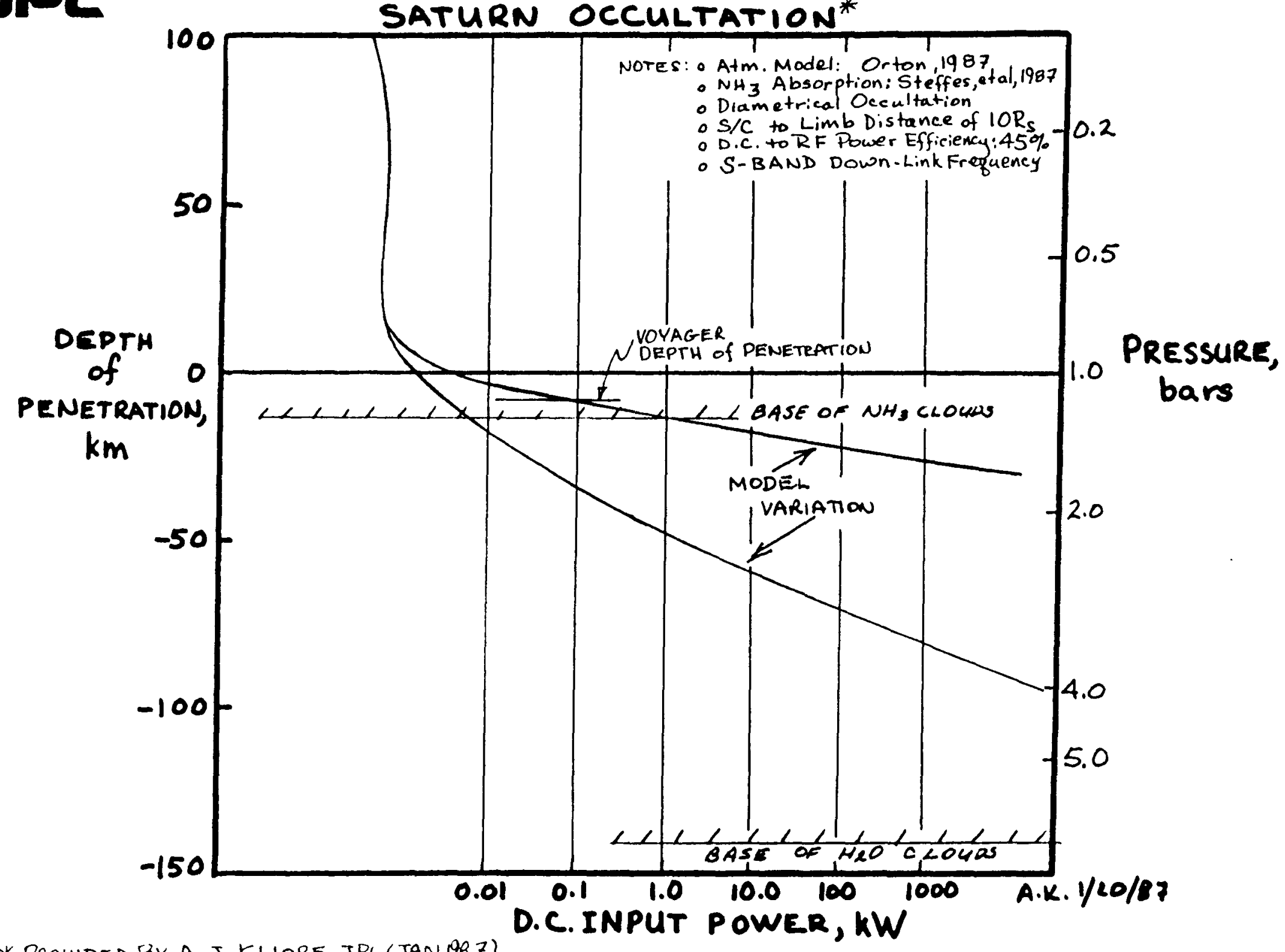




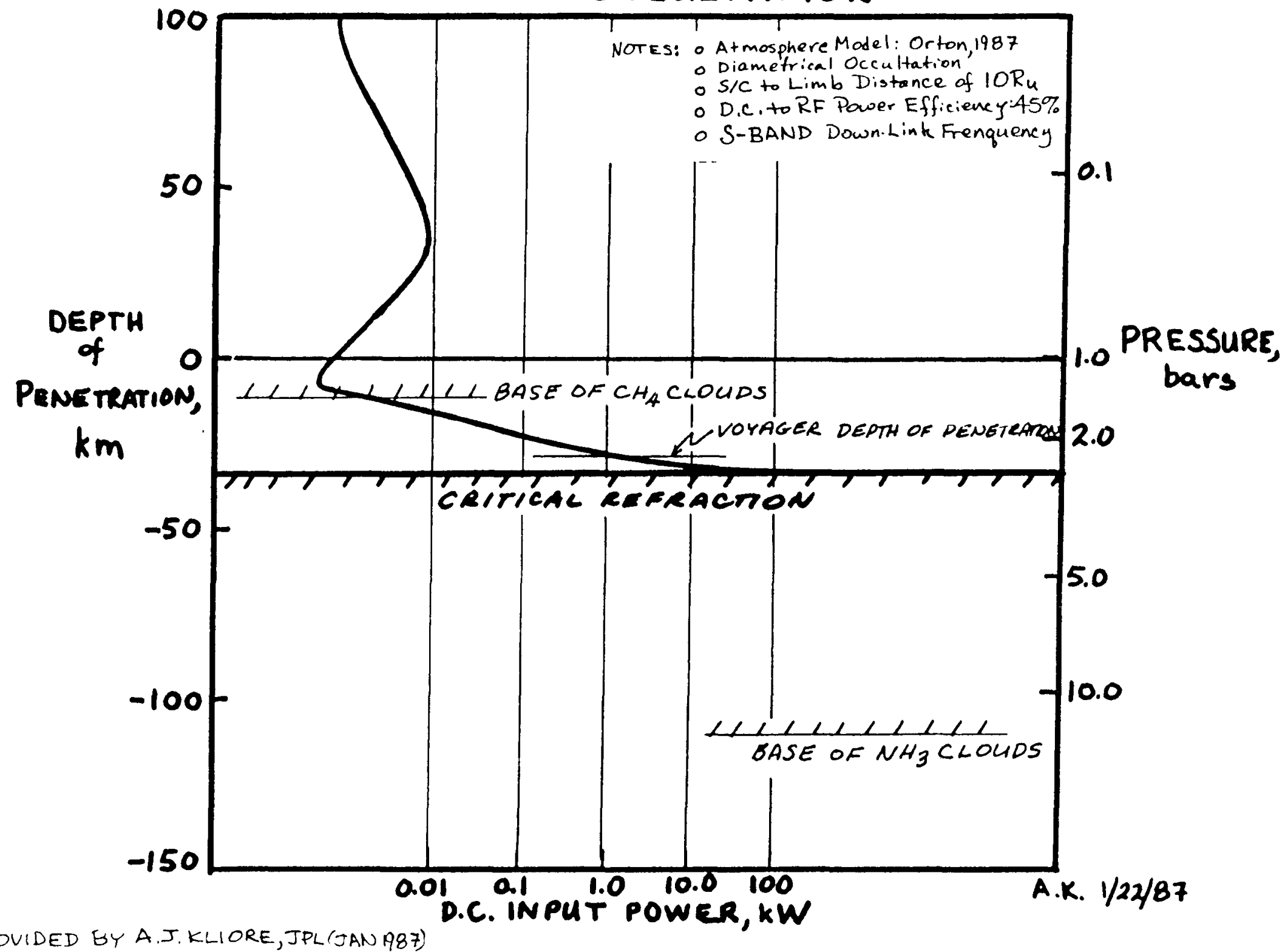




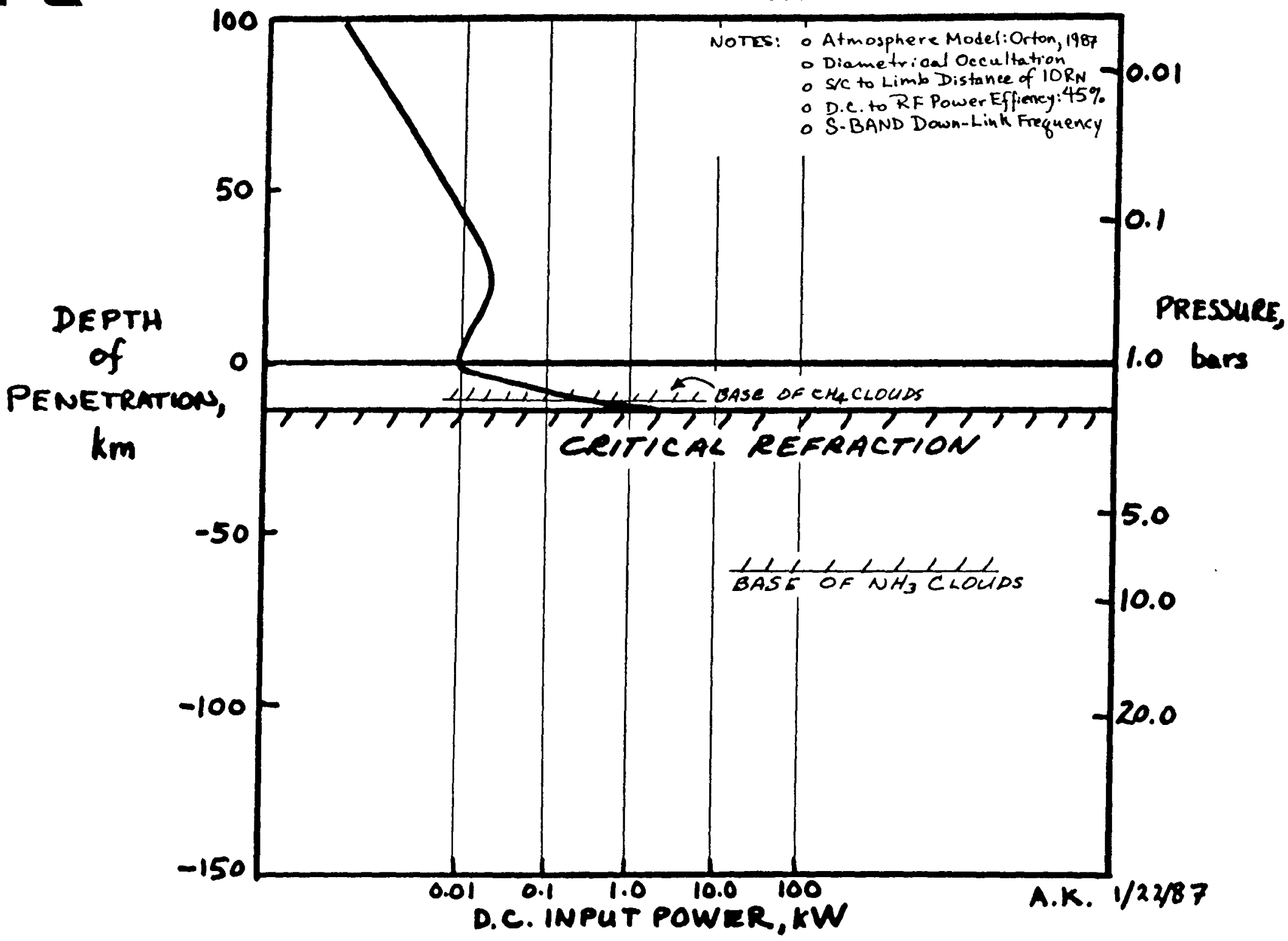

* Provided by a. J kliore, jpli (Jan 1987) 


\section{PLANETARY SCIENCE ENHANCEMENT THROUGH INCREASED POWER}

RELATIVITY INVESTIGATIONS

- GRAVITY WAVE DETECTION

- Gravity Wave Signatire Degraded By Mrdium and $S / C$ Radio SYSTEM

- Multi-link Doppler Radio System With Highfr Transmission Power Allows Resolution of Gravity wave Signature.

- TIME DELAY MEASUREMENTS

- Caused by RF-Signal path Curving throngh gravity Well.

- More Power Allows Ray Paths deeper in the Solar gravity Well with Longer/More Easily Measured time Mflays.

O REV SHIFT MEASUREMENTS

- Calised By RF-Signal frequency Shift in gravity Well.

- Multi-link Doppler Radio System With higher transmission Power Allows Deeper Pfinetration Into gravity Well With Largfir Frequency Shift More Easily Measijed $\left(\frac{1}{R}\right)$.

O ORBIT PERTURBATION MEASUREMENTS

- Orbit Perihelion Precession Is Relativity test.

- Larger Precession With Closfer Orbit Pfrihelion.

- Higher Transmission Power Allows Precision 0rbit Determination Closer to Sun.

INCREASED POWER COULD BE ENABLING FOR SOME INVESTIGATIONS 
$\vec{\perp}$

Relativity Detection (Gravity waves)* WITH INCREASED POWER

PRELIMINARY

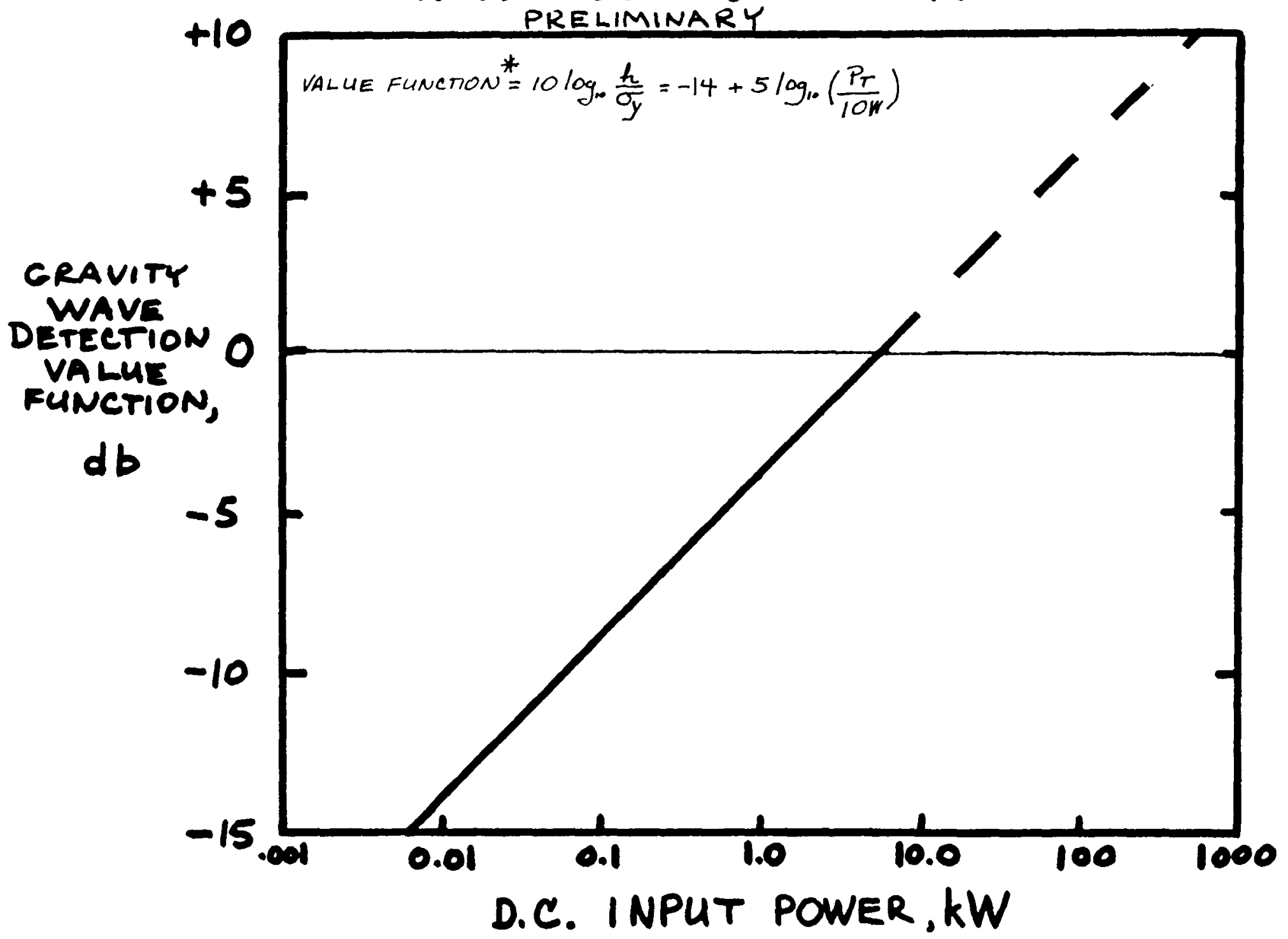

* PROVIDED BY J.D. ANDERSON, JPL (JAN 1987) -Preliminary Analysis 
O COOLING

- DUTER PLANET INSTRUMENT SENSORS

- RELATIVITY INVESTI GATIONS

- tRANSMITTERS FOR RELATIVITY, OCCULTATION, highER dDATA RATES

- INNER PLANET/SOLAR MISSIONS

- RADAR

- MAPPING RESOLITIION

- COMPOSITION \& AGE OF SURFACE:DISCRIMINATION

- PARTICLES \& FIELDS

- SPECTRUM WIDTH BROADENED

- NUMBER UF FREQUENCIES INCREASED

- ENHANCEMENT TO ABOUT $1 \mathrm{~kW}$

- LASER BOMBARDMENT

- LOW SPEED/LOW ALTITUDE APPROACH

- SURFACE BUMBARDMENT

- REMOTE SPECTROGRAPHIC INVESTIGATION

- DEBRIS CLOUD PENETRATION - IN-SITU MEASUREMENTS

JPL

PLANETARY SCIENCE ENHANCEMENT THROUGH INCREASED POWER

0 PRELIMINARY RESULTS

- POTENTIAL FOLLOW-ONS

- INVESTIGATION INTO

- RELATIVITY

- radar

- laser bombardment

- radio occultation (OUter planet rings)

- FURTHER deTAIL FOR DATA RATE \& OCCULTATION

- power system integration reQ'ts

- MASS/SIZE/COOLING REQ'TS

- NEW APPLICATIONS 
BLANK 
TABLE I.-SUMMARY OF NUCLEAR FEASIBILITY AND CRITICALITY SAFETY RESULTS

\begin{tabular}{|c|c|c|c|c|c|c|}
\hline \multicolumn{3}{|c|}{ REACTOR CHARACTERISTICS } & \multicolumn{4}{|c|}{$\begin{array}{l}\text { EFFECTIVE NEUTRON MULTIPLICATION FACTOR } \\
\text { BEST CASE/WORST CASE }\end{array}$} \\
\hline FUEL & CLAD & COOLING & $\begin{array}{l}\text { MAXIMUM } \\
\text { REACTIVITY }\end{array}$ & $\begin{array}{c}\text { LAUNCH } \\
\text { CONFIGURATION }\end{array}$ & $\begin{array}{l}\text { WATER } \\
\text { IMMERSION }\end{array}$ & $\begin{array}{l}\text { WATER } \\
\text { FLOODING }\end{array}$ \\
\hline$U-Y H$ & $\begin{array}{l}\text { MoRe } \\
\text { STANLESS } \\
\text { STEEL }\end{array}$ & $\begin{array}{c}\text { HEAT PPE } \\
\text { NaK } \\
\text { CONVECTION }\end{array}$ & $1.07 / 0.84$ & $0.57 / 0.75$ & $0.83 / 0.93$ & $1.01 / 1.12$ \\
\hline $\mathrm{UC}_{2}-\mathrm{Be}$ & - & HEAT PIPE & 1.07 & $0.78 / 1.00$ & 0.78 & $0.93 / 1.16$ \\
\hline $\mathrm{uC}_{2}$ & - & RADIATION & $1.05 / 1.04$ & $0.93 / 0.95$ & $0.99 / 0.95$ & $1.03 / 1.07$ \\
\hline $\mathrm{UO}_{2}$ & Mo $R e$ & HEAT PIPE & $1.07 / 1.04$ & $0.93 / 0.96$ & $0.97 / 0.99$ & $0.96 / 1.13$ \\
\hline UN & $\mathrm{Nb}-1 \% \mathrm{Zr}$ & Li CONVECTION & 1.08 & 0.91 & 0.95 & 1.02 \\
\hline & & TARGET GOAL & $\geq 1.05$ & $\leq 0.90$ & $\leq 0.95$ & $\leq 0.95$ \\
\hline
\end{tabular}


TABLE II.-SUMMARY OF SELECTED REACTOR POWER SYSTEM MASS ${ }^{a}$ RESULTS

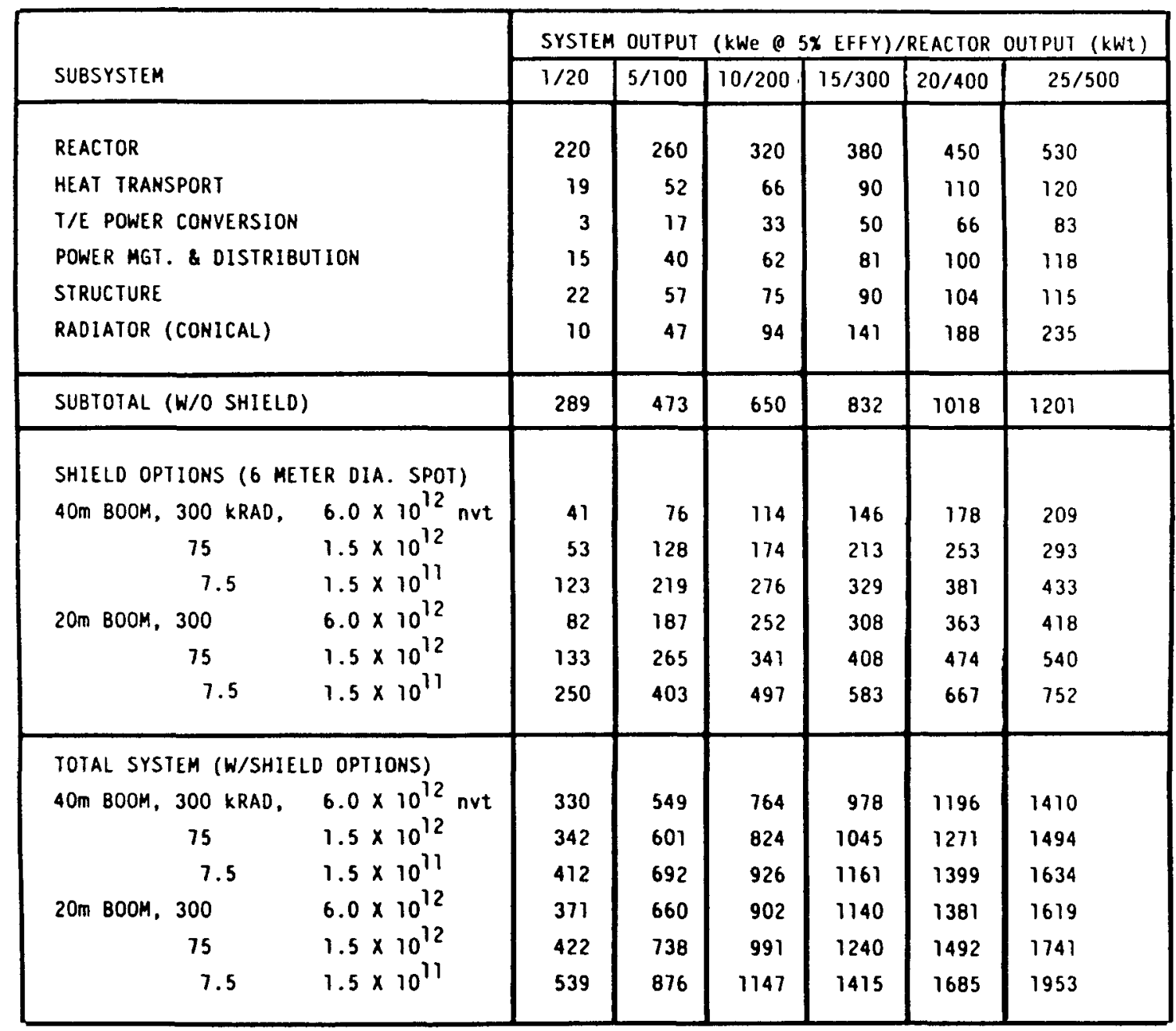

aAll masses in kilograms. 
TABLE III._SUMMARY OF INCREASED SCIENCE CAPABILITY(1)

\begin{tabular}{|c|c|c|}
\hline INSTRUMENT/DEVICE & ADDITIONAL CAPABILITY & POWER ( $k W e)$ \\
\hline $\begin{array}{l}\text { RADAR } \\
\text { ALTIMETER/RANGING } \\
\text { SOUNDER } \\
\text { ORBITAL MAPPER } \\
\text { SYNTHETIC APERTURE }\end{array}$ & $\begin{array}{l}\text { TRACKING FROM } 10^{4} \mathrm{~km} \\
\text { DEEP SUBSURFACE MAPPING } \\
\text { DISTANT MAPPING } \\
\text { INCREASED RESOLUTION/DETAIL }\end{array}$ & $\begin{aligned} 0.1 & -1.0 \\
0.5 & -5.0 \\
1 & -200 \\
0.5 & -1.0\end{aligned}$ \\
\hline $\begin{array}{l}\text { LASER } \\
\text { BOMBARDMENT }\end{array}$ & $\begin{array}{l}\text { REMOTE, DETAIL SURFACE } \\
\text { SPECTROSCOPY, DEBRIS \& CLOUD } \\
\text { PENETRATION/DETECT. }\end{array}$ & $0.1-1.0$ \\
\hline $\begin{array}{l}\text { RADIO } \\
\text { OCCULATION } \\
\text { TRANSMISSION }\end{array}$ & $\begin{array}{l}\text { INCREASED RF SIGNAL DEPTH INTO } \\
\text { PLANETARY ATMOSPHERE } \\
\text { JUPITER } 0-40 \mathrm{~km} \\
\text { SATURN } 10-60 \mathrm{~km} \\
\text { URANUS } 30-40 \mathrm{~km} \\
\text { INCREASED SCIENCE DATA RATES, } \\
\text { MAINTAIN CURRENT DSN SENSITIVITY, } \\
\text { RELAXED POINTING, SIZE \& TESTING } \\
\text { 1000 KBPS - JUPITER } \\
1000 \mathrm{KBPS}-\text { NEPTUNE }\end{array}$ & $\geqslant 20$ \\
\hline LOW TEMPERATURE & $\begin{array}{l}\text { ADD'L CRYO COOLING FOR MOREI } \\
\text { LARGER SENSORS \& TRANSMITTERS }\end{array}$ & $\begin{array}{l}1 \text { PER } \\
10 \text { WATTS } \\
\text { COOLING }\end{array}$ \\
\hline
\end{tabular}

(1) FROM JPL 660-66, AUG 1977 
SMALL REACTOR MASS MODEL

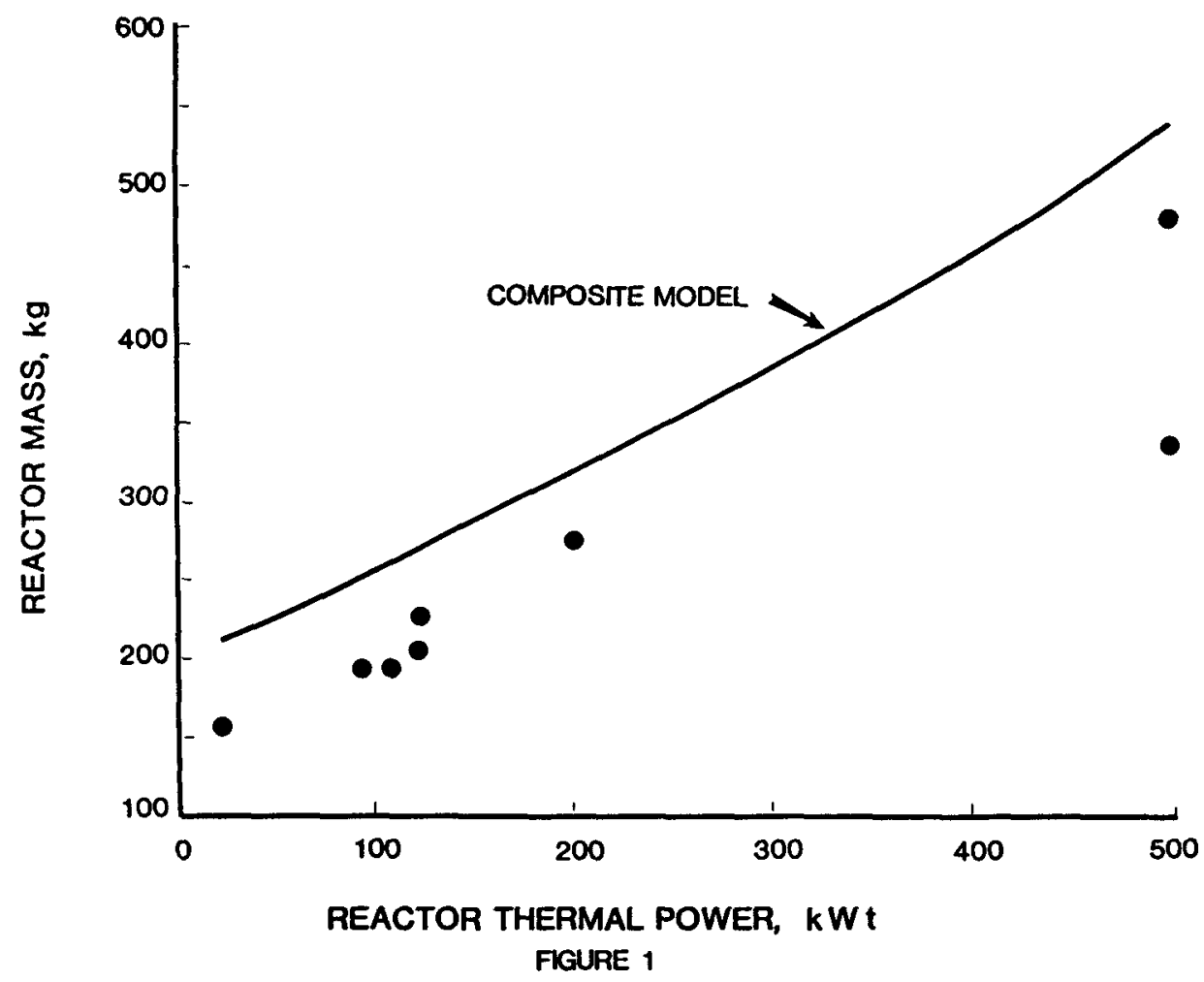

NON-NUCLEAR SUBSYSTEM MASS MODEL

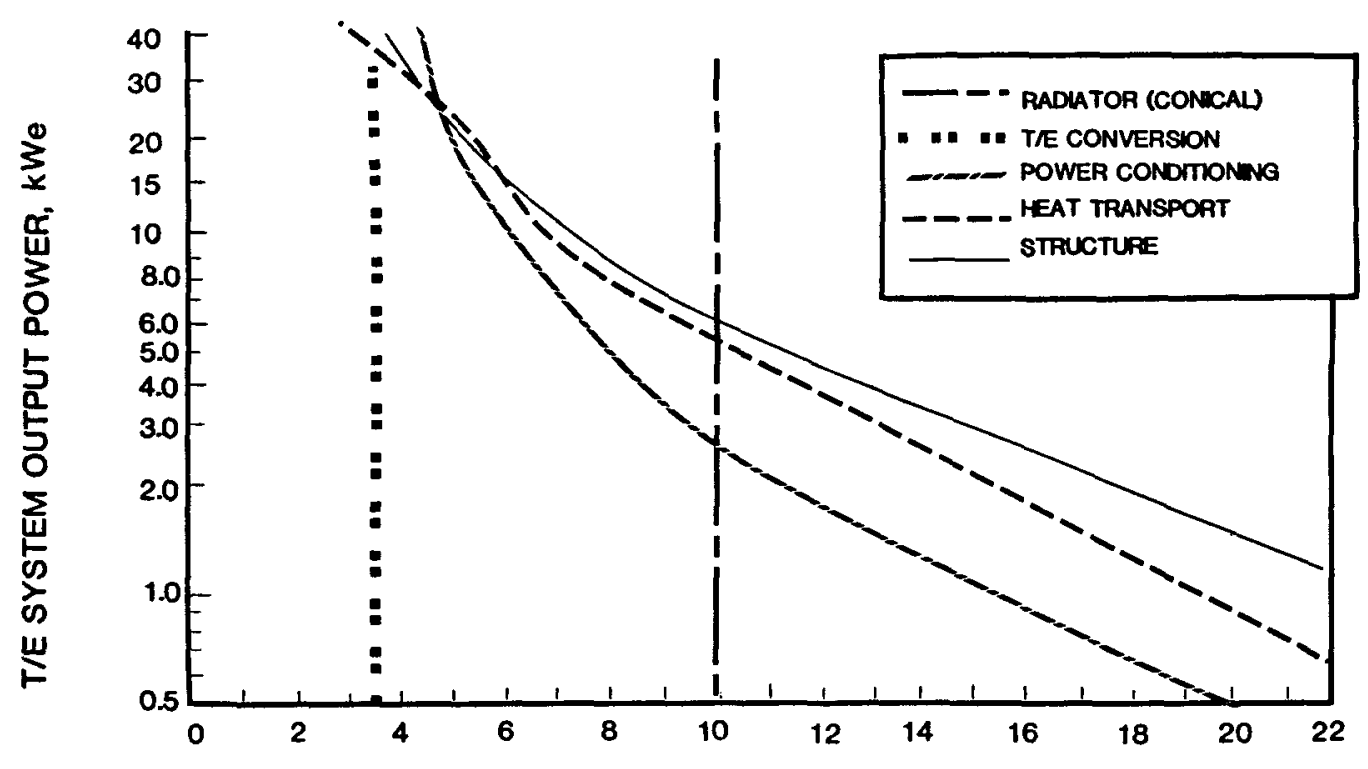

SPECIFIC MASS, $\mathrm{kg} / \mathrm{kWe}$

FIGURE 2 
REACTOR POWER SYSTEM/ CASSINI SPACECRAFT ONE KILOWATT REACTOR POWER SYSTEM OUTPUT MISSION FLIGHT TIME \& PENALTY

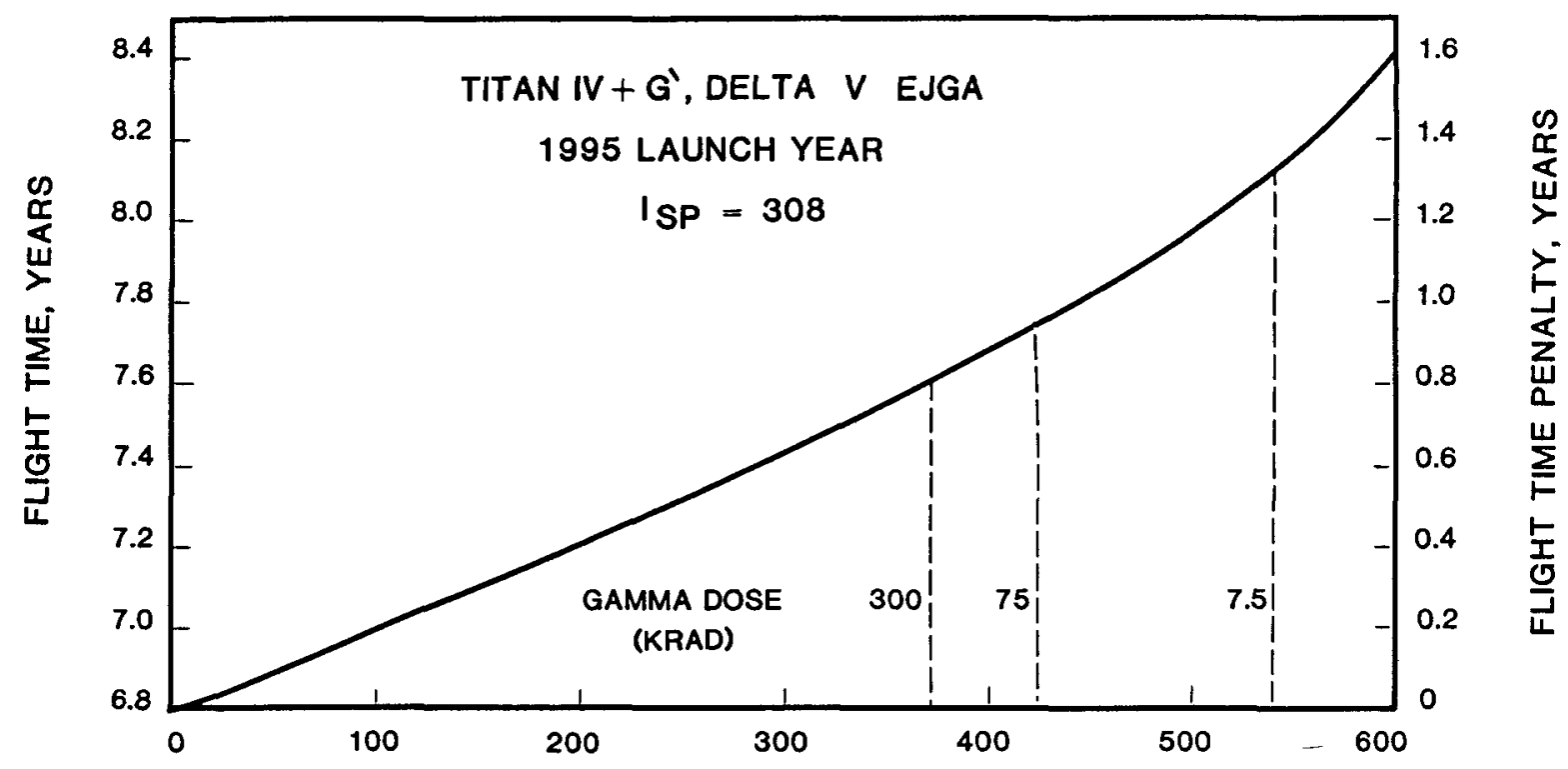

REACTOR POWER SYSTEM MASS, $\mathrm{kg}$

FIGURE 3

\section{SUMMARY OF NUCLEAR ELECTRIC PROPULSION RESULTS}

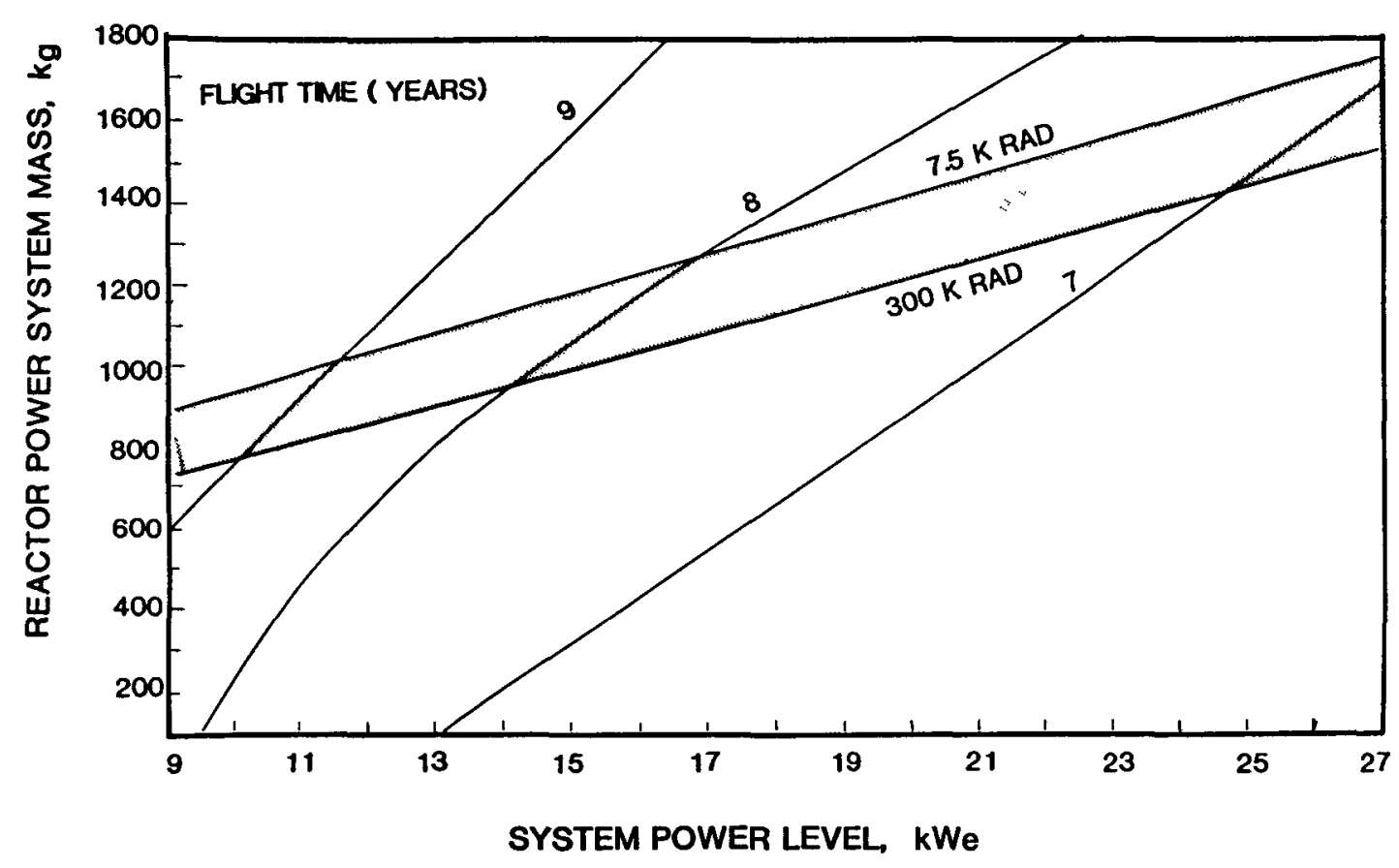

FIGURE 4 


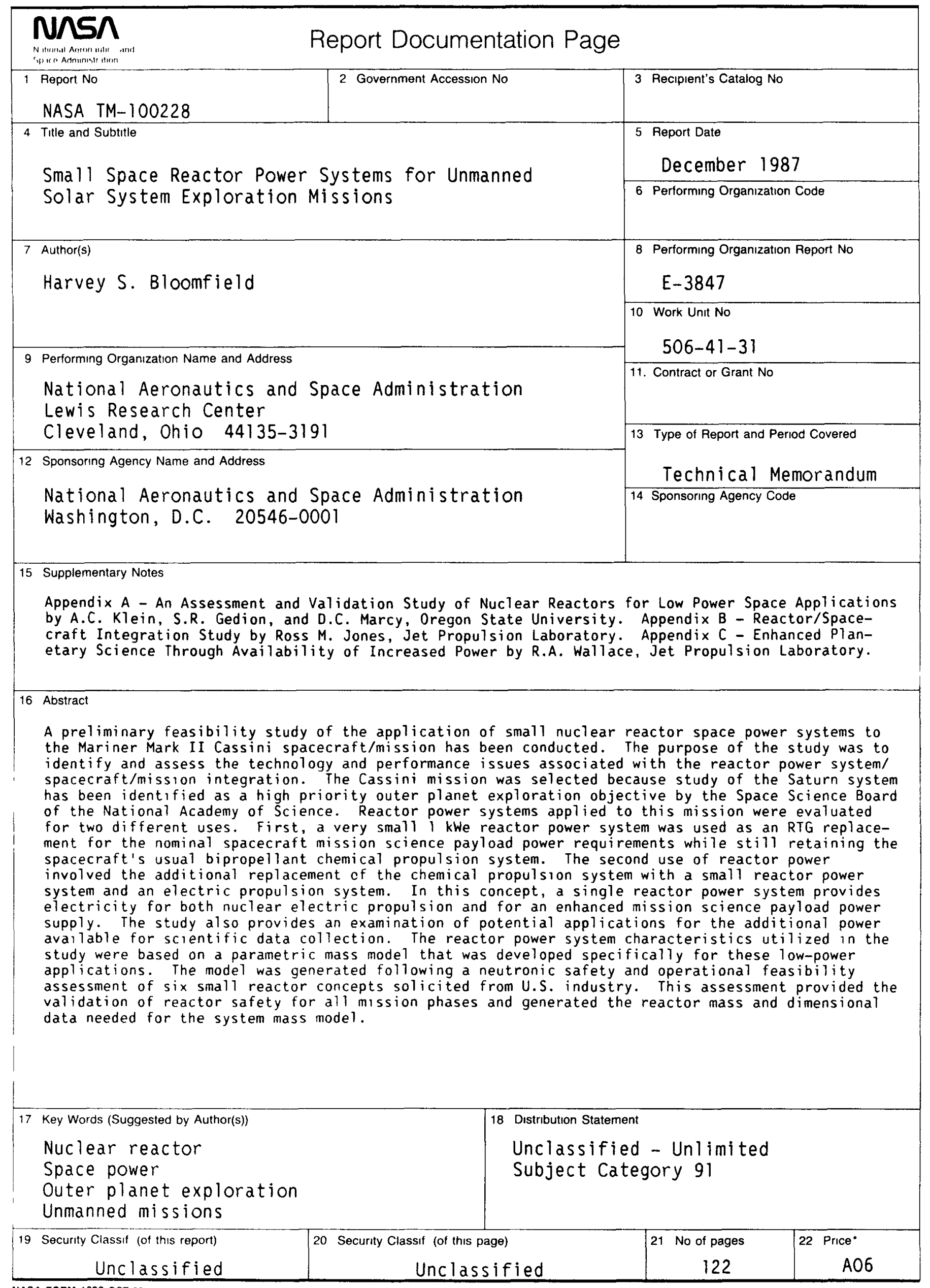

16 Abstract
A prelimi
the Mariner
identify
spacecraf
has been
of the Nat
for two d
ment for
spacecraf
involved
system an
electrici
supply.
avallable
study wer
applicati
assessment
validation
data need 
National Aeronautics and Space Admınıstratıon

Lewis Research Center

Cleveland. Ohı 44135

\section{Oniciad Business}

Penally for Pitvate Ube 5000
SECOND CLASS MAIL

ADDRESS CORRECTION REQUESTED
Postage and Fees Paid National Aoronautics and Space Administration NASA-451

*. 